\title{
Exercise training and physical activity in patients with mild to moderate COPD in primary care
}

Citation for published version (APA):

Fastenau, A. (2015). Exercise training and physical activity in patients with mild to moderate COPD in primary care. [Doctoral Thesis, Maastricht University]. Datawyse / Universitaire Pers Maastricht. https://doi.org/10.26481/dis.20150409af

Document status and date:

Published: 01/01/2015

DOI:

10.26481/dis.20150409af

Document Version:

Publisher's PDF, also known as Version of record

\section{Please check the document version of this publication:}

- A submitted manuscript is the version of the article upon submission and before peer-review. There can be important differences between the submitted version and the official published version of record.

People interested in the research are advised to contact the author for the final version of the publication, or visit the DOI to the publisher's website.

- The final author version and the galley proof are versions of the publication after peer review.

- The final published version features the final layout of the paper including the volume, issue and page numbers.

Link to publication

\footnotetext{
General rights rights.

- You may freely distribute the URL identifying the publication in the public portal. please follow below link for the End User Agreement:

www.umlib.nl/taverne-license

Take down policy

If you believe that this document breaches copyright please contact us at:

repository@maastrichtuniversity.nl

providing details and we will investigate your claim.
}

Copyright and moral rights for the publications made accessible in the public portal are retained by the authors and/or other copyright owners and it is a condition of accessing publications that users recognise and abide by the legal requirements associated with these

- Users may download and print one copy of any publication from the public portal for the purpose of private study or research.

- You may not further distribute the material or use it for any profit-making activity or commercial gain

If the publication is distributed under the terms of Article $25 \mathrm{fa}$ of the Dutch Copyright Act, indicated by the "Taverne" license above, 


\section{Exercise training and physical activity in patients with mild to moderate COPD in primary care}

Annemieke Fastenau

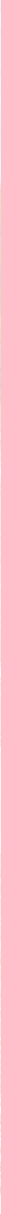


(C) Copyright Annemieke Fastenau, Maastricht 2015

Layout: Tiny Wouters

Cover: Datawyse | Universitaire Pers Maastricht

Production: Datawyse | Universitaire Pers Maastricht

ISBN: 9789461594235

The research presented in this thesis was conducted at the School for Public Health and Primary Care (CAPHRI), Department of Family Medicine, Maastricht University. CAPHRI participates in the Netherlands School of Primary Care Research (CaRe). CAPHRI was classified as "excellent" by the external evaluation committee of leading international experts that reviewed CAPHRI in December 2010.

The research presented in this dissertation was funded by the MUMC MOVE programme of Maastricht University and a grant from Boehringer Ingelheim BV. Financial support for the printing of this thesis was kindly provided by Boehringer Ingelheim BV. 


\section{Exercise training and physical activity}

\section{in patients with mild to moderate}

\section{COPD in primary care}

\section{ACADEMISCH PROEFSCHRIFT}

ter verkrijging van de graad van doctor aan de Universiteit Maastricht, op gezag van de Rector Magnificus, Prof. dr. L.L.G. Soete volgens het besluit van het College van Decanen, in het openbaar te verdedigen op donderdag 9 april 2015 om 12:00 uur

door

Annemieke Fastenau

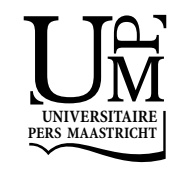


Promotores:

Prof. dr. J.W.M. Muris

Prof. dr. C.P. van Schayck

\section{Copromotores:}

Prof. dr. R. Gosselink

Dr. B. Winkens

\section{Beoordelingscommissie:}

Prof. dr. J.F.M. Metsemakers (voorzitter)

Dr. A. van 't Hul

Prof. dr. N.L.U. van Meeteren

Prof. dr. T. Troosters

Prof. dr. G. Wesseling 


\section{Table of contents}

$\begin{array}{lll}\text { Chapter } 1 & \text { General introduction } & 7\end{array}$

Chapter 2 Insight in physical activity patterns in COPD patients: 19 a starting point for treatment?

Chapter 3 Efficacy of a physical exercise training programme COPD in primary care: study protocol of a randomized controlled trial

Chapter 4 Discrepancy between functional exercise capacity and daily physical activity: a cross-sectional study in patients with mild to moderate COPD

Chapter 5 Efficacy of a physical exercise training programme COPD in 59 primary care: a randomized controlled trial

Chapter 6 Do patient characteristics and baseline burden of disease 79 modify the effect of a physical exercise training programme on exercise capacity in patients with mild to moderate COPD?

Chapter 7 General discussion

Summary

Samenvatting

Valorization

Ervaringen van betrokken

Dankwoord

Curriculum Vitae 



\section{Chapter 1}

General introduction 


\section{General introduction}

\section{COPD}

Chronic obstructive pulmonary disease (COPD) is a preventable and treatable disease and is characterized by a persistent airflow limitation that is usually progressive and associated with an enhanced chronic inflammatory response in the airways and the lung to noxious particles or gasses. ${ }^{1}$ Major consequences are dyspnoea, impaired exercise capacity and a significantly reduced quality of life. COPD is a leading cause of morbidity and mortality worldwide and results in an increasing economic and social burden. $^{2}$ It is estimated that $8 \%$ to $10 \%$ of the adult population has COPD, with cigarette smoking as the main risk factor. ${ }^{3}$ In 2012, COPD was the third leading cause of death worldwide. ${ }^{4}$

Although COPD is characterized primarily by airflow limitation, there is increasing evidence that COPD can no longer be considered as a disease that is restricted to the lungs, it is also associated with significant systemic consequences. ${ }^{1,5,6}$ Systemic consequences can be defined as non-pulmonary manifestations of COPD with an immediate cause-and-effect relationship. Comorbidities on the other hand, are diseases that are associated with COPD, perhaps because of shared risk-factors. ${ }^{7}$ These concepts are summarized in Figure 1.1.

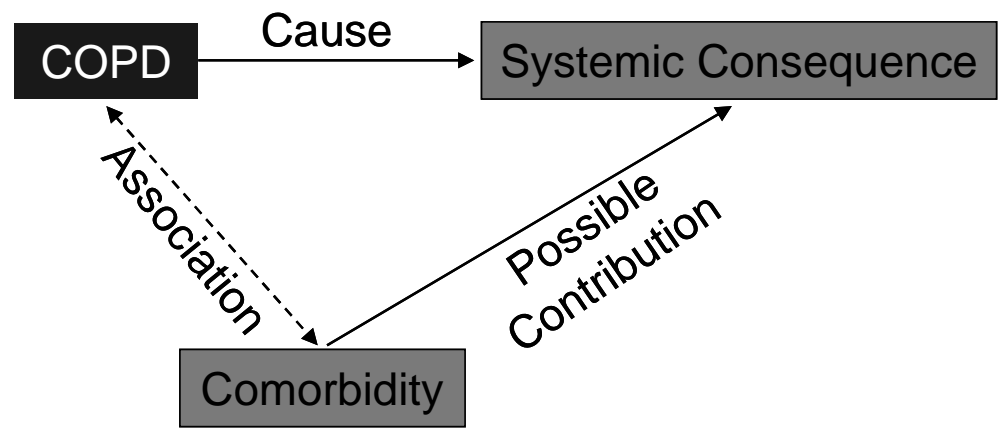

Figure 1.1 Interrelationships between COPD, systemic consequences and comorbidities (from Decramer et al., 2008).

The most prevalent systemic effects or comorbidities include: skeletal muscle dysfunction and exercise intolerance, systemic inflammation, nutritional abnormalities and weight loss, and others (such as cardiovascular, nervous system and 
osteoskeletal effects)..$^{7-9}$ There is ongoing debate about the major contributing factors to the development of systemic effects of COPD, but it is suggested that physical inactivity, systemic inflammation, poor nutrition, hypoxia and medication are all involved. ${ }^{7-9}$ Because of the scope of this thesis, the focus will be on the systemic consequences of skeletal muscle dysfunction and exercise intolerance. Systemic inflammation will be dwelled upon shortly, because of the direct or indirect link between the two processes.

The main structural changes of the skeletal muscles that have been reported are atrophy, shift in fibre-type, poor oxidative capacity, mitochondrial dysfunction and weakness (Figure 1.2). Most of these structural changes have been found in the quadriceps. The upper limb muscles are relatively preserved from these structural changes. $^{10}$

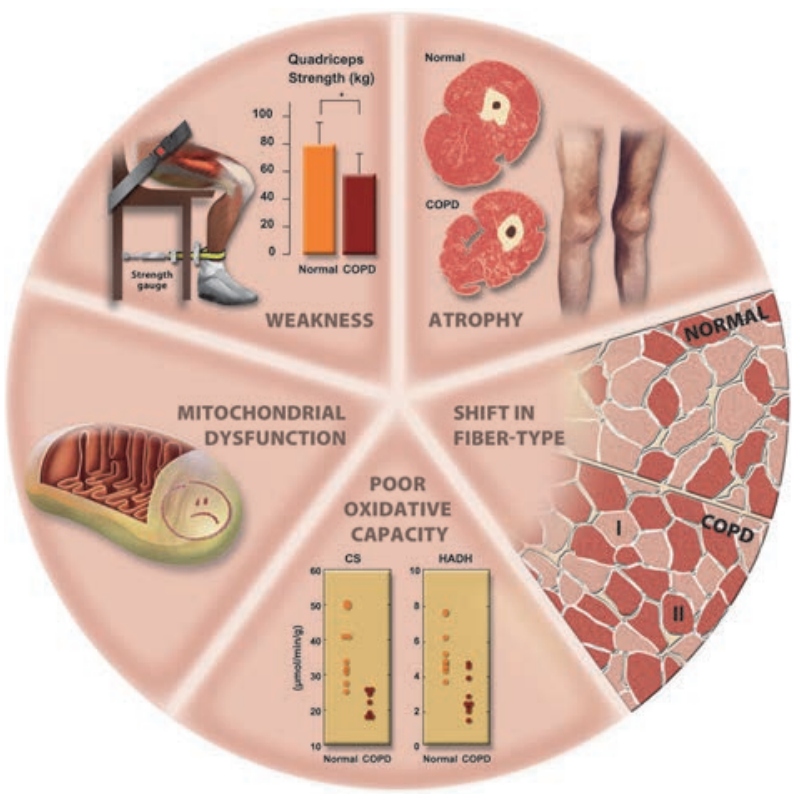

Figure 1.2 Morphological and structural alterations reported in skeletal muscles in patients with COPD (from Maltais et al., 2014).

These structural changes can result in an alteration of skeletal muscle function, for example muscle weakness and reduced endurance. In patients with mild to moderate COPD, a population in which muscle weakness would not be expected as a major issue, a total of $20 \%$ has shown to have muscle weakness. ${ }^{11}$ Skeletal muscle 
dysfunction has a negative impact on physical activity, exercise tolerance, quality of life, health care use and even survival. ${ }^{10}$ However, attention must be paid to the fact that the far majority of the studies on skeletal muscle dysfunction have only involved patients with severe to very severe COPD. Skeletal muscle dysfunction is linked with increased levels of systemic inflammation and therefore, these processes are likely to be interrelated. ${ }^{9}$ Low-grade systemic inflammation, particularly in those with higher resting energy expenditure and lower fat-free mass, have been found in patients with COPD. ${ }^{9}$ Several theories regarding the mechanisms of the systemic inflammation in COPD have been proposed. It was previously thought that spill-over of the local inflammatory response might be a driver of the systemic inflammatory response ${ }^{12}$, but more recent evidence has shown that COPD may result from accelerated lung aging (the senescence hypothesis). ${ }^{9,13,14}$ The basic of the senescence hypothesis is that oxidative stress related to cigarette smoking, increases cell turnover and induces direct DNA damage, causing the cells to age. At organ and tissue level, this can lead to accelerated loss in function contributing to the local and systemic manifestations of COPD. ${ }^{12,14,15}$

Symptoms in COPD do not solely arise from the degree of airflow limitation, but the systemic effects and comorbidities contribute substantially to its burden and prognosis. ${ }^{8,9}$ And importantly, most of these are treatable. ${ }^{8}$ Pulmonary rehabilitation targets the systemic manifestations of COPD and has been proven to be very effective in reducing dyspnoea, increasing exercise capacity and improving quality of life. ${ }^{6}$ Exercise training is considered to be the cornerstone of pulmonary rehabilitation. ${ }^{6}$ Up till now, the far majority of the studies is performed in patients with moderate to severe COPD recruited, assessed and treated in pulmonary rehabilitation or hospital settings. Patients with mild to moderate COPD mainly receive their medical treatment in primary care. The Practice Guideline COPD of the Dutch College of General Practitioners (NHG standard, 2007) recommends general practitioners (GP's) to advise all patients with COPD to be sufficient physically active. ${ }^{16}$ Referral to a physical exercise training programme in a physiotherapy setting is advised only in patients with moderate to severe COPD, who have impairments in physical functioning due to dyspnoea and diminished exercise capacity.

\section{Physical activity and exercise training}

Physical activity and exercise training are closely related concepts that describe human movement. These concepts are often confused with one another and sometimes used interchangeable. ${ }^{17}$ Physical activity is defined as any bodily 
movement produced by the contraction of skeletal muscle and that substantially increases energy expenditure. ${ }^{18}$ Physical activity reflects what a person actually does on regular basis and has a strong behavioural component apart from the physical component. Exercise training is physical activity that is planned, structured, repetitive and purposive in the sense that improvement of one or more components of physical fitness is the objective. It is a subcategory of physical activity. ${ }^{17}$ A crucial element is that exercise intends to improve components of physical fitness, rather than to maintain an established level. Physical fitness, for its turn, is defined as the ability to carry out daily tasks with vigour and alertness, without undue fatigue and with ample energy to enjoy leisure time pursuits and to meet unforeseen emergencies. ${ }^{17}$ Physical fitness includes several components, including cardiorespiratory exercise capacity, muscle endurance and strength, flexibility, balance, speed and body composition. To promote and maintain health, all adults need moderate-intensity aerobic (endurance) physical activity for a minimum of 150 minutes each week or vigorous-intensity aerobic physical activity for a minimum of 75 minutes each week. In addition, every adult should perform activities that maintain or increase muscular strength and endurance a minimum of 2 days each week. ${ }^{19}$ If older adults or chronically ill cannot obtain these recommendations, they should be as physically active as their abilities and conditions allow. ${ }^{20}$ Anyhow, all adults should avoid inactivity, some physical activity is better than none. Adults who participate in any amount of physical activity gain some health benefits. However, additional benefits occur as the amount of physical activity increases through higher intensity, greater frequency and/or longer duration. $^{20}$

\section{Physical activity and exercise training in patients with COPD}

Patients with COPD are markedly inactive in daily life compared to healthy adults with the same age, most likely as a strategy to minimize dyspnoea. ${ }^{21}$ Inactivity is believed to be crucial to the development of the local and systemic consequences of COPD. ${ }^{6}$ Lower levels of physical activity in COPD have been associated with a more rapid decline in lung function, exacerbations, impaired health-related quality of life, increased health care utilization and reduced survival. ${ }^{22-26}$ Regular physical activity in COPD patients has therefore important long-term health-related benefits.

Exercise training is very effective, for the short-term, in improving exercise capacity, muscular strength, reducing breathlessness and fatigue. ${ }^{6}$ So, it seems an advantageous treatment to lower the barrier to become physically more active. Pulmonary rehabilitation and pulmonary rehabilitation-studies have traditionally 
focused on improving exercise capacity on the assumption that this would automatically lead to an enhanced physical activity. Surprisingly few studies have investigated whether pulmonary rehabilitation really increases daily physical activity. The results of these studies are inconsistent, but the majority of recent intervention studies show that improved exercise capacity after pulmonary rehabilitation is not transmitted into increased daily physical activity. ${ }^{27-31}$ It is proposed that larger randomized controlled trials are needed in this area. ${ }^{27}$

\section{Relevance}

From a patients' perspective, an increase in exercise capacity as a result of exercise training, could be beneficial in order to stop the downward spiral of symptom-induced inactivity, deconditioning, muscle weakness, the fear of movement and reduced quality of life at an early stage of the disease. To sustain the improvement in exercise capacity and to gain long term health benefits, exercise training has to be accompanied by enhanced daily physical activity, which requires structural behaviour change by the patient. ${ }^{6}$ Since behavioural research suggests that modifying behavioural patterns and coping styles takes time to be effective ${ }^{32}$, it could be proposed that regular exercise should be started early in the course of the disease for maximal effect. It seems advantageous to initiate exercise training when the symptoms of dyspnoea and deconditioning are not very pronounced. Furthermore, it is proposed that in patients with a relatively preserved lung function, the physiological reserve for improvement is much larger than in patients with (very) severe disease. ${ }^{33}$ Treatment of COPD at an early stage could also lessen the burden of disease for society. ${ }^{34}$ COPD is one of the leading causes of morbidity and mortality worldwide and imparts a substantial economic burden. ${ }^{35}$ COPD-related illness costs are disproportionately distributed, with $10 \%$ of the patients (mostly patients in the more severe stages of the disease) accounting for $73 \%$ of the total costs, in which hospitalization is the largest contributor. ${ }^{35}$ An exercise training programme in primary care can be a relatively cheap and an easily accessible intervention for more patients than an expensive hospital-based rehabilitation programme. ${ }^{36}$ Although longitudinal studies are lacking, it is suggested that early recognition of progression of exercise impairment, especially in less advanced COPD patients, is relevant to prevent further deterioration of functional capacity. ${ }^{33,37}$ 


\section{Usual care for COPD in primary care}

Current medical treatment in primary care patients with COPD consists of nonmedical treatment (smoking cessation, stimulation of physical activity and nutritional support on indication) and pharmacotherapy (bronchodilators). ${ }^{16}$ All patients with COPD are advised by the general practitioner or nurse practitioner to be sufficient physically active. Referral to a physical exercise training programme in a physiotherapy setting is recommended only in patients with moderate to severe COPD, who have impairments in physical functioning due to dyspnoea. As of 2010, there is a new development in the primary care organization of patients with chronic disease in the Netherlands, including COPD. Disease management programmes have regionally been developed by general practitioners in collaboration with other caregivers in primary care. General practitioners and/or nurse practitioners have a central role. Their COPD care entails lung function testing, prescription of pharmacotherapy and counselling on smoking cessation, inhalation technique and physical activity. There is the possibility to refer patients with mild to moderate COPD to registered physiotherapists, experienced in COPD care. The implementation of this disease management programme for COPD is encouraged by the reimbursement through so-called chained diagnose-treatment combination (DTC). ${ }^{37}$ Although in some regions in the Netherlands these disease management programmes for COPD are already implemented and serve as usual care, no evidence on the effectiveness of these programmes is available. In addition, no data are available on the added value of a physical exercise training programme compared to the advice on increasing daily physical activity in usual care. The physical exercise training programme COPD that we developed in our study region consisted of an intake/assessment procedure of 2 sessions, 8 individual sessions and 24 group sessions, implying a total duration of 4 months. Patients could enter the programme upon referral through their general practitioner or nurse practitioner.

\section{Aim and research questions}

The general aim of this PhD research was to evaluate the efficacy of a physical exercise training programme in patients with mild to moderate COPD. This thesis focuses on the following research questions:

- What are the clinical characteristics of patients with mild to moderate COPD who are referred to a physical exercise training programme? 
- What is the relationship between exercise capacity and physical activity in patients with mild to moderate COPD referred to an exercise training programme?

- What is the efficacy of a physical exercise training programme COPD in primary care in comparison to advise on increasing daily physical activity?

- Which clinical characteristics and/or burden of disease factors modify the effect of this programme on functional exercise capacity?

\section{Outline of the thesis}

While the study to the efficacy of a physical exercise training programme COPD in a RCT setting is the main aim of the research project, there is one common theme in this thesis: exercise training and physical activity in patients with mild to moderate COPD.

In the last decade, much more attention is paid to daily physical activity in patients with COPD, due to the development of electronic devices like accelerometers and activity monitors. Hence, the awareness of the low physical activity levels in general in these patients is acknowledged nowadays. In chapter $\mathbf{2}$, the insight in individual physical activity patterns are described and the purpose/usefulness of physical activity measurement in clinical practice is elaborated upon. Insight in actual physical activity patterns of a COPD patient could enable practitioners to fine tune referral to pulmonary rehabilitation or an exercise training programme. Furthermore, it might be a starting point for individual advice or a training programme.

In chapter 3, the study protocol of the randomized controlled trial regarding the efficacy of a physical exercise training programme for patients with mild to moderate COPD is described. An extensive description of the background, intervention and control treatment, randomization, sample size calculation, outcome measures and planned analysis is given. Moreover, specific choices in methods, limitations and potential barriers are elaborated upon.

There is little information on the population of patients with mild to moderate COPD present in primary care who are referred to an exercise training programme. In chapter 4 , baseline characteristics of the study population are described. We were particularly interested in the relationship between exercise capacity and physical activity. From studies in patients with moderate to severe COPD, it was observed that a moderate relationship exists between exercise capacity and physical activity. As a result, the six-minute walk test is validated as a test to reflect functional exercise level for daily physical activity. It is unknown if this also applies to patients with mild to 
moderate COPD, so the relationship between functional exercise capacity and physical activity in this patient category is assessed.

Chapter 5 describes the clinical outcomes of the randomized controlled trial evaluating the efficacy of a physical exercise training programme in patients with mild to moderate COPD in primary care. Data from 90 patients were analysed and the results can be regarded as the basis of this thesis.

Regardless of a potential efficacy of exercise training on group level, some patients with COPD find much benefit in such a programme, whereas others show hardly any or no improvement at all. To offer personalised care, it is important to understand which factors influence the effect of the treatment. In chapter 6, if and how patient characteristics and baseline burden of disease modify the effect of a physical exercise training programme on functional exercise capacity are explored.

In the general discussion in chapter $\mathbf{7}$, the major findings are summarized and their implications for clinical practice and future research are discussed. 


\section{References}

1. Vestbo J, Hurd SS, Agustí AG, Jones PW, Vogelmeier C, Anzueto A, Barnes PJ, Fabbri LM, Martinez FJ, Nishimura M, Stockley RA, Sin DD, Rodriguez-Roisin R. Global strategy for the diagnosis, management, and prevention of chronic obstructive pulmonary disease: GOLD executive summary. Am J Respir Crit Care Med 2013;187:347-65.

2. Lopez AD, Shibuya K, Rao C, Mathers CD, Hansell AL, Held LS, Schmid V, Buist S. Chronic obstructive pulmonary disease: current burden and future projections. Eur Respir J 2006;27:397-412.

3. Diaz-Guzman E, Mannino DM. Epidemiology and prevalence of chronic obstructive pulmonary disease. Clin Chest Med 2014;35:7-16.

4. World Health Organization (WHO). Factsheet N.310. Updated May 2014 [Available at: www.who.int/mediacentre/factsheets/fs310/en/]

5. Nussbaumer-Ochsner Y, Rabe KF. Systemic manifestations of COPD. Chest 2011;139:165-73.

6. Spruit MA, Singh SJ, Garvey C, ZuWallack R, Nici L, Rochester C, Hill K, Holland AE, Lareau SC, Man WD, Pitta F, Sewell L, Raskin J, Bourbeau J, Crouch R, Franssen FM, Casaburi R, Vercoulen JH, Vogiatzis I, Gosselink R, Clini EM, Effing TW, Maltais F, van der Palen J, Troosters T, Janssen DJ, Collins E, GarciaAymerich J, Brooks D, Fahy BF, Puhan MA, Hoogendoorn M, Garrod R, Schols AM, Carlin B, Benzo R, Meek P, Morgan M, Rutten-van Mölken MP, Ries AL, Make B, Goldstein RS, Dowson CA, Brozek JL, Donner CF, Wouters EF; ATS/ERS Task Force on Pulmonary Rehabilitation. An Official American Thoracic Society/European Respiratory Society Statement: Key Concepts and Advances in Pulmonary Rehabilitation. Am J Respir Crit Care Med 2013;188:e13-e64.

7. Decramer M, Rennard S, Troosters T, Mapel DW, Giardino N, Mannino D, Wouters E, Sethi S, Cooper $\mathrm{CB}$. COPD as a lung disease with systemic consequences--clinical impact, mechanisms, and potential for early intervention. COPD 2008;5:235-56.

8. Agusti A, Soriano JB. COPD as a systemic disease. COPD 2008;5:133-8.

9. Evans RA, Morgan MD. The systemic nature of chronic lung disease. Clinics in chest medicine 2014; 35:283-93.

10. Maltais F, Decramer M, Casaburi R, Barreiro E, Burelle $Y$, Debigaré R, Dekhuijzen PN, Franssen F, Gayan-Ramirez G, Gea J, Gosker HR, Gosselink R, Hayot M, Hussain SN, Janssens W, Polkey MI, Roca J, Saey D, Schols AM, Spruit MA, Steiner M, Taivassalo T, Troosters T, Vogiatzis I, Wagner PD; ATS/ERS Ad Hoc Committee on Limb Muscle Dysfunction in COPD. An official American Thoracic Society/European Respiratory Society statement: update on limb muscle dysfunction in chronic obstructive pulmonary disease. Am J Respir Crit Care Med 2014;189:e15-62.

11. Seymour JM, Spruit MA, Hopkinson NS, Natanek SA, Man WD, Jackson A, Gosker HR, Schols AM, Moxham J, Polkey MI, Wouters EF. The prevalence of quadriceps weakness in COPD and the relationship with disease severity. Eur Respir J 2010;36:81-8.

12. Fabbri LM, Rabe KF. From COPD to chronic systemic inflammatory syndrome? Lancet 2007;370:797-9.

13. Ito K, Barnes PJ. COPD as a disease of accelerated lung aging. Chest 2009;135:173-80.

14. Lee J, Sandford A, Man P, Sin DD. Is the aging process accelerated in chronic obstructive pulmonary disease? Curr Opin Pulm Med 2011;17:90-7.

15. MacNee W. Accelerated lung aging: a novel pathogenic mechanism of chronic obstructive pulmonary disease (COPD). Bioche Soc Trans 2009;37:819-23.

16. Smeele IJM VWC, Van Schayck CP, Van der, Molen T TB, Schermer T, Sachs APE, Muris, JWM CN Kolnaar BGM, Grol MH, RMM. G. NHG-Standaard COPD, tweede herziening Huisarts Wet 2007;50: 362-379.

17. Caspersen CJ, Powell KE, Christenson GM. Physical activity, exercise, and physical fitness: definitions and distinctions for health-related research. Public Health Rep 1985;100:126-31. 
18. Thompson PD, Buchner D, Pina IL, Balady GJ, Williams MA, Marcus BH, Berra K, Blair SN, Costa F, Franklin B, Fletcher GF, Gordon NF, Pate RR, Rodriguez BL, Yancey AK, Wenger NK; American Heart Association Council on Clinical Cardiology Subcommittee on Exercise, Rehabilitation, and Prevention; American Heart Association Council on Nutrition, Physical Activity, and Metabolism Subcommittee on Physical Activity. Exercise and physical activity in the prevention and treatment of atherosclerotic cardiovascular disease: a statement from the Council on Clinical Cardiology (Subcommittee on Exercise, Rehabilitation, and Prevention) and the Council on Nutrition, Physical Activity, and Metabolism (Subcommittee on Physical Activity). Circulation 2003;107:3109-16.

19. Haskell WL, Lee IM, Pate RR, Powell KE, Blair SN, Franklin BA, Macera CA, Heath GW, Thompson PD, Bauman A. Physical activity and public health: updated recommendation for adults from the American College of Sports Medicine and the American Heart Association. Med Sci Sports Exerc 2007; 39:1423-34.

20. American College of Sports M, Chodzko-Zajko WJ, Proctor DN, Fiatarone Singh MA, Minson CT, Nigg CR, Salem GJ, Skinner JS. American College of Sports Medicine position stand. Exercise and physical activity for older adults. Med Sci Sports Exerc 2009;41:1510-30.

21. Pitta F, Troosters T, Spruit MA, Probst VS, Decramer M, Gosselink R. Characteristics of physical activities in daily life in chronic obstructive pulmonary disease. Am J Respir Crit Care Med 2005;171: 972-7.

22. Garcia Aymerich J, Lange P, Benet M, Schnohr P, Anto JM. Regular physical activity modifies smokingrelated lung function decline and reduces risk of chronic obstructive pulmonary disease: a populationbased cohort study. Am J Respir Crit Care Med 2007;175:458-63.

23. Garcia Aymerich J, Lange P, Benet M, Schnohr P, Anto JM; Regular physical activity reduces hospital admission and mortality in chronic obstructive pulmonary disease: a population based cohort study. Thorax 2006;61:772-8.

24. Schlenk EA, Erlen JA, Dunbar-Jacob J, McDowell J, Engberg S, Sereika SM, Rohay JM, Bernier MJ. Health-related quality of life in chronic disorders: a comparison across studies using the MOS SF-36. Qual Life Res 1998;7:57-65.

25. Pitta F, Troosters T, Probst VS, Spruit MA, Decramer M, Gosselink R. Quantifying physical activity in daily life with questionnaires and motion sensors in COPD. Eur Respir J 2006;27:1040-55.

26. Watz H, Waschki B, Boehme C, Claussen M, Meyer T, Magnussen H. Extrapulmonary effects of chronic obstructive pulmonary disease on physical activity: a cross-sectional study. Am J Respir Crit Care Med 2008;177:743-51.

27. Cindy Ng LW, Mackney J, Jenkins S, Hill K. Does exercise training change physical activity in people with COPD? A systematic review and meta-analysis. Chron Respir Dis 2012;9:17-26.

28. Egan C, Deering BM, Blake C, Fullen BM, McCormack NM, Spruit MA, Costello RW. Short term and long term effects of pulmonary rehabilitation on physical activity in COPD. Respir Med 2012; 106:1671-9.

29. Mador MJ, Patel AN, Nadler J. Effects of pulmonary rehabilitation on activity levels in patients with chronic obstructive pulmonary disease. J Cardiopulm Rehabil Prev 2011;31:52-9.

30. Probst VS, Kovelis D, Hernandes NA, Camillo CA, Cavalheri V, Pitta F. Effects of 2 exercise training programs on physical activity in daily life in patients with COPD. Respir Care 2011;56:1799-807.

31. Zwerink $M$, van der Palen J, van der Valk $P$, Brusse Keizer M, Effing $T$ : Relationship between daily physical activity and exercise capacity in patients with COPD. Respir Med 2013;107:242-8.

32. Wempe JB, Wijkstra PJ: The influence of rehabilitation on behaviour modification in COPD. Patient Educ Couns 2004;52:237-41.

33. Chavannes NH, Grijsen M, van den Akker M, Schepers H, Nijdam M, Tiep B, Muris J. Integrated disease management improves one-year quality of life in primary care COPD patients: a controlled clinical trial. Prim Care Respir J 2009;18:171-6.

34. Van der Molen T. Chronic Obstructive Pulmonary Disease - The burden of mild to moderate disease. Eur Res Dis 2010;6:24-7.

35. Sullivan SD, Ramsey SD, Lee TA. The economic burden of COPD. Chest 2000;117(2 Suppl):5s-9s.

36. Hoogendoorn $M$, van Wetering $C R$, Schols $A M$, Rutten van Molken MP. Is INTERdisciplinary COMmunity-based COPD management (INTERCOM) cost-effective? Eur Respir J 2010;35:79-87. 
37. Van Wetering CR. Clinical evaluation and cost-effectiveness of a community-based COPD management program. PhD thesis. Maastricht: Maastricht University; 2010. 


\section{Chapter 2}

Insight in physical activity patterns in COPD patients: a starting point for treatment?

Annemieke Fastenau, Geertjan Wesseling, Jean WM Muris, Onno CP van Schayck Eur Respir Dis 2011;7:134-6 


\section{Abstract}

Patients with COPD are very inactive. If they could increase their level of physical activity, they would experience substantial health benefits.

The aim of therapeutic interventions should be the enhancement of physical activity.

We propose to use data from actual physical activity, not only as an outcome measure, but as a starting point for treatment in order to fine-tune coaching and exercise training for the individual patient. 


\section{Introduction}

There is a strong link between physical inactivity and chronic diseases. ${ }^{1}$ Especially in COPD there is a "logical" explanation for the existing inactivity. Patients with COPD experience shortness of breath particularly during activities. This may lead to a vicious circle of avoiding physical activities, deconditioning, muscle weakness, more shortness of breath and sometimes even the fear of physical activity. Since, in general, COPD is a slowly developing disease, patients unintentionally adjust their lifestyle and do not trigger their symptoms by being very active.

Even in early stages of the disease (Gold Stage II) there is a significant reduction in physical activity compared to healthy age-matched persons. ${ }^{2}$

Why is it so important for patients with COPD to have regular physical activity? In the long term, it is suggested that patients with COPD who had regular physical activity, have a lower risk of hospital admissions and mortality in comparison with inactive patients with COPD. ${ }^{3}$ In the short term, physical activity is a non-pharmacological treatment that can successfully counteract the consequences of the vicious circle. Inactivity is believed to be crucial to the development of systemic consequences of COPD, such as skeletal muscle weakness, osteoporosis and cardiovascular disease. Epidemiological data suggest that low levels of physical activity may lead to more rapid decline in lung function. ${ }^{5}$

It is seen, in those patients who succeeded in becoming more physically active, that there are beneficial physiologic effects, for example an improved muscular skeletal muscle oxidative capacity and a reduction in arterial lactic acid concentration and minute ventilation for a given exercise level. ${ }^{6,7}$

Therefore, current COPD guidelines recommend patients to increase their levels of regular physical activity.

Nowadays, referral to pulmonary rehabilitation (PR) or a physical exercise training programme (PETP) in primary care is primarily based upon lung function and complaints of dyspnoea and deconditioning. However, it is known that immediately after PR, lung function in COPD patients is not subject to great changes, if at all. In some patients, also the degree of dyspnea will not be diminished after PR, but the amount of activities will be increased with the same experienced shortness of breath. In other words, with a certain amount of dyspnea, a person could sit down on the sofa all day or could be physically and socially active after PR. 
On the other hand, the capacity to exercise could be improved, but whether the patient actually uses this improved capacity to be more active in daily life remains unclear.

Therefore, the ultimate goal should be to enhance the physical activity of the patient in daily life (a behavioural change) and to enable patients to perform those activities that they wish to perform or are required.

We wonder why there is so little emphasis in diagnosis and treatment regarding physical activity patterns of COPD patients. It is our assumption that more insight in individual physical activity patterns is not only a useful outcome measure for treatment, but it helps clinicians in primary and secondary care to fine-tune their coaching and treatment strategies.

\section{Pilot study}

To get more insight in the physical activity patterns in daily life we conducted a pilot study in patients with mild to moderate COPD, who were referred to a PETP in primary care.

In patients with mild to moderate COPD, daily activity was measured during 3 days and nights with an accelerometer-based activity monitor (Dynaport; McRoberts BV). In addition to general information about time spent on different activities and body positions, amount of steps and average movement intensity during walking, we also collected data of activity patterns (daily trends). Furthermore, patients kept a diary in which they recorded their activities.

So far, 15 patients have completed all measurements. Steps per day ranged from 1608 to nearly 12000 . Only 2 patients reached the recommended 10000 steps per day. ${ }^{8}$ Five patients did not even reach 3000 steps per day.

Daily activity patterns were very variable in terms of duration and frequency of activities, body positions and movement intensities.

Patients who could be overall classified as equally active ( $27 \%$ vs. $26 \%$ during the day), show a very different activity pattern. We would like to illustrate this with an example of 2 patients (with no comorbidities), see Figure 2.1. 
Patient 1 (less pulmonary obstruction, but more dyspnea and poorer functional capacity) was on average highly active during one period of the day (cycling for 20 minutes) and was relatively inactive during the rest of the day.

Patient 2 (more pulmonary obstruction, less dyspnea and a better functional capacity) had a lower movement intensity during his activities, but had active moments in all periods of the day.

General Information

Relative active, sedentary and not worn time

Patient 1
$\begin{array}{ll}\text { Age } & 42 \\ \text { BMI } & 25 \\ \text { FEV1\%pred } & 68 \\ \text { MRC } & 3 \\ \text { 6MWD\%pred } & 52\end{array}$

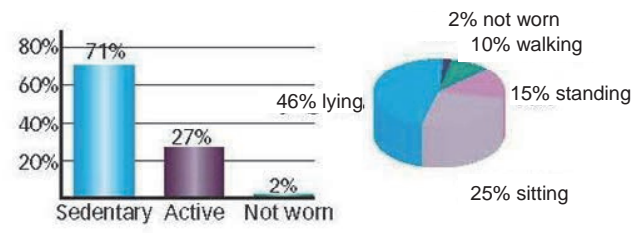

Avtivity on Tue 24th August 2010

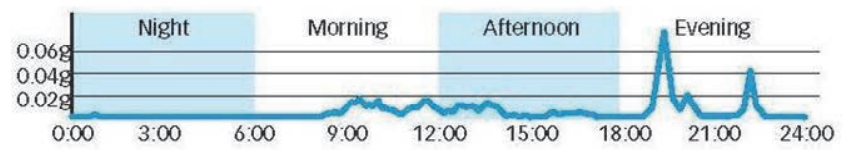

General Information

Relative active, sedentary and not worn time

Patient 2

$\begin{array}{ll}\text { Age } & 66 \\ \text { BMI } & 31 \\ \text { FEV1\%pred } & 51 \\ \text { MRC } & 2 \\ \text { 6MWD\%pred } & 73\end{array}$

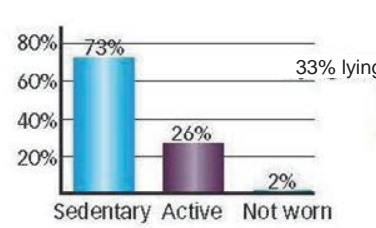

$2 \%$ not worn

$4 \%$ walking

Avtivity on Thu 10th Feb 2011

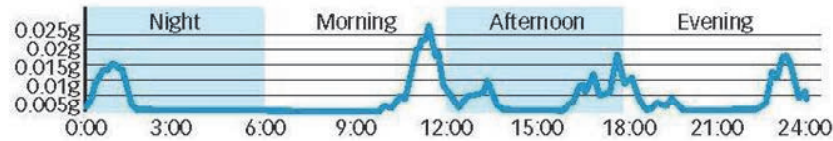

Figure 2.1 Two examples of physical activity patterns of patients with COPD. 


\section{Discussion}

Our pilot study confirms physical inactivity in patients with COPD. Activity patterns vary a lot in terms of duration, frequency, intensity and kind of activities.

For research purposes it is interesting to quantify physical activities in patients with COPD and compare them with healthy persons or to use it as an outcome measure of therapeutic interventions. For individual patients though, there should be more benefits.

Physical activity measurement could be a feedback instrument which facilitates coaching strategies and optimises an exercise training programme. For the patient, this could lead to improvement in awareness of his/her physical activity.

For example, according to the data of our 2 patients, the first patient should consider to increase his frequency of physical activities during the day. The other patient could try to perform his activities or exercise training programme with more intensity.

In the elderly, it is assumed that regular moderate-intensity physical activity has other health benefits than more strenuous exercises. The former is considered to have its effects on whole body metabolism and reductions in risk factors for chronic diseases and all-cause mortality. ${ }^{9}$ The latter has got additional impact on skeletal muscle. ${ }^{10}$ Musculoskeletal fitness appears to be particularly important for elderly people and their ability to maintain functional independence. In fact, many activities of daily living do not require a large aerobic output but depend on one or more of the musculoskeletal fitness components. ${ }^{11,12}$

We support the statement of Morgan ${ }^{13}$ in which he describes that spontaneous daily activity is clearly a different domain of outcome assessment from the traditional measures of airway function, functional exercise capacity and quality of life. And that we should be able to develop a greater insight into the lives of people who are disabled by breathlessness and offer treatment that really gets to the heart of the matter. ${ }^{13}$ We would like to elaborate on this discussion by adding that reliable information about physical activity patterns of patients with COPD will result in more insight in actual physical behaviour, for the clinician as well for the patient him/herself.

This should be the starting point of a tailor-made advice and/or exercise training programme. As a consequence, the aims of the treatment will be relevant to the individual patient. Endpoints of research will meet the requirements of the COPD 
patients. And finally, physical activity measurements can be used to fine-tune the referral for PR or a PETP and in the assessment of the effectiveness of treatment.

Beyond all doubt, exercise training of patients with COPD should be according to current scientific knowledge. ${ }^{14}$ Preferably, results of a maximal ergometry test should be the base for the endurance component of a training programme.

In addition, we propose to use data from daily activity patterns to ensure a tailormade advice or exercise training programme for the individual patient, especially in primary care. A primary care setting is very close to the daily life situation of the patient and treatment can be applied to daily life easier than in other medical settings.

Conclusion: insight in physical activity patterns in COPD patients could be a starting point of diagnosis and treatment, especially in primary care. Further research is needed to underpin this point of view. 


\section{References}

1. Warburton DE, Nicol CW, Bredin SS. Health benefits of physical activity: the evidence. CAMJ 2006;174:801-9.

2. Troosters T, Sciurba F, Battaglia S, Langer D, Valluri SR, Martino L, Benzo R, Andre D, Weisman I, Decramer M. Physical inactivity in patients with COPD, a controlled multi-center pilot-study. Respiratory Medicine 2010;104:1005-11.

3. Garcia-Aymerich J, Lange P, Benet M, Schnohr P, Antó JM. Regular physical activity reduces hospital admission and mortality in chronic obstructive pulmonary disease: a population based cohort study. Thorax 2006;61:772-8.

4. Booth FW, Gordon SE, Carlson CJ, Hamilton MT. Waging war on modern chronic diseases: primary prevention through exercise biology. J Appl Physiol 2000;88:774-87.

5. Garcia-Aymerich J, Lange P, Benet M, Schnohr P, Antó JM. Regular physical activity modifies smokingrelated lung function decline and reduces risk of chronic obstructive pulmonary disease: a populationbased cohort study. Am J Respir Crit Care Med 2007;175:458-63.

6. Casaburi R, Patessio A, Ioli F, Zanaboni S, Donner CF, Wasserman K. Reductions in exercise lactic acidosis and ventilation as a result of exercise training in patients with obstructive lung disease. $A m$ Rev Respir Dis 1991;143:9-18.

7. Maltais F, LeBlanc P, Simard C, Jobin J, Bérubé C, Bruneau J, Carrier L, Belleau R. Skeletal muscle adaptation to endurance training in patients with chronic obstructive pulmonary disease. Am J Respir Crit Care Med 1996;154:442-7.

8. Tudor-Locke C, Basset Jr DR. How many steps/day are enough? Preliminary pedometer indices for public health. Sports Med 2004;34:1-8.

9. Pate RR, Pratt M, Blair SN, Haskell WL, Macera CA, Bouchard C, Buchner D, Ettinger W, Heath GW King $A C$, et al. Physical activity and public health: a recommendation from the CDC and ACSM. JAMA 1995;273:402-7.

10. Kirkendall DT, Garrett WE Jr. The effects of aging and training on skeletal muscle. Am J Sports Med 1998;26:598-602.

11. Warburton DE, Gledhill N, Quinney A. Musculoskeletal fitness and health. Can J Appl Physiol 2001;26:217-37.

12. Warburton DE, Glendhill N, Quinney A. The effects of changes in musculoskeletal fitness on health. Can J Appl Physio, 2001;26:161-216.

13. Morgan M. Life in slow motion: quantifying physical activity in COPD. Thorax. 2008;63:663-4.

14. Nici L, Donner C, Wouters E, Zuwallack R, Ambrosino N, Bourbeau J, Carone M, Celli B, Engelen M, Fahy B, Garvey C, Goldstein R, Gosselink R, Lareau S, Maclntyre N, Maltais F, Morgan M, O'Donnell D, Prefault C, Reardon J, Rochester C, Schols A, Singh S, Troosters T; ATS/ERS Pulmonary Rehabilitation Writing Committee. ATS/ERS Pulmonary Rehabilitation Writing Committee. American Thoracic Society/European Respiratory Society statement on pulmonary rehabilitation. Am J Respir Crit Care Med. 2006;173:1390-413. 


\section{Chapter 3}

Efficacy of a physical exercise training programme COPD in primary care: study protocol of a randomized controlled trial

Annemieke Fastenau, Jean WM Muris, Rob A de Bie, Erik JM Hendriks, Guus M Asijee, Emmylou Beekman, Rik Gosselink, Onno CP van Schayck BMC Public Health 2014;14:788 


\section{Abstract}

\section{Background}

Chronic obstructive pulmonary disease (COPD) is recognized as a systemic illness with significant extra-pulmonary features, such as exercise intolerance and muscle weakness. Pulmonary rehabilitation has been shown to be very effective in counteracting these consequences in patients with more advanced COPD. However, limited data is available on the efficacy of a physical exercise training programme in patients with mild to moderate COPD in primary care. Furthermore, it is unknown if improved exercise capacity translates into enhanced daily physical activities. The aim of this paper is to describe the design of a randomized controlled trial to assess the efficacy of a physical exercise training programme in patients with mild to moderate COPD.

\section{Methods/design}

In this randomized controlled trial situated in the primary care setting, 102 patients with mild to moderate airflow obstruction ( $\mathrm{FEV}_{1} \geq 50 \%$ of predicted), dyspnoea and a physically inactive lifestyle will be randomized to an intervention or control group. The intervention group receives a 4-month physical exercise training programme at a local physiotherapy practice, which includes exercise training, resistance training, breathing exercises and advises on how to increase the level of physical activity. The control group receives usual care, i.e. advises on how to increase the level of physical activity and a sham treatment at a local physiotherapy practice of which no physiological training stimulus can be expected. Primary outcome is functional exercise capacity at 4-months measured on the six-minute walk distance. Secondary outcomes include peripheral muscle strength, physical activity in daily life, health related quality of life, Medical Research Council (MRC) dyspnoea score and patients' perceived effectiveness. Followup measurement will take place at 6 months after baseline.

\section{Discussion}

This will be one of the first studies to evaluate the efficacy of a physical exercise training programme in patients with mild to moderate COPD completely recruited and assessed in primary care. The results of this trial may give a unique insight into the potential of the implementation of an easy, close-to-home rehabilitation programme. 


\section{Background}

In patients with chronic obstructive pulmonary disease (COPD), disease severity and prognosis are not only determined by lung function impairment, but are also related to extra-pulmonary consequences of COPD such as muscle weakness and exercise intolerance. ${ }^{1-3}$ The exercise training component of pulmonary rehabilitation (PR) has been shown to be very effective in improving exercise capacity, dyspnoea and quality of life. ${ }^{4}$ As a result, for patients with moderate to very severe COPD and breathlessness (MRC dyspnoea score $>2$ ) exercise training is recommended as part of $P R$ in national and international guidelines. ${ }^{1,5}$ Another extra-pulmonary feature of COPD is the decline in daily physical activity (PA). ${ }^{6}$ Only a few trials have investigated the effect of exercise training on changes in daily physical activity. ${ }^{7-11}$ These studies showed contradictory results, ranging from significant improvements in $\mathrm{PA}^{8,9}$ after exercise training, to small or moderate effects ${ }^{7,10}$ and no effects at all. ${ }^{11}$ Overall, current data indicate that exercise training results in a significant but small effect on PA and that larger randomized controlled trials ( $\mathrm{RCT}^{\prime} \mathrm{s}$ ) are needed in this area. ${ }^{12}$

A differentiation should be made in the improvement of exercise capacity on the one hand and improvement of daily physical activity on the other. Improvement in exercise capacity fulfils the short-term goal of reducing breathlessness and fatigue ${ }^{11}$, improving muscle strength and thus lowers the barriers to be physically more active. ${ }^{10}$ Regular physical activity in COPD patients has important long-term health-related benefits, like a lower risk of COPD related hospital admissions and decreased mortality. ${ }^{13}$ Furthermore, low physical activity has been associated with systemic inflammation, cardiac dysfunction and lung function decline. ${ }^{13,14}$

All abovementioned studies were performed in a clinical or rehabilitation setting in COPD patients in more advanced GOLD stages. ${ }^{4}$ However, patients with moderate COPD also have impairments in exercise capacity, respiratory muscle function, limb muscle force and quality of life. ${ }^{15-18}$ In addition, the level of physical activity is already decreased in patients with moderate COPD compared to healthy control subjects. ${ }^{14,19,20}$ Scant information is available on the effects of community-based exercise training programmes in general and even less about their effect on daily activity. ${ }^{9}$ Exercise training programmes in patients with moderate to severe COPD, when incorporated in (self)-management or integrated disease management programmes in primary care, result in improvements in health-related quality of life, breathlessness, exercise capacity, muscle strength, daily physical activity, reduced hospital admissions and hospital days per person., ${ }^{91-24}$ Recruitment and assessment was done in the respiratory department of general hospitals ${ }^{9,21}$ or the intervention was multifaceted (i.e. involved more than exercise therapy alone). ${ }^{22}$ To our knowledge 
hardly any data are available on the efficacy of physical exercise training programmes in patients with mild to moderate COPD that are recruited and treated solely in primary care.

\section{Relevance}

From a patients' perspective, an increase in exercise capacity and daily physical activity during the early stage of the disease could be beneficial in order to stop the downward spiral of symptom-induced inactivity, deconditioning, muscle weakness, the fear of movement and reduced quality of life. Since behavioural research suggests that modifying behavioural patterns and coping styles takes time to be effective, regular exercise should be started early in the course of the disease for maximal effect. $^{25}$ It seems advantageous to initiate exercise training when the symptoms of dyspnoea and deconditioning are not very pronounced. Furthermore, it is proposed that in patients with a relatively preserved lung function, the physiological reserve for improvement is much larger than in patients with (very) severe disease. ${ }^{22}$

Treatment of COPD at an early stage could also lessen the burden of disease for society. ${ }^{26}$ COPD is one of the leading causes of morbidity and mortality worldwide and imparts a substantial economic burden. ${ }^{27}$ COPD-related illness costs are disproportionately distributed, with $10 \%$ of the patients (mostly patients in the more severe stages of the disease) accounting for $73 \%$ of the total costs, in which hospitalization is the largest contributor. ${ }^{27}$ An exercise training programme in primary care will be a relatively cheap and an easily accessible intervention for more patients than an expensive hospital-based rehabilitation programme. ${ }^{28}$ Although longitudinal studies are lacking, it is suggested that early recognition of progression of exercise impairment especially in less advanced COPD patients is relevant to prevent further deterioration of functional capacity. ${ }^{22,29}$

\section{Current daily care for COPD}

\section{Objectives}

The primary objective of our study is to evaluate the efficacy of a physical exercise training programme (PETP) in patients with mild to moderate COPD in the primary care setting on exercise capacity, physical activity, dyspnoea and quality of life. The 6 month time point is aimed at gaining more insight into the lasting of the effects.

The secondary objective is to assess how patient characteristics and baseline burden of disease modify the effect of a physical exercise training programme on functional exercise capacity in patients with mild to moderate COPD in primary care. 


\section{Methods/design}

\section{Study design}

A randomized controlled trial performed in the primary care setting in which the effects of a 4-month physical exercise training programme for patients with mild to moderate COPD will be compared to a control programme. The latter includes advices concerning physical activity according to the Practice Guidelines of the Dutch College of General Practitioners ${ }^{5}$ and a sham-treatment (ST) in physiotherapy practice.

General practice is the primary entrance for patients to participate in the trial. If a patient is a potential trial participant, the GP or nurse practitioner explains to the patient that it is important to enhance his physical activity level. For professional support to achieve this goal, the patient is referred to a COPD-certificated physiotherapist. If the patient is willing to undergo the physiotherapy treatment, he/she makes an appointment at the physiotherapy practice. The physiotherapist will give extensive information about the study procedures and the patient will have one week to consider participation in the trial. If the patient wants to participate, randomization will take place after obtaining informed consent. Patients of both treatment groups will be assessed in physiotherapy practice at baseline, at the end of the programme (after four months) and six months after baseline assessment. The measurements done by the physiotherapist are part of their routine assessments and are imbedded in the intake procedures. The results of this intake procedure will be the starting point of the treatment. Figure 3.1 illustrates the flow of the study.

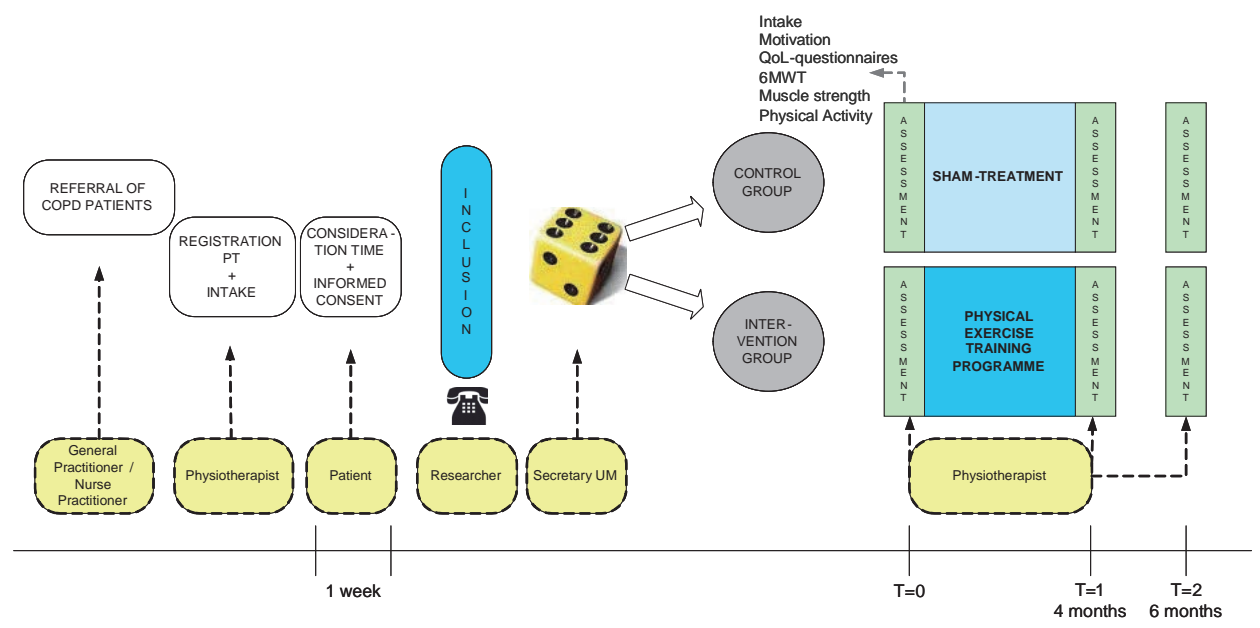

Figure 3.1 Overview of the flow of the study. 
The ethics committee of Maastricht University has approved the study protocol, procedures and informed consent and the trial has been registered at The Netherlands National Trial Register NTR1471.

\section{Setting}

This multicenter trial is coordinated by the CAPHRI School for Public Health and Primary Care of Maastricht University and conducted in several general practices and physiotherapy practices in the southern part of the Netherlands.

\section{Study population}

Participants for the trial will be recruited from general practices in Limburg, in the southern part of the Netherlands. There are 614 general practices in this region covering a population of over $1.000 .000 .^{30}$ Statistics suggest that $1,7 \%$ of the Dutch population is likely to have COPD. ${ }^{31}$ The population in Limburg is the least physically active population of the Netherlands. ${ }^{32}$

Inclusion will be based on patients with a clinical diagnosis of mild to moderate COPD (post-bronchodilator $\mathrm{FEV}_{1} / \mathrm{FVC}$ ratio $<0,7$ and $\mathrm{FEV}_{1} \geq 50 \%$ of predicted); who not have a minimum of 30 minutes of physical activity at moderate intensity, on at least 5 days per week, according to the ACSM-recommendation ${ }^{33}$; having a stable situation (no exacerbations in the last 8 weeks) and adequate and optimal inhalation technique, are competent enough to understand and speak the Dutch language and having provided written informed consent. According to the Practice Guidelines of the Dutch College of General Practitioners, a maximal cardiopulmonary exercise test prior to exercise training will be conducted by a pulmonologist, cardiologist or a sports medicine physician in COPD patients who suffer from cardiopulmonary comorbidities. ${ }^{5,34}$

Patients will be excluded from the trial, when they: already receive or have received a physical exercise training programme or rehabilitation therapy in the past year; have had respiratory tract infections within the last 8 weeks; are suffering from serious co morbid conditions, which would interfere with regular exercise training (including severe orthopaedic, muscular, neurological disorders or cardiovascular conditions) and patients who are expected to be lost for follow-up (e.g. because of a planned change of residency or a long holiday break).

\section{Randomization and blinding}

After informed consent is obtained, patients will be randomly assigned to the intervention group or the control group in a 1:1 ratio, with the help of computer 
generated random number tables. Randomization will be performed by a centralized and independent person who has a concealed list. The researcher is not involved in allocation to treatment group or setting. Full blinding procedures are not applicable in this study. The participating general practitioners, nurse practitioners and physiotherapists and also the patients cannot be blinded to allocation of individuals to the intervention group or control group. Although patients will be aware of the existence of two treatment arms, they are not informed about the exact content of the other treatment arm. Also, patients of both groups will not be in the same physiotherapy setting for treatment at the same time. The researcher will be fully blinded to the randomization list until the clinical database is unlocked at the end of the trial.

\section{Sample size calculation}

We performed a pilot study in one physiotherapy setting in order to get a rough idea of the improvement in six-minute walk distance (6MWD) in this group of patients after a 4-month physical exercise training programme. Data of six patients with mild to moderate COPD were collected. Their mean 6MWD was 475 metres with a standard deviation of 62. These patients increased their 6MWD by a mean of 52 metres. Troosters et al. (2000) reported a mean difference in change from baseline of 52 metres between the intervention group and control group, in a study of the short- and longer-term benefits of 6 months pulmonary rehabilitation. ${ }^{35}$ A more recent study showed an improvement of 54 metres with a standard deviation of 78 metres after a 7 week pulmonary rehabilitation programme. ${ }^{11}$ Our assumptions for this study are that the mean difference in change from baseline between the intervention group and the control group $(\delta)$ is 52 metres $(52-0 \mathrm{~m})$, with a standard deviation $(\sigma)$ of 78 metres. ${ }^{11}$ According to the effect size measures for two independent groups this implies a large effect size (Cohen's $d=\delta / \sigma=52 / 78=0.66) .{ }^{36}$ The sample size needs to be 36 patients per treatment arm (72 in total), whereby $\alpha=0.05$ ( 2 tailed), $80 \%$ power and a ratio of control to experimental patients of $1: 1$. This sample size calculation is done by using the PS power and sample size program of Dupont and Plummer. ${ }^{37,38}$

A total patient number of 102 participants (51 per treatment arm) is needed, based on the abovementioned calculation and allowing for dropouts (30\%). Previous studies showed a drop-out rate varying from 26 to $31 \%{ }^{11,35,39,40}$ 


\section{Intervention}

The treatment period is set at four months and consists of either the physical exercise training programme or the sham-treatment. The intervention will be carried out by physiotherapists working in a primary care setting, with broad expertise and education in COPD. The treatment protocol is standardised, the Dutch Guideline Physiotherapy in COPD serves as a framework, and based on individual problems and possibilities of the patient. $^{41}$

\section{Intervention group (Physical Exercise Training Programme)}

The physical exercise training programme has four main goals; improvement in exercise capacity, muscle strength, daily physical activity and breathing technique. The physical training component entails endurance training and/or interval training. ${ }^{41}$ Walking speed on the treadmill is executed with an intensity of $75 \%$ or higher of the results of the six-minute walk test (6MWT). Ratings of perceived exertion and dyspnoea of five and higher on the modified Borg-scale (0-10) are used to tailor exercise intensity. ${ }^{42}$

Resistance training in addition to endurance or interval training is recommended in all patients, especially important in patients with peripheral muscle weakness. In the absence of any comparative studies it is recommended to use both upper limb and lower limb resistance weight training at an intensity of at least $60-80 \%$ of the one repetition maximum, 2 to 3 sets of $8-12$ repetitions are preferable. ${ }^{41}$

Much emphasis is given to the assessment and treatment of physical inactivity in daily life. Patients are advised to increase their total physical activity. Patient and physiotherapist together define a strategy to meet the ACSM-recommendation for physical activity, i.e. performing moderately intense physical activity for 30 minutes on at least five days a week. ${ }^{33}$

Breathing exercise is an embracing term for a range of exercises such as active expiration, slow and deep breathing, pursed lips breathing, relaxation therapy, body positions such as forward leaning and diaphragmatic breathing. ${ }^{41}$

The physical exercise training programme will consist of two supervised sessions per week in the physiotherapy setting in primary care. These sessions will be with 1-5 patients at the time and the duration of each session will be 60-90 minutes, depending on group size. From an organisational and practical point of view it is not feasible to ask patients to come to a physical therapy setting more often. Furthermore, as mentioned before, an important part of the programme is enhancement of daily physical activity. So, patients are requested to perform an additional training session at home, including walking and/or cycling and they have to 
report these activities weekly to the physiotherapist. It is our aim to enhance the awareness and responsibility of our patients to change their physical activity behaviour for the long term and this encompasses enhancement of self-management and self-efficacy.

\section{Control group (sham-treatment)}

According to the national guidelines of the Dutch College of General Practitioners (NHG) and the Multidisciplinary Guideline on non-pharmacological treatment of COPD, the GP and the nurse practitioner should give advice to improve the physical condition. ${ }^{5,43}$ Verbal advice will be supported by a written brochure. This brochure is developed in collaboration with the NHG as part of a preceding implementation project of physiotherapy for COPD patients in primary care. ${ }^{44}$

In addition, the patients in the control group will participate in a sham-treatment at the physiotherapy practice. This treatment consists of 30 minutes once a week "exercise" training, with ratings of perceived exertion and dyspnoea of 2 or lower on a modified Borg-scale. It is unlikely that a physiologic training stimulus will occur at these levels of exertion. There will be no breathing exercises or resistance training. Furthermore, patients will be advised to do at least 30 minutes of moderate intense physical activities on at least five days a week according to the ACSMrecommendation for physical activity. ${ }^{33}$

\section{Outcome measures}

All outcomes will be assessed at baseline (T0), at the end of intervention after four months (T1) and at the end of follow-up (T2) at six months.

\section{Primary outcome measure}

The primary outcome measure will be the functional exercise capacity measured by the increase in the six-minute walk distance (6MWD) at 4 months compared to baseline. The six-minute walk test (6MWT) will be performed in accordance with the ATS Statement: guidelines for the $6 \mathrm{MWT}^{45}$, except that a standard 30 -meter corridor will not always be feasible in a primary care physiotherapy practice, but the minimal track will be 10 meter. The results will be expressed in absolute values and as percent of the predicted value. ${ }^{46}$ During the walk test, perceived fatigue and dyspnoea will be measured on a modified Borg scale ranging from zero (nothing at all) to ten (very, very severe). ${ }^{47}$ Oxygen saturation and pulse rate will be measured by a finger pulse oximeter (Onyx 9500). ${ }^{45}$ 


\section{Secondary outcome measures}

Isometric handgrip force will be measured with a hydraulic handheld dynamometer (Yamar Preston, Jackson MI). Peak handgrip force (in Newton) will be assessed the dominant side with the elbow at 90 degrees flexion, with the underarm and wrist in neutral position. ${ }^{48}$ Isometric knee extension and shoulder abduction force will be measured in standardised positions by a handheld dynamometer by means of the break method. ${ }^{42,49}$ Peak torques will be measured at the dominant side according to Andrews et al. (1996). ${ }^{49}$ At least three attempts will be performed for all muscle tests. Self-reported daily physical activity will be assessed by the brief physical activity assessment tool. ${ }^{50}$ Objective daily physical activity will be measured during 3 consecutive days and nights with an accelerometer-based activity monitor (Dynaport; McRoberts BV). Data of both intensity of movement and duration will be collected, like steps per day, total active time per day, time spent in moderate intense physical activities and vigorous activities and physical activity level (PAL). All patients will be carefully instructed on how the activity monitor should be positioned and they will receive a manual with clear instructions and figures. They will also have to fill out a checklist to verify if their day was a representative one and to indicate any possible hindrance of the activity monitor.

The level of dyspnoea will be assessed by the Medical Research Council (MRC) dyspnoea score. ${ }^{51}$ Specific Health Related Quality of Life (HRQL) will be assessed by means of the Clinical COPD Questionnaire $(\mathrm{CCQ})^{52,53}$ and the Chronic Respiratory Questionnaire (CRQ-SR). ${ }^{54-56}$ The global perceived effect (GPE) of the treatment according to the patients will be measured on a GPE scale. ${ }^{57,58}$

Furthermore, the following baseline characteristics will be measured, height, weight, Body Mass Index (BMI) and level of motivation by means of the questionnaire (Dutch translation) according to Miller (2005) and Rollnick et al. ${ }^{59-61}$

\section{Data analysis}

The descriptive characteristics will be presented quantitatively as means ( \pm standard deviation) for continuous variables and as medians for categorical variables and will be presented for the total group, as well as for the separate groups. Unpaired t-tests will be used to compare the effects of the treatment between the intervention group and control group at the end of the physical exercise training programme (4 months). P-values smaller than 0.05 will be considered as statistically significant.

Group (intervention vs. control) by time (pretest vs. posttests) repeated measurements analysis of variance (RM ANOVA) will be performed to examine (1) 
intervention main effect, (2) time main effect, and (3) intervention by time interaction effect on each of the continuous primary and secondary outcomes. An analysis of covariance will be done to evaluate the relationship between covariates and the dependent variable. The random effect will also be evaluated, since participants from both arms will be nested within the same physiotherapy setting. To evaluate which factors predict a positive outcome, i.e. the physical exercise training programme is effective, a multiple linear regression analysis will be done, using interaction terms between predictors and physical exercise. A predictor variable will make a significant contribution to predicting the outcome when P-value is smaller than 0.05 . The following possible predictors are taken into account, baseline: MRC dyspnoea score, walking distance, peripheral muscle strength, level of daily physical activities and compliance with the training programme. ${ }^{62-64}$

\section{Discussion}

This will be one of the first studies to evaluate the efficacy of a physical exercise training programme in patients with mild to moderate COPD completely recruited and assessed in primary care. If the results of this study show that this training programme is effective, this would mean a big step ahead in the follow-up of patients with mild to moderate COPD. Patients are actively involved in their disease management in an early phase and the intervention can ameliorate further deterioration and influence their prognosis in the long term. ${ }^{22}$ Exercise training has been shown to positively affect some aspects of health status (exercise capacity, muscle force, blood pressure, bone mass). ${ }^{65}$ Using an active lifestyle is necessary to break out of the negative spiral of dyspnoea and deconditioning and is probably essential for a long lasting change in improvements in daily physical activity. The availability of a physical exercise training programme close to the patient's home most likely improves compliance to the enhanced physical activity. ${ }^{22}$ With this enhanced physical activity and the benefits of an improved exercise capacity, a patient can regain his social contacts. ${ }^{22}$ This will give a great impact of a patient's quality of life.

\section{Bias, confounders and limitations}

From a methodological point of view, a cluster randomized design would be the most sound design for the study. The rationale for performing an individually randomized trial is that we observed in a pilot study ${ }^{44}$, that physiotherapists were not very keen to deliver a treatment without a proper training programme, although hard evidence of 
efficacy of a physical exercise training programme COPD was still lacking. Therefore, it would be impossible to recruit sufficient physiotherapy practices with treating only control patients. We have found a solution to this problem by allowing the physiotherapist offering the possibility for patients in the control group to participate in the physical exercise training programme after the study-period, in case the intervention has proven to be efficacious. To tackle contamination, we will train and instruct the physiotherapists thoroughly in advance of the study and monitor and instruct them throughout the intervention period. Physiotherapists can only participate if they are willing to deliver both the intervention treatment and shamtreatment. Another strategy to minimize contamination is that patients of the intervention and control group will not be in the same physiotherapy setting at the same time. So, the physiotherapists can focus their mind on just one treatment at the time.

Both the physiotherapists and the patients are not blinded during this study, since they are aware of the treatment procedures. Physiotherapists will conduct the measurements as well as the treatment in patients. Due to practical considerations it is not feasible to perform all measurements in many different practice settings by a single researcher. To assure a high quality and univocal treatment, the participating physiotherapists will be trained and instructed extensively before the start of the training. Also, throughout the intervention period the physiotherapists will be monitored continuously. The researcher will visit the participating physiotherapy practices frequently and will have regular contact by telephone and email in order to check the compliance with the treatment protocols.

As the population in Limburg is the least physically active population of the Netherlands, this might influence the external validity of the study. Another limitation is that the six-minute walk tests are performed on different tracks, which will influence the variability. An advantage of the randomization on patient level instead of physiotherapy practice level is that patients are assigned to smaller and longer passages in a non-differential manner and an equal distribution of patients from the intervention group and control group can be expected per physiotherapy practice. Since we are interested in the difference scores ( 4 or 6 months minus baseline measurement) and participants are assessed in the same passage on all occasions, we think that the variability is acceptable.

\section{Potential barriers}

From the feasibility study of Faulkner et al. (2009) it is known that recruitment of patients with moderate COPD for a physical activity intervention in primary care is 
very difficult. ${ }^{40}$ The reported main recruitment issue for caregivers in that study was lack of available time to participate in research activities. ${ }^{40}$ Furthermore, in general practice no objective tool to measure daily physical activity is available, only subjective questionnaires. As a consequence, general practitioners or practice nurses might have a lack of information on this topic and will not consider a follow-up strategy, including referral to a physical exercise training programme.

One of the first major symptoms in COPD is exertional breathlessness. To avoid confrontation with this symptom, patients with COPD are more inclined to adapt their lifestyle, for example taking the elevator instead of climbing the stairs. In this way impairments in daily life are not noticed by the patient. So, on patients' level it might be a barrier that patients with only a mild airway obstruction and moderate exercise limitation do not feel the need to participate in a physical exercise training programme. ${ }^{66}$ In this mild to moderate category, many patients will probably have work commitments and lack of time might be a problem. ${ }^{40}$

A key factor in the recruitment of patients is the teamwork between the different healthcare professionals in primary care. From June 2006 till November 2007, our research group has executed an implementation project of physiotherapy for COPD patients in primary care in the region to be studied. ${ }^{44}$ One of the main objectives was to start up and improve collaboration between general practitioners, nurse practitioners and physiotherapists. As a result of the project referral policy of COPD patients to physiotherapists in primary care in this region improved. In this way, we expect to minimize recruitment problems.

Given the evidence of the efficacy of pulmonary rehabilitation on functional exercise capacity, dyspnoea and quality of life in patients with moderate to severe COPD, there is now an urgent need to determine whether similar observations apply in the larger group of patients with earlier disease characteristics. ${ }^{40}$ 


\section{References}

1. Nici L, Donner C, Wouters E, Zuwallack R, Ambrosino N, Bourbeau J, Carone M, Celli B, Engelen M, Fahy B, Garvey C, Goldstein R, Gosselink R, Lareau S, Maclntyre N, Maltais F, Morgan M, O'Donnell D, Prefault C, Reardon J, Rochester C, Schols A, Singh S, Troosters T. American Thoracic Society/European Respiratory Society statement on pulmonary rehabilitation. Am J Respir Crit Care Med 2006;173:1390-413.

2. Troosters T, Casaburi R, Gosselink R, Decramer M. Pulmonary rehabilitation in chronic obstructive pulmonary disease. Am J Respir Crit Care Med 2005;172:19-38.

3. Vestbo J, Hurd SS, Agusti AG, Jones PW, Vogelmeier C, Anzueto A, Barnes PJ, Fabbri LM, Martinez FJ, Nishimura M, Stockley RA, Sin DD, Rodriguez Roisin R. Global strategy for the diagnosis, management, and prevention of chronic obstructive pulmonary disease: GOLD executive summary. Am J Respir Crit Care Med 2013;187:347-65.

4. Lacasse Y, Martin S, Lasserson TJ, Goldstein RS. Meta-analysis of respiratory rehabilitation in chronic obstructive pulmonary disease. A Cochrane systematic review. Eura Medicophys 2007;43:475-85.

5. Smeele IJM VWC, Van Schayck CP, Van der Molen TTB, Schermer T, Sachs APE, Muris JWMCN, Kolnaar BGM, Grol MH, RMM G. NHG-Standaard COPD, tweede herziening. Huisarts Wet 2007;50:362-79.

6. Pitta F, Troosters T, Spruit MA, Probst VS, Decramer M, Gosselink R. Characteristics of physical activities in daily life in chronic obstructive pulmonary disease. Am J Respir Crit Care Med 2005; 171:972-7.

7. Mador MJ, Patel AN, Nadler J. Effects of pulmonary rehabilitation on activity levels in patients with chronic obstructive pulmonary disease. J Cardiopulm Rehabil Prev 2011;31:52-9.

8. Pitta F, Troosters T, Probst VS, Langer D, Decramer M, Gosselink R; Are patients with COPD more active after pulmonary rehabilitation? Chest 2008;134:273-80.

9. Effing $\mathrm{T}$, Zielhuis $\mathrm{G}$, Kerstjens $\mathrm{H}$, van der Valk $\mathrm{P}$, van der Palen J. Community based physiotherapeutic exercise in COPD self-management: a randomised controlled trial. Respir Med 2011;105:418-26.

10. Zwerink M, van der Palen J, van der Valk P, Brusse Keizer M, Effing T; Relationship between daily physical activity and exercise capacity in patients with COPD. Respir Med 2013;107:242-8.

11. Egan C, Deering BM, Blake C, Fullen BM, McCormack NM, Spruit MA, Costello RW. Short term and long term effects of pulmonary rehabilitation on physical activity in COPD. Respir Med 2012; 106:1671-9.

12. Cindy Ng LW, Mackney J, Jenkins S, Hill K. Does exercise training change physical activity in people with COPD? A systematic review and meta-analysis. Chron Respir Dis 2012;9:17-26.

13. Garcia Aymerich J, Lange P, Benet M, Schnohr P, Anto JM. Regular physical activity reduces hospital admission and mortality in chronic obstructive pulmonary disease: a population based cohort study. Thorax 2006;61:772-8.

14. Watz H, Waschki B, Boehme C, Claussen M, Meyer T, Magnussen H. Extrapulmonary effects of chronic obstructive pulmonary disease on physical activity: a cross-sectional study. Am J Respir Crit Care Med 2008;177:743-51.

15. Seymour JM, Spruit MA, Hopkinson NS, Natanek SA, Man WD, Jackson A, Gosker HR, Schols AM, Moxham J, Polkey MI, Wouters EF. The prevalence of quadriceps weakness in COPD and the relationship with disease severity. Eur Respir J 2010;36:81-8.

16. Huijsmans RJ, de Haan A, ten Hacken NN, Straver RV, van't Hul AJ. The clinical utility of the GOLD classification of COPD disease severity in pulmonary rehabilitation. Respir Med 2008;102:162-71.

17. van Wetering CR, van Nooten FE, Mol SJ, Hoogendoorn M, Rutten Van Molken MP, Schols AM. Systemic impairment in relation to disease burden in patients with moderate COPD eligible for a lifestyle program. Findings from the INTERCOM trial. Int J Chron Obstruct Pulmon Dis 2008;3:443-51.

18. Hamilton AL, Killian KJ, Summers E, Jones NL. Muscle strength, symptom intensity, and exercise capacity in patients with cardiorespiratory disorders. Am J Respir Crit Care Med 1995;152:2021-31.

19. Watz H, Waschki B, Meyer T, Magnussen H. Physical activity in patients with COPD. Eur Respir J 2009; 33:262-72. 
20. Troosters T, Sciurba F, Battaglia S, Langer D, Valluri SR, Martino L, Benzo R, Andre D, Weisman I, Decramer M. Physical inactivity in patients with COPD, a controlled multi-center pilot-study. Respir Med 2010;104:1005-11.

21. van Wetering CR, Hoogendoorn M, Mol SJ, van Molken MP R, Schols AM. Short- and long-term efficacy of a community-based COPD management programme in less advanced COPD: a randomised controlled trial. Thorax 2010;65:7-13.

22. Chavannes $\mathbf{N H}$, Grijsen $M$, van den Akker $M$, Schepers $H$, Nijdam $M$, Tiep B, Muris J. Integrated disease management improves one-year quality of life in primary care COPD patients: a controlled clinical trial. Prim Care Resp J 2009;18:171-6.

23. Roman M, Larraz C, Gomez A, Ripoll J, Mir I, Miranda EZ, Macho A, Thomas V, Esteva M. Efficacy of pulmonary rehabilitation in patients with moderate chronic obstructive pulmonary disease: a randomized controlled trial. BMC Fam Pract 2013;14:21.

24. Kruis AL, Smidt N, Assendelft WJ, Gussekloo J, Boland MR, Rutten-van Molken M, Chavannes NH. Integrated disease management interventions for patients with chronic obstructive pulmonary disease. Cochrane Database Syst Rev 2013;10:CD009437.

25. Wempe JB, Wijkstra PJ. The influence of rehabilitation on behaviour modification in COPD. Patient Educ Couns 2004;52:237-41.

26. Van der Molen T. Chronic Obstructive Pulmonary Disease - The burden of mild to moderate disease. Eur Res Dis 2010;6:24-7.

27. Sullivan SD, Ramsey SD, Lee TA. The economic burden of COPD. Chest 2000;117(2 Suppl):5s-9s.

28. Hoogendoorn M, van Wetering CR, Schols AM, van Molken MP R. Is INTERdisciplinary COMmunitybased COPD management (INTERCOM) cost-effective? Eur Respir J 2010;35:79-87.

29. Van Wetering CR. Clinical evaluation and cost-effectiveness of a community-based COPD management program. PhD thesis. Maastricht: Maastricht University; 2010.

30. NIVEL [http://nivel.nl/databank].

31. Rijksinstituut voor Volksgezondheid en Milieu [http://www.nationaalkompas.nl/gezondheid-enziekte/ziekten-en-aandoeningen/ademhalingswegen/copd/omvang/].

32. Harbers MM. Lichamelijke activiteit: Zijn er binnen Nederland verschillen naar regio? In Volksgezondheid Toekomst Verkenning, Nationaal Kompas Volksgezondheid. Bilthoven: RIVM. 2010.

33. Haskell WL, Lee IM, Pate RR, Powell KE, Blair SN, Franklin BA, Macera CA, Heath GW, Thompson PD, Bauman A. Physical activity and public health: updated recommendation for adults from the American College of Sports Medicine and the American Heart Association. Med Sci Sports Exerc 2007;39:1423-34.

34. Guazzi M, Adams V, Conraads V, Halle M, Mezzani A, Vanhees L, Arena R, Fletcher GF, Forman DE, Kitzman DW, Lavie CJ, Myers J. Eacpr/aha scientific statement. Clinical recommendations for cardiopulmonary exercise testing data assessment in specific patient populations. Circulation 2012; 126:2261-74.

35. Troosters T, Gosselink R, Decramer M. Short- and long-term effects of outpatient rehabilitation in patients with chronic obstructive pulmonary disease: a randomized trial. Am J Med 2000;109:207-12.

36. Cohen J: Statistical power analysis for the behavioral sciences. 2nd edition. Hillsdale, NJ. Lawrence Earlbaum Associates; 1988.

37. Dupont WD, Plummer WD Jr. Power and sample size calculations. A review and computer program. Control Clin Trials 1990;11:116-28.

38. Dupont WD, Plummer WD. PS power and sample size program available for free on the internet. Controlled Clin Trials 1997;18:274.

39. Cambach W, Chadwick Straver RV, Wagenaar RC, van Keimpema AR, Kemper HC. The effects of a community-based pulmonary rehabilitation programme on exercise tolerance and quality of life: a randomized controlled trial. Eur Respir J 1997;10:104-13.

40. Faulkner J, Walshaw E, Campbell J, Jones R, Taylor R, Price D, Taylor AH. The feasibility of recruiting patients with early COPD to a pilot trial assessing the effects of a physical activity intervention. Prim Care Respir J 2010;19:124-30. 
41. Gosselink R, Langer D, Burtin C, Probst VS, Hendriks HJM, van der Schans CP, Paterson WJ, Verhoef-de Wijk MCE, Straver RVM, Klaassen M, Troosters T, Decramer M, Ninane V, Delguste P, Muris JWM, Wempe J. KNGF-richtlijn Chronisch obstructieve longziekten. Ned T Fys supp/ 2008;118:1-60.

42. Gosselink R, Decramer M. Rehabilitation in chronic obstructive pulmonary disease [Revalidatie bij chronische obstructieve longziekten]. Elsevier Gezondheidszorg: Maarssen; 2001.

43. Lakerveld-Heyl KBL, Geijer RMM, Gosselink R, Muris JWM, Vermeeren MAP, Van Hensbergen W, Verhoef M, Flikweert S, Van Ravensberg CD. Landelijke Eerstelijns Samenwerkings Afspraak COPD. Huisarts Wet 2007;50:S21-7.

44. Fastenau A, Muris JWM, Smeele IJM, Gosselink R, Alders A, Veldhuizen HJ, Alders C. Implementatietraject voor ketenzorg beweegprogramma's voor patiënten met licht tot matig COPD in de eerste lijn. Leusden: Stichting Ketenkwaliteit COPD; 2007.

45. AmericanThoracicSociety. Committee on Proficiency Standards for Clinical Pulmonary Function Laboratories, ATS statement: guidelines for the six-minute walk test. Am J Respir Crit Care Med 2002; 166:111-7.

46. Enright PL, Sherrill DL. Reference equations for the six-minute walk in healthy adults. Am J Respir Crit Care Med 1998;158(5 Pt 1):1384-7.

47. Mahler DA, Horowitz MB. Perception of breathlessness during exercise in patients with respiratory disease. Med Sci Sports Exerc 1994;26:1078-81.

48. Mathiowetz V, Kashman N, Volland G, Weber K, Dowe M, Rogers S. Grip and pinch strength: normative data for adults. Arch Phys Med Rehabil 1985;66:69-74.

49. Andrews AW, Thomas MW, Bohannon RW. Normative values for isometric muscle force measurements obtained with hand-held dynamometers. Phys Ther 1996;76:248-59.

50. Marshall AL, Smith BJ, Bauman AE, Kaur S. Reliability and validity of a brief physical activity assessment for use by family doctors. Br J Sports Med 2005;39:294-7.

51. Bestall JC, Paul EA, Garrod R, Garnham R, Jones PW, Wedzicha JA. Usefulness of the Medical Research Council (MRC) dyspnoea scale as a measure of disability in patients with chronic obstructive pulmonary disease. Thorax 1999;54:581-6.

52. Kocks JW, Tuinenga MG, Uil SM, van den Berg JW, Stahl E, van der Molen T. Health status measurement in COPD: the minimal clinically important difference of the clinical COPD questionnaire. Respir Res 2006;7:62.

53. van der Molen T, Willemse BW, Schokker S, ten Hacken NH, Postma DS, Juniper EF. Development, validity and responsiveness of the Clinical COPD Questionnaire. Health Qual Life Outcomes 2003; 1:13.

54. Guyatt GH, Berman LB, Townsend M, Pugsley SO, Chambers LW. A measure of quality of life for clinical trials in chronic lung disease. Thorax 1987;42:773-8.

55. Williams JE, Singh SJ, Sewell L, Guyatt GH, Morgan MD. Development of a self-reported Chronic Respiratory Questionnaire (CRQ-SR). Thorax 2001;56:954-9.

56. Williams JE, Singh SJ, Sewell L, Morgan MD. Health status measurement: sensitivity of the selfreported Chronic Respiratory Questionnaire (CRQ-SR) in pulmonary rehabilitation. Thorax 2003; 58:515-8.

57. de Vet HC, Ostelo RW, Terwee CB, van der Roer N, Knol DL, Beckerman H, Boers M, Bouter LM. Minimally important change determined by a visual method integrating an anchor-based and a distribution-based approach. Qual Life Res 2007;16:131-42.

58. Jaeschke R, Singer J, Guyatt GH. Measurement of health status. Ascertaining the minimal clinically important difference. Control Clin Trials 1989;10:407-15.

59. Miller WR. Enhancing patient motivation for health behavior change. J Cardiopulm Rehabil 2005; 25:207-9.

60. Rollnick S, Butler CC, Stott N. Helping smokers make decisions: the enhancement of brief intervention for general medical practice. Patient Educ Couns 1997;31:191-203.

61. Rollnick S, Butler CC, McCambridge J, Kinnersley P, Elwyn G, Resnicow K. Consultations about changing behaviour. BMJ 2005;331:961-3. 
62. Zu Wallack RL, Patel K, Reardon JZ, Clark BA 3rd, Normandin EA. Predictors of improvement in the 12minute walking distance following a six-week outpatient pulmonary rehabilitation program. Chest 1991;99:805-8.

63. Garrod R, Marshall J, Barley E, Jones PW. Predictors of success and failure in pulmonary rehabilitation. Eur Respir J 2006;27:788-94.

64. Troosters T, Gosselink R, Decramer M. Exercise training in COPD: how to distinguish responders from nonresponders. J Cardiopulm Rehabil 2001;21:10-7.

65. Garber CE, Blissmer B, Deschenes MR, Franklin BA, Lamonte MJ, Lee IM, Nieman DC, Swain DP. American College of Sports Medicine position stand. Quantity and quality of exercise for developing and maintaining cardiorespiratory, musculoskeletal, and neuromotor fitness in apparently healthy adults: guidance for prescribing exercise. Med Sci Sports Exerc 2011;43:1334-59.

66. Fastenau A, Wesseling G, Muris JW, van Schayck OCP. Insight into physical activity patterns in patients with chronic obstructive pulmonary disease - A starting point for treatment? European Respiratory Disease 2011;7:134-6. 



\section{Chapter 4}

Discrepancy between functional exercise capacity and daily physical activity: a cross-sectional study in patients with mild to moderate COPD

Annemieke Fastenau, Onno CP van Schayck, Rik Gosselink, Karin CPM Aretz, Jean WM Muris

Prim Care Respir J 2013;22:425-430 


\section{Abstract}

\section{Background}

In patients with moderate to severe COPD the six-minute walk distance reflects functional exercise level for daily physical activity. It is unknown if this applies to patients with mild to moderate COPD in primary care as well.

\section{Aim}

To assess the relationship between functional exercise capacity and physical activity in patients with mild to moderate COPD.

\section{Methods}

A cross-sectional study was performed in 51 patients with mild to moderate COPD in primary care. Functional exercise capacity was assessed by the six-minute walk test and physical activity was measured with an accelerometer-based activity monitor (Dynaport; McRoberts BV).

\section{Results}

Functional exercise capacity was close to normal values. On the other hand, daily physical activity of the patients could be classified as 'sedentary' and 'low active'. No significant correlations were observed between $6 \mathrm{MWD}$ (\%pred.) and any of the physical activity variables (steps per day, movement intensity during walking, total active time, total walking time, Physical Activity Level and time spent in moderate physical activity).

\section{Conclusions}

A discrepancy was found between functional exercise capacity and daily physical activity in patients with mild to moderate COPD recruited and assessed in primary care. We conclude that these variables represent two different concepts. Our results reinforce the importance of measuring daily physical activity in order to fine-tune treatment (i.e. focussing on enhancement of exercise capacity or behavioural change or both). 


\section{Introduction}

Chronic Obstructive Pulmonary Disease (COPD) is a chronic disease characterized by poorly reversible airflow limitation. However, COPD is now recognized as a systemic illness with significant extra-pulmonary features, such as muscle wasting and weakness. ${ }^{1}$ In most patients shortness of breath during exercise is the first major symptom. To avoid confrontation with this symptom, patients with COPD are more inclined to adapt their lifestyle. And thus a vicious circle will be created; shortness of breath results in decreased activity, which provokes a decline in exercise capacity and muscle strength, which in turn leads to more shortness of breath and so on.

Exercise training programmes have been shown to be very effective in improving exercise capacity. ${ }^{2}$ Consequently, it is not surprising that most rehabilitation training programmes for patients with COPD focus on increasing exercise capacity. Functional exercise capacity reflects what a person is capable of doing under controlled circumstances in a laboratory setting. ${ }^{3}$ Another modifiable extra-pulmonary feature of COPD is the decline in daily physical activity. Physical activity is defined as "any bodily movement that is produced by the contraction of skeletal muscle and that substantially increases energy expenditure". ${ }^{4}$ The dimensions of physical activity are: type, intensity, frequency, duration and the context of the activity. Physical activity reflects what a person actually does on a regular basis. In the last decade, with the development of activity monitors, there is much more insight in physical activity levels in patients with COPD. As a result we are now aware that what people with COPD are capable of doing might be different from what people actually do.

Recent studies show that the physical activity level gradually declines with severity of disease $^{6-8}$ and is the strongest predictor of all-cause mortality. ${ }^{9}$ Low levels of physical activity have been associated with systemic inflammation, left cardiac dysfunction ${ }^{10}$ and to lung function decline, hospitalisations and mortality. ${ }^{11}$ The review of $\mathrm{Ng}$ et al. (2012) suggests that the effect of exercise training on physical activity in people with COPD is small. ${ }^{12}$ Findings of more recent intervention studies show that improved exercise capacity after pulmonary rehabilitation (PR) was not transmitted into increased daily physical activity. ${ }^{13-16}$

Most of the studies concerning physical activity levels of patients with COPD are performed in patients with moderate to severe COPD, who are recruited in a rehabilitation setting or an outpatient clinic. From these studies it is known that COPD patients are very inactive in daily life. A moderate relationship between exercise capacity and physical activity was observed, so that the six-minute walk test (6MWT) can be validated as a test to reflect functional exercise level for daily physical activity. ${ }^{6,17,18}$ However, in patients with a higher six-minute walk distance (6MWD), 
physical activities in daily life are highly variable, non predictable and require objective measurement. ${ }^{6}$

Although the far majority of patients with COPD is classified as having mild to moderate COPD ${ }^{19}$, there is hardly any insight in the relationship between functional exercise capacity and daily physical activity in these patients. We hypothesize that exercise capacity and daily physical activity are two different concepts in this patient category, as opposed to moderate to severe COPD.

Therefore, it is our aim to investigate the relationship between functional exercise capacity and physical activity.

\section{Materials and methods}

\section{Study population}

In this cross-sectional study, a sample of 51 patients with mild to moderate COPD was recruited in 20 general practices in the southern part of the Netherlands. These patients were referred by their general practitioner or practice nurse to participate in a Physical Exercise Training Programme COPD at a local physiotherapy practice. Inclusion was based on symptoms of dyspnoea, impairments in exercise capacity and a low level of self-reported physical activity.

Patients were in a stable condition and did not suffer from respiratory tract infections or exacerbations at least 6 weeks prior to participation in the study. Subjects could participate if they had no significant co-morbid conditions that would impede the ability to improve physical activity, like severe cardiac failure, orthopaedic or neurological disorders.

All patients provided written informed consent, and the study was approved by the ethical review board of the Maastricht University Medical Centre.

\section{Clinical, functional and patient-reported characteristics}

All patients performed standardized post-bronchodilator spirometry according to guidelines of the American Thoracic Society (ATS) and the European Respiratory Society (ERS). ${ }^{20}$ All had a forced expiratory volume in one second and forced vital capacity ratio $\left(F E V_{1} / F V C\right)<0.7$, and a post-bronchodilator $\mathrm{FEV}_{1}$ of $\geq 50 \%$ of predicted. Functional exercise capacity was assessed by the 6MWT with reference values from Enright. $^{21}$ The test was conducted according to the ATS guidelines ${ }^{22}$, except that a standard 30-meter corridor was not always feasible but the minimal length of a 
corridor was 10 meter. Dyspnoea was assessed by the Medical Research Council (MRC) dyspnoea scale. ${ }^{23}$

\section{Physical activity assessment}

Daily physical activity was measured during 3 days and nights with an accelerometerbased activity monitor (Dynaport Minimod; McRoberts BV). Prior to the measurement the patient was asked if he/she had different physical activity patterns during weekdays or weekends. If the answer was no, then it did not matter on which days the measurement did occur. If the answer was positive then there was at least one weekday and one day of the weekend included in the measurement. Afterwards we verified if the measurement days were representative days. If the answer was negative then the measurement was repeated.

The Dynaport Minimod is among three of the best activity monitors to assess daily physical activity in patients with COPD. ${ }^{24}$ As we were interested in the relationship between walking capacity and daily physical activity we have particularly collected walking-related data of physical activity, including average steps per day, average movement intensity during walking and total walking time per day. In addition, we also gathered more general information about physical activity, like total active time per day, time spent in moderate intense physical activities and vigorous activities and physical activity level (PAL).

PAL was calculated by dividing a person's total energy expenditure by his Basal Metabolic Rate (BMR). ${ }^{25}$ A PAL $<1.40$ indicates a very inactive person. A PAL of 1.4-1.69 defines a predominantly sedentary person. ${ }^{26}$ Moderate activity was defined as the time spent in activities between 3 and 5.9 metabolic equivalents (METs), such as brisk walking, sweeping floors and vacuuming. ${ }^{27}$ Vigorous activities were defined as physical activity performed at an intensity above 6 METs, like jogging, shovelling or carrying heavy loads. ${ }^{27}$

Steps per day and time spent in moderate intense physical activities were regarded as co-primary endpoints since these parameters contain information on both the amount of daily activity and intensity. ${ }^{7}$ Average movement intensity during walking, total walking time per day, total active time per day, vigorous activities and PAL were used as secondary outcomes.

Data were collected from June 2010 until July 2012, covering all yearly seasons.

\section{Statistical analyses}

Baseline characteristics are reported as mean \pm standard deviation (SD) and range for continuous variables and as median and range for categorical variables. The 
relationship between variables was tested by calculating Pearson correlation coefficients and plots. Correlation coefficients were considered to be statistically significant when the $p$-value was smaller than 0.05. All data were analyzed using SPSS version 19.

\section{Results}

\section{Characteristics}

Clinical characteristics of the COPD patients are presented in Table 4.1.

Table 4.1 Patients' characteristics.

\begin{tabular}{|c|c|c|c|}
\hline & & Mean (SD) & Range \\
\hline \multirow[t]{4}{*}{ Demographics } & Age (year) & $62(9)$ & 41 to 80 \\
\hline & Gender (female/male) & $26 / 25$ & \\
\hline & Height $(\mathrm{cm})$ & $169(9)$ & 153 to 198 \\
\hline & Body mass index $\left(\mathrm{kg} / \mathrm{m}^{2}\right)$ & $27.4(5.0)$ & 19.9 to 40.4 \\
\hline \multirow[t]{9}{*}{ Lung function } & $\mathrm{FEV}_{1}(\mathrm{~L})$ & $2.02(0.58)$ & 1.07 to 3.25 \\
\hline & $\mathrm{FEV}_{1}(\%$ of predicted) & $74(14)$ & 51 to 113 \\
\hline & GOLD I - II (n) & $13-38$ & \\
\hline & & $(25 \%-75 \%)$ & \\
\hline & $\mathrm{FEV}_{1} / \mathrm{FVC}$ & $57(9)$ & 31 to 69.9 \\
\hline & Years of diagnosis COPD & $<1$ year: $30 \%$ & \\
\hline & & 1-5 years: $52 \%$ & \\
\hline & & $>5-10$ years: $16 \%$ & \\
\hline & & $>10$ years: $2 \%$ & \\
\hline
\end{tabular}

cm: centimetres; kg: kilogram; m: metres; L: litres; $\mathrm{n}$ : number; FEV1: forced expiratory volume in one second; FVC: forced vital capacity; GOLD: Global initiative for chronic Lung Disease; COPD: chronic obstructive pulmonary disease.

The age spectrum of participants varied from relatively young COPD patients up to rather old patients. There was an almost equal distribution of men and women and they generally had an overweight BMI. Patients had a mean FEV $_{1}$ of $74 \%$ predicted, indicating moderate COPD (close to mild COPD). The majority of patients was recently diagnosed as having COPD.

There was a large variation in the extent of experienced dyspnoea as indicated by the MRC score (Table 4.2). Some participants were only breathless during strenuous exercise, while others were hardly able to walk more than 100 meters or capable of leaving the house.

Functional exercise capacity was close to what might be expected according to healthy persons (Table 4.2). In addition, the lowest oxygen saturation during the 
$6 \mathrm{MWT}$ was $83 \%$, while the mean value was $92 \%$ (SD 3.4). Twenty-one percent of the patients had an oxygen saturation below $90 \%$ during the test, indicating a significant decrease in oxygenation during exertion. ${ }^{28}$ The resting oxygen saturation had a mean value of $96 \%$ (SD 1.5), with a range of 92 to $99 \%$.

Patients were classified as sedentary, with a mean PAL of 1.45 and only $65 \%$ of the recommended 10.000 steps per day (Table 4.2).

Table 4.2 Patients' characteristics, exercise capacity and physical activity.

\begin{tabular}{|c|c|c|c|}
\hline & & Mean/Median (SD) & Range \\
\hline $\begin{array}{l}\text { Patient-reported } \\
\text { Outcomes }\end{array}$ & MRC dyspnea scale & $2(0.9)$ & 1 to 5 \\
\hline \multirow[t]{3}{*}{ Exercise Capacity } & 6-min walk distance (meters) & $487(86)$ & 320 to 650 \\
\hline & 6-min walk distance (\% of predicted) & $94(14)$ & 60 to 121 \\
\hline & $\begin{array}{l}\text { Lowest oxygen saturation during 6-min } \\
\text { walk test (\%) }\end{array}$ & $92(3,4)$ & 83 to 98 \\
\hline \multirow[t]{7}{*}{ Physical Activity } & Steps per day & 6459 (2994) & 1853 to 15437 \\
\hline & Movement intensity during walking (g) & $0.20(0.039)$ & 0.15 to 0.40 \\
\hline & Time spent walking per day (h.m) & 1h.19m (0h.32m) & Oh. $25 \mathrm{~m}$ to $2 \mathrm{~h} .38 \mathrm{~m}$ \\
\hline & Total active time (h.m) & 5h.20m (1h.42m) & $1 \mathrm{~h} .34 \mathrm{~m}$ to $9 \mathrm{~h} .39 \mathrm{~m}$ \\
\hline & Time in moderate physical activity (h.m) & 1h.37m (0h.35m) & Oh. $34 \mathrm{~m}$ to $3 \mathrm{~h} .30 \mathrm{~m}$ \\
\hline & Time in vigorous physical activity (h.m) & 0h.9m (0h.13m) & $0 \mathrm{~m}$ to $1 \mathrm{~h} .10 \mathrm{~m}$ \\
\hline & Physical Activity Level & $1.45(0.12)$ & 1.21 to 1.88 \\
\hline
\end{tabular}

SD: standard deviation; MRC: medical research council; g: gravity; h: hours; m: minutes.

\section{Functional exercise capacity, pulmonary function and clinical characteristics}

A significant inverse correlation was found between $6 \mathrm{MWD}(\%$ pred.) and $\mathrm{MRC}$ $(R=-0.43, p=0.001)$. There was no correlation observed between $6 \mathrm{MWD}$ (\%pred.) and $\mathrm{FEV}_{1}$ (\%pred.), age and BMI.

\section{Daily physical activity, pulmonary function and clinical characteristics}

A significant modest inverse correlation was found between steps per day, PAL, total walking time per day, time spent in moderate PA and $\mathrm{BMI}(R=-0.32, p=0.022, R=-0.42$, $p=0.003, R=-0.38, p=0.006, R=-0.29, p=0.038$, respectively). There were also significant modest inverse correlations found between steps per day, $P A L$, total walking time per day, total active time, time spent in moderate PA and $\operatorname{MRC}(R=-0.35, p=0.012, R=-0.34$, $p=0.019, R=-0.35, p=0.011, R=-0.36, p=0.010, R=-0.29, p=0.037$, respectively).

There was no correlation observed between any of the PA variables and FEV $(\%$ pred.). 


\section{Functional exercise capacity and daily physical activity}

No significant correlations were observed between 6MWD(\%pred.) and any of the physical activity variables (Table 4.3).

Table 4.3 Correlation between physical activity and functional exercise capacity.

\begin{tabular}{lcc}
\hline & & 6MWD (\%predicted) \\
& $R$ & $p$-value \\
\hline Steps per day & 0.22 & 0.12 \\
Movement intensity during walking & 0.17 & 0.23 \\
Total active time & 0.23 & 0.10 \\
Time spent walking & 0.21 & 0.14 \\
Physical Activity Level & 0.24 & 0.091 \\
Time in moderate physical activity & 0.21 & 0.13 \\
Time in vigorous physical activity & 0.12 & 0.40 \\
\hline
\end{tabular}

6MWD: six-minute walk distance.

Figure 4.1 illustrates the minimal relation between 6MWD and steps per day. For example, subjects with a normal functional exercise capacity display a broad range of steps per day, varying from 3000 up to 15000 steps per day.

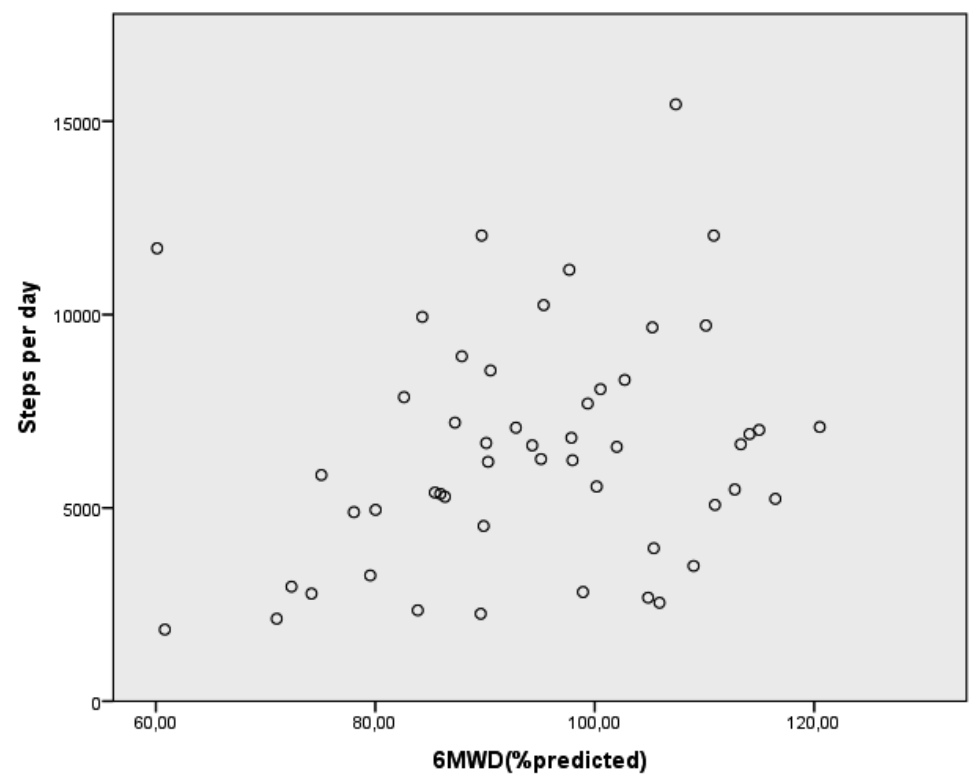

Figure 4.1 Plot of six-minute walk distance and average steps per day. 
As expected, different physical activity variables were related. A high correlation was found between steps per day and time spent in moderate physical activity ( $R=0.79$, $p=0.000$ ). A more modest correlation was found between steps per day and time spent in vigorous physical activity $(R=0.54, p=0.000)$. On the contrary, there was no correlation observed between time spent in moderate physical activity and vigorous physical activity $(\mathrm{R}=0.076, p=0.59)$.

\section{Discussion}

\section{Main findings}

In this cross-sectional study, we found a minimal relationship between functional exercise capacity and daily physical activity in patients with mild and moderate COPD in a primary care setting. Baseline characteristics showed that functional exercise capacity was close to normal values, $94 \%$ of predicted. Despite the reasonable distance walked on the 6MWT, a substantial group of subjects showed a significant decrease in oxygenation during exertion. The primary causes of hypoxemia with exertion are considered to be ventilation to perfusion mismatching and diffusion-type limitation $^{28}$, so a substantial part of our study population showed pulmonary constraints. On the other hand, daily physical activity was diminished. A mean PAL of 1.45 indicates a very sedentary population ${ }^{26}$ and a mean of 6459 steps per day is characterized as 'low active'. ${ }^{29}$

\section{Strength and limitations}

To our knowledge, this is one of the first studies in which COPD patients are recruited and assessed solely in the primary care setting. It was our purpose to make a direct link with current COPD care in the Netherlands by using not very restrictive inclusion criteria that are congruous with daily practice. This is reflected by the large variation in all baseline characteristics, from breathlessness, to exercise capacity and physical activity.

There are several limitations that need to be addressed. First, the number of assessment days plays an important role. There is evidence that three days of assessment with an activity monitor provides an acceptable intraclass reliability coefficient. ${ }^{30}$ In healthy adults however, an acceptable measurement may range from three to seven days. It is possible that in our study population three days of 
measurement was not sufficient to collect representative data. Secondly, we included only patients who were motivated to participate in an exercise-training programme and excluded patients who were already very active. Therefore, our conclusions can not be generalized to all patients with mild to moderate COPD.

\section{Interpretation of findings in relation to previously published work}

The absolute value on the 6MWT of our study population (487 meters) is comparable with results (490 and 462 meters) of other studies in patients with mild and moderate COPD. ${ }^{8,31}$ On the contrary, our results concerning daily physical activity differ from findings of Troosters et al and Watz et al. They found for patients with COPD Gold 1 and 2 a mean of 7357 and 7619 steps per day respectively and a PAL of 1.63 as opposed to 6459 steps per day and a PAL of 1.45 in our study. ${ }^{7,8}$ In the study of Watz et al. the measurement period was not during the winter months. ${ }^{8}$ This could explain the difference with our results, because it is known that seasonal variations affect physical activity patterns. ${ }^{32}$ Furthermore, the southern part of the Netherlands is known as a region with less physical activity than the rest of the country. ${ }^{33}$

We found a mean duration of time spent at moderate physical activity of 1:37 hrs. This is much shorter than a mean time of 2:40 hrs (above 2.5 METs) and 2:49 hrs in age-matched controls. ${ }^{7,8}$

The main result in our study was the minimal relationship between functional exercise capacity and daily physical activity. A previously published study with a similar study population found a higher correlation between functional exercise capacity and physical activity. ${ }^{31}$ This might be explained by their inclusion of patients with severe COPD, since it is shown that this relationship is stronger in this patient category. ${ }^{6,8,14,16}$ This is according to our hypothesis, patients with a better preserved lung function and exercise capacity do have 'a choice' in being physically active or not. In patients with severe COPD, limited exercise capacity constitutes a barrier for being physically active.

To date, there is not a single parameter which reflects overall daily physical activity best. So, all studies concerning physical activity in COPD patients have used several different parameters. In our study, we specifically collected many different walkingrelated physical activity-parameters, because functional exercise capacity was also measured by a walking test. We assumed that if there would be a correlation between these concepts, it would come forward by correlating these variables. Interestingly, these variables did not show a significant correlation at all. 
The choice of the reference value on the 6MWT might have played a role in the correlation analysis. We used the reference value of Enright (1998) because of the study population, testing protocol and the shorter length of the corridor used. ${ }^{21}$ For completeness, we also performed analyses with another reference value. ${ }^{34}$ As a result, there was a mean distance walked of 76\%predicted (SD 11,2) and there were significant correlations between 6MWD and physical activity-variables, but the correlations were only weak, ranging from $\mathrm{R}=0.29, p=0.042$ to $\mathrm{R}=0.31, p=0.028$. So, even when we had chosen to use other reference values, the overall conclusion would be a poor relationship between functional exercise capacity and daily physical activity.

\section{Implications for future research, policy and practice}

Environmental and personal factors were beyond the scope of this study. For future research it might be useful to gain more insight in these factors, so that causes for physical inactivity can be explored.

The present study reinforces the idea that although $\mathrm{FEV}_{1}, \mathrm{MRC}$ and even functional exercise capacity might be important outcomes to indicate the severity of the disease (like in BODE-index ${ }^{35}$ ), daily physical activity provides a supplementary concept, especially in patients with mild to moderate COPD. We suggest that there are actually four concepts that could be considered to describe the consequences of COPD in a broader perspective; pulmonary function (reflecting pathology), dyspnea (reflecting symptoms), exercise capacity (reflecting ability) and physical activity (reflecting actual function).

According to our results, we could consider behavioural change with regard to daily physical activity as an important treatment goal in primary care, as functional exercise capacity was not remarkably decreased and physical activity was clearly diminished. This is in line with the suggestion of Egan et al, who proposed a two-tiered approach, whereby programmes in secondary care should focus on functional capacity and primary care should focus on physical activity. ${ }^{13}$ We want to refine this statement, because also in primary care there is a substantial group of patients who could benefit from enhancing exercise capacity. Consequently, measuring daily physical activity is an essential part of the assessment in primary care in order to fine-tune treatment. It enables practitioners and physiotherapists to deliver personalised care. We can illustrate this best by looking at Figure 4.1. Patients in the lower right quadrant have a normal to good functional exercise capacity, whereas their daily physical activity is below normal values. In these patients the focus of treatment should be on improving physical activity behaviour. Patients in the lower left part of the plot might benefit from increasing both functional exercise capacity and daily physical activity. Patients 
in the upper right quadrant are doing well and should only be encouraged to continue their current approach. And the focus of treatment of patients in the upper left quadrant might be on enhancing functional exercise capacity and finding a balance between load and load-bearing capacity.

\section{Conclusions}

The results of this study show a discrepancy between functional exercise capacity and daily physical activity in patients with mild to moderate COPD recruited and assessed in primary care. These results reinforce the importance of measuring daily physical activity in order to fine-tune treatment. 


\section{References}

1. Fabbri LM, Rabe KF. From COPD to chronic systemic inflammatory syndrome? Lancet 2007;370: 797-9.

2. Lacasse Y, Martin S, Lasserson TJ, Goldstein RS. Meta-analysis of respiratory rehabilitation in chronic obstructive pulmonary disease. A Cochrane systematic review. Eura Medicophys 2007;43:475-85.

3. Larson JL. Functional performance and physical activity in chronic obstructive pulmonary disease: theoretical perspectives. COPD 2007;4:237-42.

4. Thompson PD, Buchner D, Pina IL, Balady GJ, Williams MA, Marcus BH, Berra K, Blair SN, Costa F, Franklin B, Fletcher GF, Gordon NF, Pate RR, Rodriguez BL, Yancey AK, Wenger NK; American Heart Association Council on Clinical Cardiology Subcommittee on Exercise, Rehabilitation, and Prevention; American Heart Association Council on Nutrition, Physical Activity, and Metabolism Subcommittee on Physical Activity. Exercise and physical activity in the prevention and treatment of atherosclerotic cardiovascular disease: a statement from the Council on Clinical Cardiology (Subcommittee on Exercise, Rehabilitation, and Prevention) and the Council on Nutrition, Physical Activity, and Metabolism (Subcommittee on Physical Activity). Circulation 2003;107:3109-16.

5. Zuwallack RL. How do we increase activity and participation in our patients? Semin Respir Crit Care Med 2009;30:708-12.

6. Pitta F, Troosters T, Spruit MA, Probst VS, Decramer M, Gosselink R. Characteristics of physical activities in daily life in chronic obstructive pulmonary disease. Am J Respir Crit Care Med 2005; 171:972-7.

7. Troosters T, Sciurba F, Battaglia S, Langer D, Valluri SR, Martino L, Benzo R, Andre D, Weisman I, Decramer M. Physical inactivity in patients with COPD, a controlled multi-center pilot-study. Respir Med 2010;104:1005-11.

8. Watz H, Waschki B, Meyer T, Magnussen H. Physical activity in patients with COPD. Eur Respir J 2009; 33:262-72.

9. Waschki B, Kirsten A, Holz O, Müller KC, Meyer T, Watz H, Magnussen H. Physical activity is the strongest predictor of all-cause mortality in patients with COPD: a prospective cohort study. Chest 2011;140:331-42.

10. Watz H, Waschki B, Boehme C, Claussen M, Meyer T, Magnussen H. Extrapulmonary effects of chronic obstructive pulmonary disease on physical activity: a cross-sectional study. Am J Respir Crit Care Med 2008;177:743-51.

11. Garcia Aymerich J, Lange P, Benet M, Schnohr P, Anto JM. Regular physical activity reduces hospital admission and mortality in chronic obstructive pulmonary disease: a population based cohort study. Thorax 2006;61:772-8.

12. Cindy Ng LW, Mackney J, Jenkins S, Hill K. Does exercise training change physical activity in people with COPD? A systematic review and meta-analysis. Chron Respir Dis 2012;9:17-26.

13. Egan C, Deering BM, Blake C, Fullen BM, McCormack NM, Spruit MA, Costello RW. Short term and long term effects of pulmonary rehabilitation on physical activity in COPD. Respir Med 2012;106:1671-9..

14. Mador MJ, Patel AN, Nadler J. Effects of pulmonary rehabilitation on activity levels in patients with chronic obstructive pulmonary disease. J Cardiopulm Rehabil Prev 2011;31:52-9.

15. Probst VS, Kovelis D, Hernandes NA, Camillo CA, Cavalheri V, Pitta F. Effects of 2 exercise training programs on physical activity in daily life in patients with COPD. Respir Care 2011;56:1799-807.

16. Zwerink $M$, van der Palen J, van der Valk $P$, Brusse Keizer M, Effing $T$. Relationship between daily physical activity and exercise capacity in patients with COPD. Respir Med 2013;107:242-8.

17. Belza B, Steele BG, Hunziker J, Lakshminaryan S, Holt L, Buchner DM. Correlates of physical activity in chronic obstructive pulmonary disease. Nurs Res 2001;50:195-202.

18. Steele BG, Holt L, Belza B, Ferris S, Lakshminaryan S, Buchner DM. Quantitating physical activity in COPD using a triaxial accelerometer. Chest 2000;117:1359-67. 
19. Steuten LM, Creutzberg EC, Vrijhoef HJ, Wouters EF. COPD as a multicomponent disease: inventory of dyspnoea, underweight, obesity and fat free mass depletion in primary care. Prim Care Respir J 2006; 15:84-91.

20. Miller MR, Hankinson J, Brusasco V, Burgos F, Casaburi R, Coates A, Crapo R, Enright P, van der Grinten CP, Gustafsson P, Jensen R, Johnson DC, Maclntyre N, McKay R, Navajas D, Pedersen OF, Pellegrino R, Viegi G, Wanger J; ATS/ERS Task Force. Standardisation of spirometry. Eur Respir J 2005;26:319-38.

21. Enright PL, Sherrill DL. Reference equations for the six-minute walk in healthy adults. Am J Respir Crit Care Med 1998;158:1384-7.

22. ATS statement: guidelines for the six-minute walk test. Am J Respir Crit Care Med 2002;166:111-7.

23. Bestall JC, Paul EA, Garrod R, Garnham R, Jones PW, Wedzicha JA. Usefulness of the Medical Research Council (MRC) dyspnoea scale as a measure of disability in patients with chronic obstructive pulmonary disease. Thorax 1999;54:581-6.

24. Van Remoortel H, Raste Y, Louvaris Z, Giavedoni S, Burtin C, Langer D, Wilson F, Rabinovich R, Vogiatzis I, Hopkinson NS, Troosters T; PROactive consortium. Validity of six activity monitors in chronic obstructive pulmonary disease: a comparison with indirect calorimetry. PLoS One 2012;7:e39198.

25. Hunter GR, Larson Meyer DE, Sirikul B, Newcomer BR. Muscle metabolic function and free-living physical activity. J Appl Physiol 2006;101:1356-61.

26. Black AE, Coward WA, Cole TJ, Prentice AM. Human energy expenditure in affluent societies: an analysis of 574 doubly-labelled water measurements. Eur J Clin Nutr 1996;50:72-92.

27. Ainsworth BE, Haskell WL, Whitt MC, Irwin ML, Swartz AM, Strath SJ, O'Brien WL, Bassett DR Jr, Schmitz KH, Emplaincourt PO, Jacobs DR Jr, Leon AS. Compendium of physical activities: an update of activity codes and MET intensities. Med Sci Sports Exerc 2000;32(9 Suppl):S498-504.

28. Panos RJ, Eschenbacher W. Exertional desaturation in patients with chronic obstructive pulmonary disease. COPD 2009;6:478-87.

29. Tudor Locke C, Bassett DR, Jr. How many steps/day are enough? Preliminary pedometer indices for public health. Sports Med 2004;34:1-8.

30. Pitta F, Troosters T, Probst VS, Spruit MA, Decramer M, Gosselink R. Quantifying physical activity in daily life with questionnaires and motion sensors in COPD. Eur Respir J 2006;27:1040-55.

31. Eliason G, Zakrisson AB, Piehl Aulin K, Hurtig Wennlof A. Physical activity patterns in patients in different stages of chronic obstructive pulmonary disease. COPD 2012;8:369-74.

32. Levin S, Jacobs DR, Jr., Ainsworth BE, Richardson MT, Leon AS. Intra-individual variation and estimates of usual physical activity. Ann Epidemiol 1999;9:481-8.

33. Harbers. Lichamelijke activiteit: Zijn er binnen Nederland verschillen naar regio? Volksgezondheid Toekomst Verkenning, Nationaal Kompas Volksgezondheid. Bilthoven: RIVM, 2010.

34. Troosters T, Gosselink R, Decramer M. Six minute walking distance in healthy elderly subjects. Eur Respir J 1999;14:270-4.

35. Celli BR, Cote CG, Marin JM, Casanova C, Montes de Oca M, Mendez RA, Pinto Plata V, Cabral HJ. The body-mass index, airflow obstruction, dyspnea, and exercise capacity index in chronic obstructive pulmonary disease. N Engl J Med 2004;350:1005-12. 


\section{Chapter 5}

Efficacy of a physical exercise training programme COPD in primary care: a randomized controlled trial

Annemieke Fastenau, Onno CP van Schayck, Bjorn Winkens, Karin CPM Aretz, Guus M Asijee, Rik Gosselink, Jean WM Muris

Submitted 


\section{Abstract}

\section{Background}

Little is known about the added value of an exercise training programme in primary care, on top of promoting physical activity, in patients with mild to moderate COPD. We evaluated the efficacy of a Physical Exercise Training Programme COPD on exercise capacity, muscle strength, daily physical activity, breathlessness, quality of life and global perceived effect.

\section{Methods}

104 patients with mild to moderate COPD were randomized to a Physical Exercise Training Programme or usual care. Primary outcome was improvement in functional exercise capacity at 4 months, assessed by the six-minute walk test. Secondary outcomes were muscle strength, objective daily physical activity, breathlessness, health-related quality of life and global perceived effectiveness of the treatment.

\section{Results}

In the primary outcome, there was a statistically and clinically relevant between-group difference of $26.6 \mathrm{~m}(p=0.020)$ in favour of the intervention group. For the secondary outcome measures, significant between-group differences were found for shoulder abduction strength $23.9 \mathrm{Nm}(p=0.035)$ at 4 months, handgrip force $1.9 \mathrm{KgF}(p=0.028)$, CRQ mastery sub score 0.5 $(p=0.035)$ and mean steps per period 3.2 steps $(p=0.016)$ at 6 months. Nearly, all the other daily physical activity variables showed a positive trend at 6 months compared to baseline, but the between-group differences did not reach statistical significance.

\section{Conclusions}

A Physical Exercise Training Programme in primary care on top of promoting physical activity has an added value in improving exercise capacity in patients with mild to moderate COPD. These improvements are not translated into significant between-group differences in daily physical activity. 


\section{Introduction}

Pulmonary rehabilitation (PR) is very effective in improving exercise capacity, dyspnoea and quality of life in patients with moderate to severe COPD. ${ }^{1}$ PR is considered to be an interdisciplinary intervention, in which exercise training is the cornerstone. ${ }^{2}$ The large majority of research in the field of exercise training in COPD is performed in patients with moderate to severe COPD recruited and assessed in clinical or rehabilitation settings. ${ }^{1}$ Nowadays, it is recognised that also patients with mild to moderate COPD do have impairments in exercise capacity, quadriceps strength, health-related quality of life and physical activity levels. ${ }^{3-6}$ Early intervention could be beneficial to control symptoms and potentially affect disease progression., ${ }^{5,7}$ Only scant information is available on exercise training programmes incorporated in (self-) management programmes in primary care in patients with moderate to severe COPD.

8-10 It was found that these patients can also improve health-related quality of life, breathlessness, muscle strength and exercise capacity. Increasing exercise capacity in patients with COPD reduces symptoms of fatigue and dyspnoea during exercise and removes the barrier to become more physically active. ${ }^{2,11} \mathrm{~A}$ recent study has shown that exercise capacity and physical activity are two different concepts in patients with mild to moderate disease. ${ }^{12}$

In addition to the beneficial effects of improvements in exercise capacity, increasing daily physical activity is important, because of the long-term health-related benefits. Physical inactivity in patients with COPD is associated with increased hospitalizations, mortality and faster lung function decline. ${ }^{13,14}$

Due to the limited evidence in patients with mild to moderate COPD, there seems to be no consensus in (inter)national COPD guidelines. The underpinning in the latest GOLD report 'increasing physical activity in daily life, without the need for formal exercise training for patients with mild to moderate COPD', is not evidence-based but "seems intuitively correct". ${ }^{15}$ On the other hand, the ATS/ERS Statement on PR suggests that exercise training at an earlier stage of COPD has the potential to markedly alter the course of the disease. ${ }^{2}$ At present, the added value of an exercise training programme in primary care, on top of promoting physical activity, in patients with mild to moderate COPD is debated. In this paper, we present the results of a randomized controlled trial evaluating the efficacy of a 4-month physical exercise training programme COPD compared to a control group on exercise capacity, daily physical activity, breathlessness, quality of life and global perceived effectiveness of the treatment. 


\section{Methods}

\section{Study design and population}

This study is a randomized controlled trial performed in the primary care setting, approved by the ethics committee of Maastricht University. The trial has been registered at The Netherlands National Trial Register NTR1471.

Patients were recruited from general practices in the southern part of the Netherlands. Both the intervention and control group received their measurements and treatment at physiotherapy practices. Measurements were performed at baseline, after 4 months (end of the programme) and 6 months (follow-up). Detailed information about the study protocol can be found elsewhere. ${ }^{16}$

Inclusion was based on COPD patients visiting their general practitioner because of dyspnoea, impaired exercise capacity, having a clinical diagnosis of mild to moderate COPD $^{15}$ and having a stable situation (no exacerbations in the previous 8 weeks).

\section{Intervention group (Physical Exercise Training Programme (PETP))}

For the PETP, the Dutch Guideline Physiotherapy in COPD served as a framework. ${ }^{17}$ There were four major aims: improvement in exercise capacity, muscle strength, daily physical activity and breathing technique (details have been published elsewhere). ${ }^{16}$ Throughout the training period patients were advised to do at least 30 minutes of moderate intense physical activities on at least five days a week according to the ACSM-recommendation for physical activity. ${ }^{18}$

The PETP consisted of 2 supervised sessions per week. These sessions took place with 1-5 patients at the time and duration of each session was 60-90 minutes, depending on group size. Patients were requested to perform an additional training session per week at home, including walking and/or cycling.

\section{Control group (sham-treatment)}

Patients in the control group participated in a sham-treatment, which consisted of 30 minutes once a week "exercise" training, with a perceived exertion and dyspnoea of 2 or lower on a modified Borg-scale. In this way, no physiologic training stimulus would occur. There were no breathing exercises or resistance training. Furthermore, the same advises on daily physical activities were given as in the intervention group. 


\section{Outcomes}

Primary outcome was functional exercise capacity measured by the six-minute walking test (6MWT) at 4 months. This test was executed according to ATS instructions ${ }^{19}$, except that a standard 30-meter corridor was not always feasible, but the minimal length of a corridor was 10 meter. The results are expressed in absolute values and as percent of the predicted value. ${ }^{20}$

Secondary outcomes were 6MWD at 6 months, muscle strength (handgrip force, isometric knee extension and shoulder abduction), subjective and objective daily physical activity, dyspnoea, specific health-related quality of life and global perceived effect of the treatment. ${ }^{16}$

Self-reported daily physical activity was assessed by the brief physical activity assessment tool. ${ }^{21}$ Objective daily physical activity was measured in a subgroup of patients during 3 days and nights with an accelerometer-based activity monitor (Dynaport MiniMod; McRoberts BV), details have been published previously. ${ }^{12}$ Data of both intensity and duration were collected, like: steps per day, movement intensity during walking, time spent walking per day, total active time per day, time spent in moderate intense physical activities and vigorous activities and physical activity level (PAL). Steps per day is a composite variable, consisting of number of walking periods per day and steps per walking period.

Level of dyspnoea was assessed by the Medical Research Council (MRC) dyspnoea score. ${ }^{22}$ Specific Health Related Quality of Life (HRQL) was assessed by the Clinical COPD Questionnaire (CCQ) ${ }^{23}$ and Chronic Respiratory Questionnaire (CRQ-SR). ${ }^{24}$ Global perceived effect (GPE) of the treatment according to the patients was evaluated on a GPE scale. ${ }^{25}$

The following baseline characteristics were measured: Body Mass Index (BMI) and level of motivation to become physically more active according to Miller (2005) and Rollnick et al. ${ }^{26,27}$

\section{Statistical analysis}

We calculated that 102 patients (51 per treatment arm) were required to detect a difference of 52 metres (SD 78 metres) on the 6MWT between both groups at 4 months with an independent-samples t-test, assuming $80 \%$ power and a two-sided significance-level $\alpha$ of 0.05 , and allowing for dropouts (30\%). ${ }^{16}$

For continuous variables, the longitudinal difference in primary and secondary outcomes between the groups were assessed by using linear mixed models, since these models account for the correlation between repeated measures within the same patient, correct for baseline differences to gain efficiency, and use all available 
data, also for patients who had missing data (assuming missing at random (MAR)). Time (baseline, 4 and 6 months) and group*time were included as fixed factors, where an unstructured covariance structure was assumed for the repeated measures and restricted maximum likelihood was used to obtain unbiased estimates. Estimated difference in means with the corresponding 95\% confidence interval $(\mathrm{Cl})$ is presented. Two-sided $p$-values $\leq 0.05$ were considered statistically significant. All analyses were performed using IBM SPSS Statistics for Windows (Version 21.0, Armonk, NY: IBM Corp).

\section{Results}

In total 104 patients were randomized, referred from 27 general practices and treated in 12 physiotherapy practices. Due to a lag time from inclusion to baseline measurement at the physiotherapy practice, 14 patients ( 7 male and 7 women) were excluded because of exacerbations or new/unknown comorbidities. Patient disposition and reasons for drop out are described in Figure 5.1. Data from 90 patients were retained for intention-to-treat purposes. Seven patients in the PETP-group did not complete the training programme (15\% drop-out rate) and 2 more patients could not be re-assessed for follow-up at 6 months. In the control group, 12 patients dropped out during the treatment period (27\% drop-out rate) and another 3 patients were not able to be re-assessed at 6 months. One patient who failed to attend the 4month measurement was capable to be re-assessed at 6 months.

\section{Baseline characteristics}

Baseline characteristics of the intervention and control group are comparable (Table 5.1). In the majority of patients, COPD was diagnosed less than five years before baseline measurement. Patients generally had mild to moderate COPD, an overweight $\mathrm{BMI}$, moderate dyspnoea and a high level of motivation to become physically more active. They had a rather preserved functional exercise capacity, but $16 \%$ of the patients had an oxygen saturation below $90 \%$ during the test (data not shown). They were sedentary, and $85 \%$ of the patients did not attain the recommendations of $\operatorname{ACSM}^{18}$ (Table 5.1). 


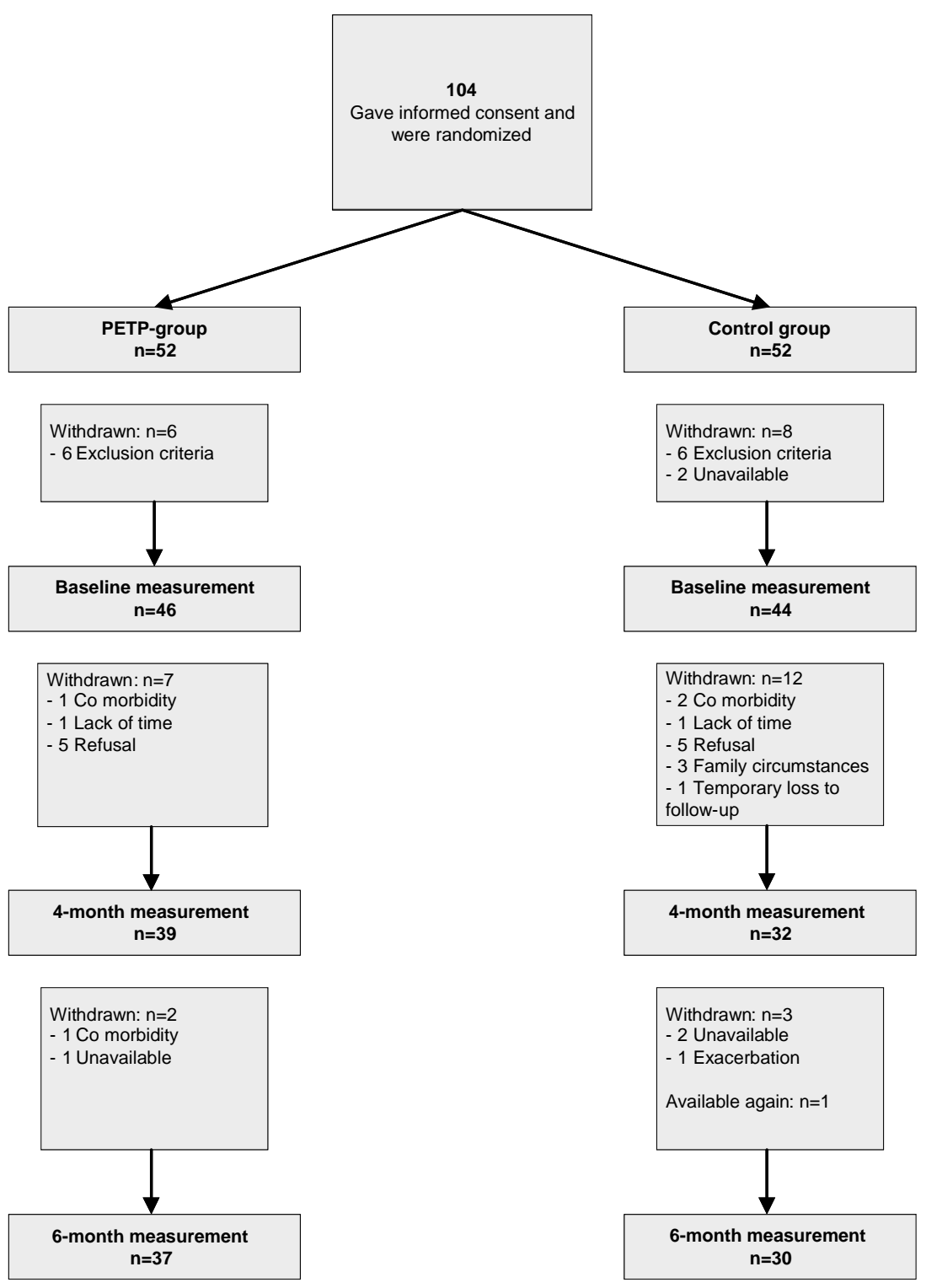

Figure 5.1 CONSORT flow diagram. 
Table 5.1 Baseline characteristics.

\begin{tabular}{|c|c|c|c|}
\hline & $\begin{array}{l}\text { Overall } \\
(n=90)\end{array}$ & $\begin{array}{c}\text { PETP } \\
(n=46)\end{array}$ & $\begin{array}{c}\text { Control Group } \\
(n=44)\end{array}$ \\
\hline \multicolumn{4}{|l|}{ General characteristics } \\
\hline Gender (male/female) & $44 / 46$ & $27 / 19$ & $17 / 27$ \\
\hline Age (years) & $62.5 \pm 9.9$ & $62.4 \pm 9.1$ & $62.6 \pm 10.8$ \\
\hline Height (cm) & $169.1 \pm 8.7$ & $170.4 \pm 8.5$ & $167.8 \pm 8.8$ \\
\hline BMI $\left(\mathrm{kg} / \mathrm{m}^{2}\right)$ & $27.8 \pm 4.9$ & $27.2 \pm 4.2$ & $28.4 \pm 5.4$ \\
\hline Fat mass $(\%)(n=30 / 31)$ & $32.6 \pm 8.9$ & $30.2 \pm 8.2$ & $35.0 \pm 9.1$ \\
\hline \multicolumn{4}{|l|}{ Pulmonary characteristics } \\
\hline $\mathrm{FEV}_{1}(\mathrm{~L})$ & $2.1 \pm 0.6$ & $2.1 \pm 0.7$ & $2.0 \pm 0.6$ \\
\hline $\mathrm{FEV}_{1} \%$ pred. & $74.2 \pm 13.5$ & $74.4 \pm 14.8$ & $74.0 \pm 12.2$ \\
\hline $\mathrm{FEV}_{1} / \mathrm{FVC}(\%)$ & $58.9 \pm 8.4$ & $57.3 \pm 9.4$ & $60.5 \pm 7.0$ \\
\hline GOLD-classification (I/II) & $24 / 66$ & $14 / 32$ & $10 / 34$ \\
\hline \multicolumn{4}{|l|}{ Years of diagnosis COPD } \\
\hline$<1$ year: & $25.8 \%$ & $26.7 \%$ & $25 \%$ \\
\hline 1-5 years: & $50.6 \%$ & $48.9 \%$ & $52.3 \%$ \\
\hline$>5-10$ years: & $21.3 \%$ & $22.2 \%$ & $20.5 \%$ \\
\hline >10 years: & $2.2 \%$ & $2.2 \%$ & $2.3 \%$ \\
\hline \multicolumn{4}{|l|}{ Smoking status } \\
\hline Smoker: & $37.9 \%$ & $45.5 \%$ & $30.2 \%$ \\
\hline Stopped smoking: & $54 \%$ & $47.7 \%$ & $60.5 \%$ \\
\hline Never smoked: & $8 \%$ & $6.8 \%$ & $9.3 \%$ \\
\hline \multicolumn{4}{|l|}{ Questionnaires } \\
\hline MRC dyspnoea score (1-5) & $2.4 \pm 0.8$ & $2.4 \pm 0.8$ & $2.4 \pm 0.8$ \\
\hline CCQ Total score (0-6) & $1.7 \pm 0.8$ & $1.7 \pm 0.7$ & $1.7 \pm 0.9$ \\
\hline CCQ Symptoms & $2.2 \pm 1.0$ & $2.2 \pm 1.0$ & $2.1 \pm 1.1$ \\
\hline CCQ Functional state & $1.7 \pm 1.0$ & $1.6 \pm 0.9$ & $1.7 \pm 1.1$ \\
\hline CCQ Mental state & $0.9 \pm 1.0$ & $0.8 \pm 1.0$ & $0.9 \pm 1.1$ \\
\hline CRQ Fatigue & $4.1 \pm 1.2$ & $4.1 \pm 1.3$ & $4.2 \pm 1.2$ \\
\hline CRQ Emotional function & $4.6 \pm 1.2$ & $4.6 \pm 1.3$ & $4.5 \pm 1.2$ \\
\hline CRQ Mastery & $5.1 \pm 1.3$ & $5.0 \pm 1.3$ & $5.1 \pm 1.3$ \\
\hline Level of motivation (0-10) & $7.8 \pm 1.2$ & $8.0 \pm 1.2$ & $7.7 \pm 1.0$ \\
\hline Level of confidence $(0-10)$ & $7.8 \pm 1.2$ & $7.9 \pm 1.3$ & $7.7 \pm 1.2$ \\
\hline \multicolumn{4}{|l|}{30 min. moderate intense physically active: } \\
\hline - 5 times per week & $15.3 \%$ & $11.6 \%$ & $19.0 \%$ \\
\hline - 3-4 times per week & $20.0 \%$ & $25.6 \%$ & $14.3 \%$ \\
\hline - 1-2 times per week & $29.4 \%$ & $37.2 \%$ & $21.4 \%$ \\
\hline - 0 times per week & $35.3 \%$ & $25.6 \%$ & $45.2 \%$ \\
\hline \multicolumn{4}{|l|}{20 min. vigorous intense physically active: } \\
\hline - 3 times per week & $1.2 \%$ & $0 \%$ & $2.4 \%$ \\
\hline - 1-2 times per week & $23.5 \%$ & $23.3 \%$ & $23.8 \%$ \\
\hline - 0 times per week & $75.3 \%$ & $76.7 \%$ & $73.8 \%$ \\
\hline \multicolumn{4}{|l|}{ Physical fitness } \\
\hline 6MWD (m) & $491.2 \pm 91.1$ & $500.9 \pm 89.3$ & $481.1 \pm 92.9$ \\
\hline 6MWD (\%pred.) & $95.8 \pm 15.2$ & $95.3 \pm 14.4$ & $96.3 \pm 16.1$ \\
\hline Handgrip force (\%pred.) (n=41/39) & $88.5 \pm 20.8$ & $87.7 \pm 22.7$ & $89.3 \pm 18.7$ \\
\hline Knee extension strength (\%pred.) (n=24/20) & $87.6 \pm 18.1$ & $87.6 \pm 21.0$ & $87.6 \pm 14.4$ \\
\hline Shoulder abduction strength (\%pred.) $(n=23 / 20)$ & $105.0 \pm 24.3$ & $101.7 \pm 25.7$ & $108.9 \pm 22.7$ \\
\hline
\end{tabular}


Table $5.1 \quad$ (continued).

\begin{tabular}{lccc}
\hline & $\begin{array}{c}\text { Overall } \\
(\mathrm{n}=90)\end{array}$ & $\begin{array}{c}\text { PETP } \\
(\mathrm{n}=46)\end{array}$ & $\begin{array}{c}\text { Control Group } \\
(\mathrm{n}=44)\end{array}$ \\
\hline Physical activity $(\mathrm{n}=29 / 22)$ & & & \\
$\quad$ Steps per day & $6459 \pm 2995$ & $6498 \pm 3155$ & $6407 \pm 2841$ \\
Walking periods per day & $462.4 \pm 213.9$ & $434.2 \pm 179.9$ & $503.3 \pm 254.9$ \\
Steps per walking period & $14.8 \pm 5.4$ & $15.3 \pm 5.8$ & $14.1 \pm 4.8$ \\
Movement intensity (m/s $\left.{ }^{2}\right)$ & $0.20 \pm 0.04$ & $0.20 \pm 0.05$ & $0.20 \pm 0.03$ \\
Time spent walking per day (h.m) & $1.19 \pm 0.32$ & $1.19 \pm 0.32$ & $1.19 \pm 0.33$ \\
Total active time (h.m) & $5.20 \pm 1.42$ & $5.03 \pm 1.39$ & $5.43 \pm 1.44$ \\
Time in moderate PA (h.m) & $1.37 \pm 0.35$ & $1.34 \pm 0.33$ & $1.40 \pm 0.38$ \\
Time in vigorous PA (h.m) & $0.09 \pm 0.13$ & $0.09 \pm 0.15$ & $0.08 \pm 0.11$ \\
PAL & $1.4 \pm 0.12$ & $1.4 \pm 0.10$ & $1.5 \pm 0.14$ \\
\hline
\end{tabular}

Data are presented as mean \pm SD for continuous variables and as number or percentage for categorical variables. BMI: Body Mass Index; FEV ${ }_{1}$ : Forced Expiratory Volume in one second, FVC: Forced Vital Capacity, GOLD: Global initiative for chronic Obstructive Lung Disease, MRC: Medical Research Council, CCQ: Clinical COPD Questionnaire, CRQ: Chronic Respiratory Disease Questionnaire, 6MWD: six-minute walking distance, h.m: hours. minutes, PA: physical activity, PAL: Physical Activity Level.

\section{Primary outcome: exercise capacity}

Figure 5.2 shows the change over time in 6MWD. At the end of the programme, i.e. at 4 months, 6MWD improved in both groups, but significantly more in the intervention group, resulting in a between-group difference in mean 6MWD of $26.6 \mathrm{~m}(p=0.020)$. During the follow-up period the mean 6MWD increased even more in both groups, but the between-group difference decreased to $20.1 \mathrm{~m}$, which was not statistically significant anymore $(p=0.136)$ (Table 5.2).

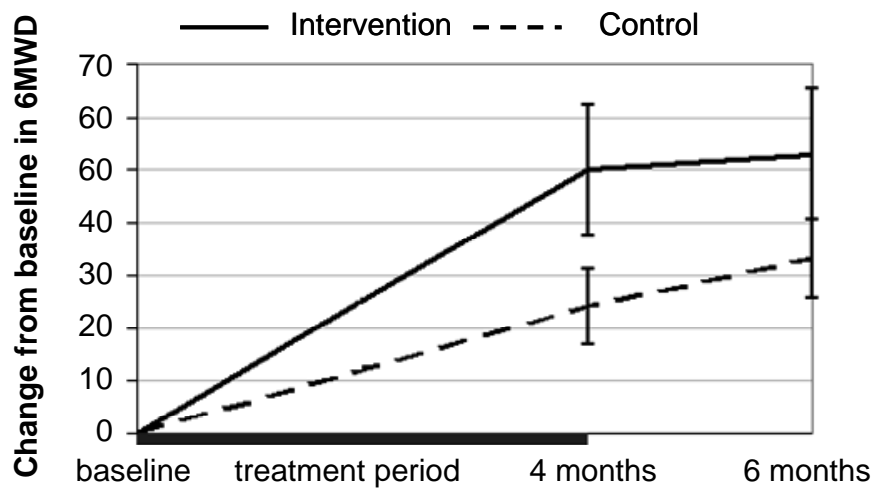

Figure 5.2 Change from baseline in 6 Minute Walking Distance at 4 and 6 months after baseline measurement (bars indicate SEM). The bar in bold on the $x$-axis indicates the treatment period. 


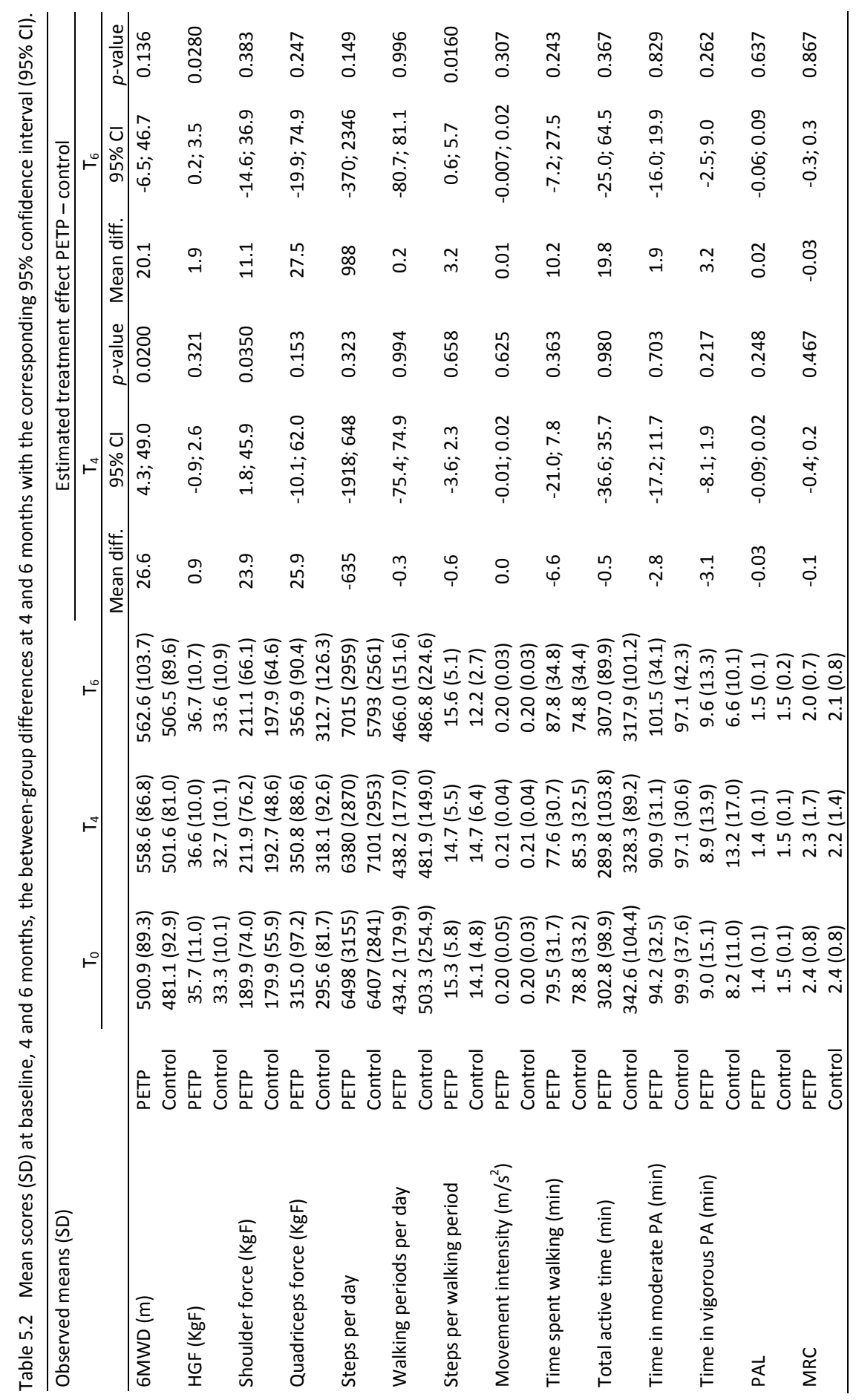




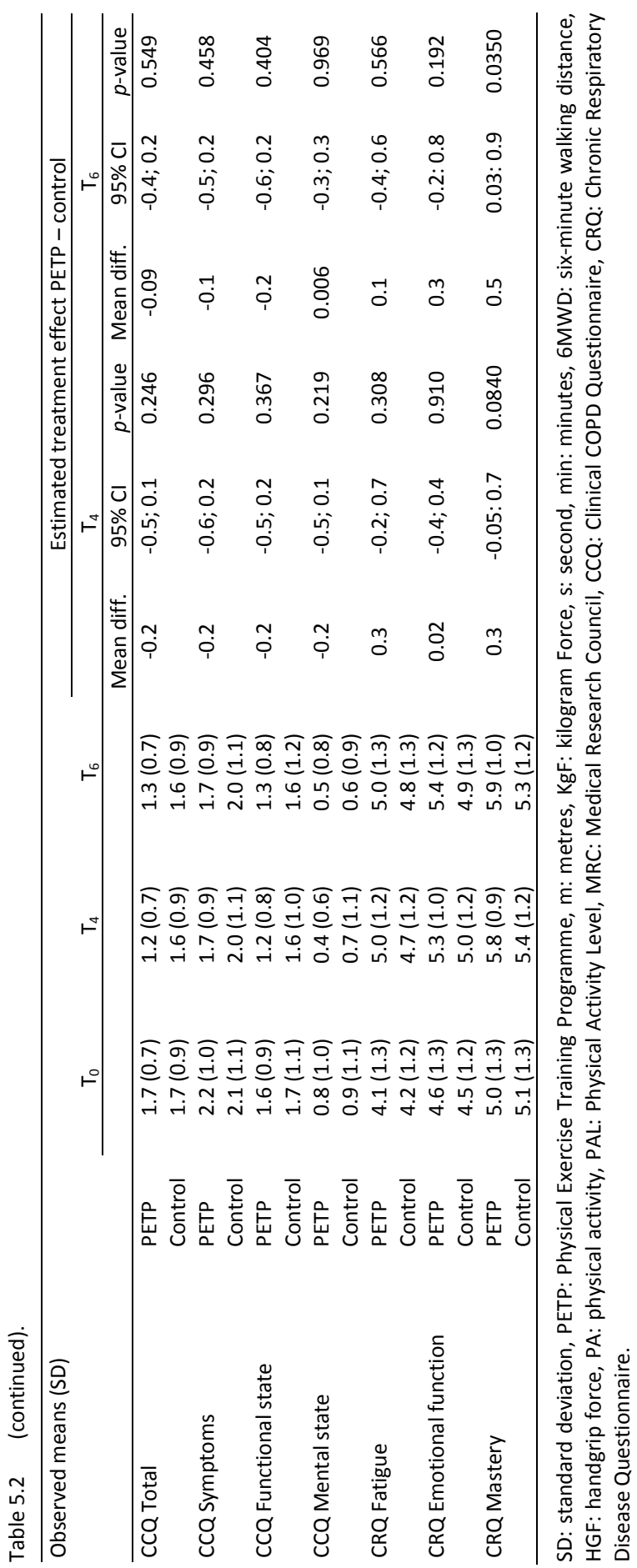




\section{Secondary outcomes}

For MRC dyspnoea score, CCQ (sub) scores and self-reported physical activity of moderate and vigorous intensity, no statistically significant between-group differences at 4 and 6 months were found (Table 5.2). CRQ dyspnoea sub score was difficult to calculate because $26 \%$ of the patients was not able to mention 5 activities which caused dyspnoea. For CRQ sub scores fatigue, emotional function and mastery no significant between-group differences were found at 4 months. At 6 months, the CRQ sub score mastery improved significantly more in the PETP group ( $p=0.035)$.

Measurements of objective physical activity were performedin a subgroup of patients, because of the time-consuming procedure. No significant between-group difference were found for the physical activity variables, except for steps taken per walking period at 6 months ( 3.2 steps, $p=0.0160$ ) (table 5.2 At 6 months though, there was a positive trend in the PETP group; all the physical activity parameters (except movement intensity) showed an improvement compared to baseline, but the between-group differences did not reach statistical significance. An example (steps per day) is shown in Figure 5.3.

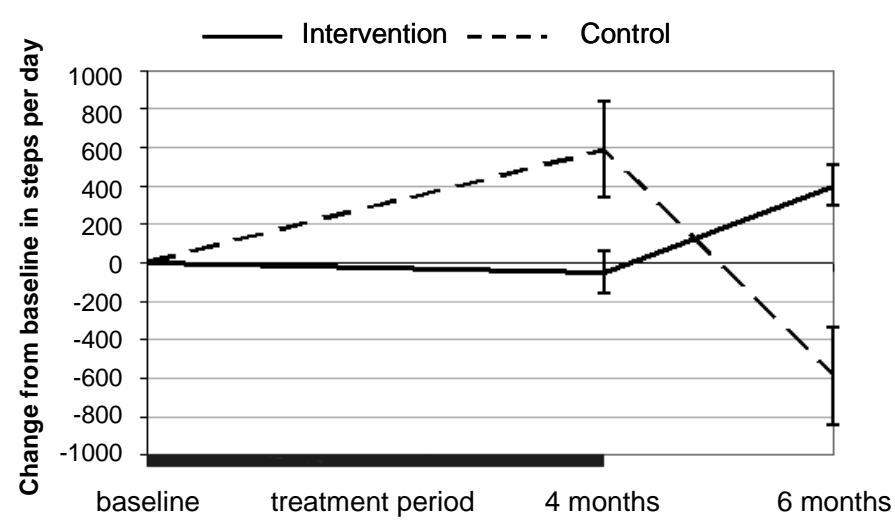

Figure 5.3 Change from baseline in steps per day at 4 and 6 months after baseline measurement (bars indicate SEM). The bar in bold on the $x$-axis indicates the treatment period.

Scores on global perceived effectiveness were high in both groups at 4 and 6 months, without a significant between-group difference. No single patient scored a worsening of perceived effect (Figure 5.4). 
For handgrip force, no statistically significant between-group difference was found at 4 months. At 6 months, there was a significant between-group difference of $1.9 \mathrm{KgF}$ $(p=0.028)$ (Table 5.2). Measurements of isometric shoulder abduction and knee extension strength were performed in a subgroup of patients because of the lack of a hand-held dynamometer or experience with the test procedure in certain physiotherapy practices. Shoulder abduction strength at 4 months increased significantly more in the PETP group compared to the control group (difference $23.9 \mathrm{Nm}(p=0.0350)$. At 6 months, shoulder abduction strength decreased in the PETP group in such way that no significant between-group difference existed anymore. Knee extension strength increased in both groups at 4 and 6 months, without a significant between-group difference.

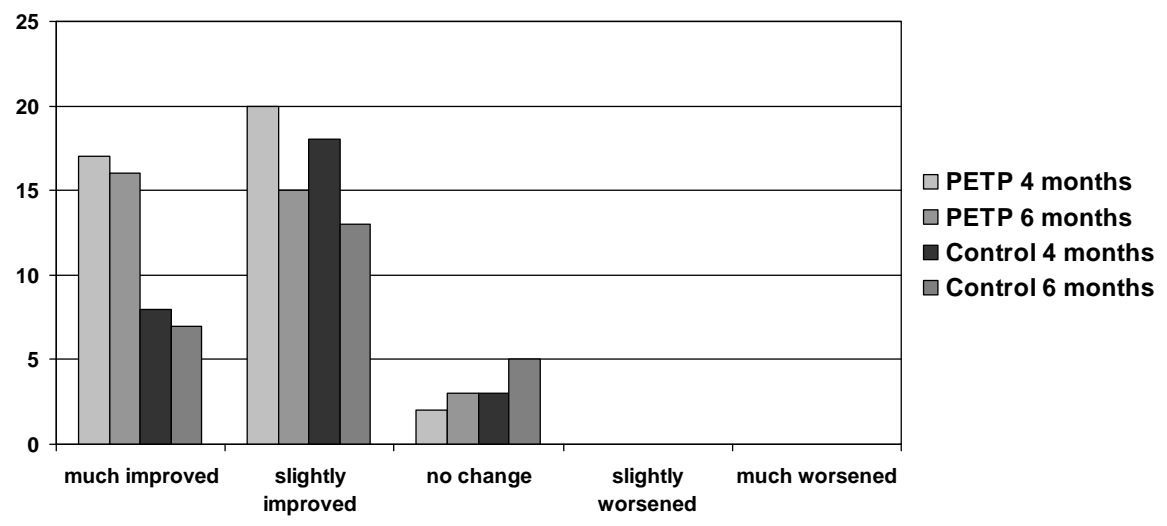

Figure 5.4 Global perceived effectiveness by patients.

\section{Discussion}

\section{Main findings}

This RCT showed that a Physical Exercise Training Programme in patients with mild to moderate COPD in primary care is effective in improving exercise capacity at 4 months, i.e. the end of the training period. For the secondary outcomes, significant improvements were seen in muscle strength (handgrip force at 6 months and shoulder abduction strength at 4 months), and CRQ mastery sub score at 6 months. Significant improvements in exercise capacity did not result into a significant 
between-group difference in daily physical activity, except for steps per walking period at 6 months.

\section{Interpretation of findings in relation to previously published work}

To our knowledge, this is one of the first studies showing the effectiveness of a Physical Exercise Training Programme in patients with mild to moderate COPD recruited, assessed and trained in primary care. Pulmonary function in our study ( mean FEV1\% predicted $=74 \%$ ) is substantially higher than in other PR studies in primary care (mean FEV1\%predicted 50-60\%). ${ }^{8,9,28,29}$ Roman et al. (2013) also conducted a RCT in a primary care setting in patients with moderate COPD, but found no changes in overall quality of life and exercise capacity after 3 and 12 months. ${ }^{29}$ Two other studies in patients with moderate to severe COPD, where recruitment and assessment was hospital-based, showed significant improvements in quality of life, breathlessness, exercise capacity, muscle strength and daily physical activity. ${ }^{8,9}$ Interestingly, both control groups in these studies showed a decline in exercise capacity and quality of life even after short term evaluation (4 and 7 months), resulting in large between-group differences. On the contrary, intervention as well as control group in our study showed improvements in exercise capacity, muscle force (except handgrip force), breathlessness and quality of life. This might be explained by the minimal intervention our control group did receive; they were made aware of the importance of being physically active. Even so, our primary outcome measure showed a significant between-group difference of $26.6 \mathrm{~m}$, compared to $13.8 \mathrm{~m}$ in another study. ${ }^{9}$ The minimal important difference for 6MWD according to the study of Holland (2010), using both anchor- and distribution-based methods, is approximately 25 meters. ${ }^{30}$ So, our results on 6MWD are not only statistically significant, but also clinical relevant.

Baseline daily physical activity in our study population was lower than in comparable patients from other studies. Troosters et al and Watz et al. found for patients with COPD Gold stage I and II a mean of 7357 and 7619 steps per day respectively and a PAL of 1.63 as opposed to 6459 steps per day and a PAL of 1.45 in our study. ${ }^{31,32}$ The southern part of the Netherlands is known as a region with less physical activity than the rest of the country. ${ }^{33}$

The PETP COPD did not only focus on improving exercise capacity, but also on enhancing daily physical activity. The results however, show significant betweengroup differences in improvements in exercise capacity and muscle force, but not in the many measured physical activity variables, except steps per period. Physical 
activity patterns in the PETP group remained unchanged immediately after the end of the training programme and showed some improvement in the follow-up period. Our explanation for this trend is that these patients were exercising on 3 days a week and might not have focused on behavioural change during the training period. This concurs with the study of Coronado et al., who found that changes in walking activity during pulmonary rehabilitation is caused by the evolution of the training process, but not due to changes in spontaneous activities. ${ }^{34}$ At the end of the training period, patients in the PETP group might have made a shift to behavioural change in order to sustain the positive effects. At 6 months, we found a non-significant between-group difference of almost 1000 steps per day in favour of the intervention group. If you reckon with the baseline score of 6498 steps per day, a difference of almost 1000 is a difference of $15 \%$. So far, it is not known how much improvement in physical activity is clinically relevant. ${ }^{2}$ Our findings are in line with other studies, which showed that improved exercise capacity after PR was not transmitted into increased daily physical activity. $^{35-37}$

\section{Strengths and limitations}

Strength of our study is the rather unique study population and setting. The study population resembles well the routine daily COPD primary care in the Netherlands. Furthermore, assessment was very extensive compared to many other studies, combining measurements of physical functioning, subjective and objective daily physical activity, symptoms, quality of life and subjective perceived effectiveness of the treatment.

Limitations of the study include the low number of participants and high drop-out rate. This is consistent with other studies with number of study participants at baseline ranging from 40 to 71 and drop-out rate of $25.8 \%$ up to $36.5 \%{ }^{28,29,37}$ Faulkner et al. (2010) were only able to evaluate 14 patients from 16 general practices and 215 patients invited. ${ }^{38}$ Difficulties in recruitment and execution of studies in primary care might be due to the fact that most patients with mild to moderate COPD are asymptomatic and do not look for medical assistance. ${ }^{6}$ In addition, this population has only been a topic of research in recent years. ${ }^{6}$ Compared to research in hospital and pulmonary rehabilitation settings, execution of studies in primary care is more time consuming, because of the many different centres and healthcare providers. They all have to be prepared in advance of the study and be monitored during the study. Another limitation is that all measurements were conducted by different physiotherapists. To assure high quality and univocal assessments though, the 
participating physiotherapists were trained and instructed intensively before and throughout the intervention period.

\section{Implications for future research, policy and practice}

Nearly all the patients who had completed the PETP-programme perceived the treatment as effective. Other studies also reported the feasibility and high motivation to exercise under guidance of a physiotherapist in primary care. ${ }^{8,9}$

Despite the reasonable distance walked on the 6MWT, a subgroup of patients showed a significant decrease in oxygen saturation during exertion. Primary causes of desaturation are ventilation to perfusion mismatching and diffusion-type limitation ${ }^{39}$, so a part of our patients could have pulmonary limitations. This was reason to further assess the desaturation.

Our results show that a PETP on top of promoting physical activity has an added value in improving exercise capacity. These improvements are not directly translated into changes in daily physical activity. In a previous study, we already showed that at baseline exercise capacity and physical activity are two different concepts. ${ }^{12}$ Assessment of physical activity should be considered as of the utmost importance. ${ }^{12,40}$ Insight in physical activity enables caregivers to deliver personalised care, focus might be on improving exercise capacity, behavioural change regarding physical activity or both. Up to now, treatments for improving exercise capacity have been proven to be effective. On top of that, there is an urgent need to find a treatment which results in long lasting improvement in actual daily physical activity. The PETP in our study might be an initial impetus, but needs to be investigated more thoroughly.

\section{Conclusions}

A Physical Exercise Training Programme in primary care on top of promoting physical activity has an added value in improving exercise capacity in patients with mild to moderate COPD. In addition, some secondary outcome measures also showed significant improvements on either 4 or 6 months, including muscle force and the CRQ mastery domain. These improvements are not translated into significant betweengroup differences in daily physical activity. 


\section{References}

1. Lacasse Y, Martin S, Lasserson TJ, Goldstein RS. Meta-analysis of respiratory rehabilitation in chronic obstructive pulmonary disease. A Cochrane systematic review. Eura Medicophys 2007;43:475-85.

2. Spruit MA, Singh SJ, Garvey C, ZuWallack R, Nici L, Rochester C, Hill K, Holland AE, Lareau SC, Man WD, Pitta F, Sewell L, Raskin J, Bourbeau J, Crouch R, Franssen FM, Casaburi R, Vercoulen JH, Vogiatzis I, Gosselink R, Clini EM, Effing TW, Maltais F, van der Palen J, Troosters T, Janssen DJ, Collins E, GarciaAymerich J, Brooks D, Fahy BF, Puhan MA, Hoogendoorn M, Garrod R, Schols AM, Carlin B, Benzo R, Meek P, Morgan M, Rutten-van Mölken MP, Ries AL, Make B, Goldstein RS, Dowson CA, Brozek JL, Donner CF, Wouters EF; ATS/ERS Task Force on Pulmonary Rehabilitation. An Official American Thoracic Society/European Respiratory Society Statement: Key Concepts and Advances in Pulmonary Rehabilitation. Am J Respir Crit Care Med 2013;188:e13-e64.

3. Seymour JM, Spruit MA, Hopkinson NS, Natanek SA, Man WD, Jackson A, Gosker HR, Schols AM, Moxham J, Polkey MI, Wouters EF. The prevalence of quadriceps weakness in COPD and the relationship with disease severity. Eur Respir J 2010;36:81-8.

4. Clark CJ, Cochrane LM, Mackay E, Paton B. Skeletal muscle strength and endurance in patients with mild COPD and the effects of weight training. Eur Respir J 2000;15:92-7.

5. Maltais F, Dennis N, Chan CK. Rationale for earlier treatment in COPD: a systematic review of published literature in mild-to-moderate COPD. COPD 2013;10:79-103.

6. Jacome $\mathrm{Cl}$, Marques AS. Pulmonary rehabilitation for mild chronic obstructive pulmonary disease: a 1 systematic review. Respir Care 2014;59:588-94

7. Price D, Freeman D, Cleland J, Kaplan A, Cerasoli F. Earlier diagnosis and earlier treatment of COPD in primary care. Prim Care Respir J 2011;20:15-22.

8. Effing $\mathrm{T}$, Zielhuis $\mathrm{G}$, Kerstjens $\mathrm{H}$, van der Valk $\mathrm{P}$, van der Palen J. Community based physiotherapeutic exercise in COPD self-management: a randomised controlled trial. Respir Med 2011;105:418-26.

9. van Wetering CR, Hoogendoorn M, Mol SJ, Rutten-van Mölken MP, Schols AM. Short- and long-term efficacy of a community-based COPD management programme in less advanced COPD: a randomised controlled trial. Thorax 2010;65:7-13.

10. Chavannes $\mathbf{N H}$, Grijsen $M$, van den Akker M, Schepers H, Nijdam M, Tiep B, Muris J. Integrated disease management improves one-year quality of life in primary care COPD patients: a controlled clinical trial. Prim Care Resp J 2009;18:171-6.

11. Zwerink $M$, van der Palen J, van der Valk $P$, Brusse-Keizer $M$, Effing $T$. Relationship between daily physical activity and exercise capacity in patients with COPD. Respir Med 2013;107:242-8.

12. Fastenau A, van Schayck OC, Gosselink R, Aretz KC, Muris JW. Discrepancy between functional exercise capacity and daily physical activity: a cross-sectional study in patients with mild to moderate COPD. Prim Care Respir J 2013;22:425-30

13. Garcia-Aymerich J, Lange $P$, Benet $M$, Schnohr P, Antó JM. Regular physical activity reduces hospital admission and mortality in chronic obstructive pulmonary disease: a population based cohort study. Thorax 2006;61:772-8.

14. Garcia-Aymerich J, Lange P, Benet M, Schnohr P, Antó JM. Regular physical activity modifies smokingrelated lung function decline and reduces risk of chronic obstructive pulmonary disease: a populationbased cohort study. Am J Respir Crit Care Med 2007;175:458-63.

15. Vestbo J, Hurd SS, Agustí AG, Jones PW, Vogelmeier C, Anzueto A, Barnes PJ, Fabbri LM, Martinez FJ, Nishimura M, Stockley RA, Sin DD, Rodriguez-Roisin R. Global strategy for the diagnosis, management, and prevention of chronic obstructive pulmonary disease: GOLD executive summary. Am J Respir Crit Care Med 2013;187:347-65.

16. Fastenau A, Muris JW, de Bie RA, Hendriks EJ, Asijee GM, Beekman E, Gosselink R, van Schayck OC. Efficacy of a physical exercise training programme COPD in primary care: study protocol of a randomized controlled trial. BMC Public Health 2014;14:788.

17. Gosselink R, Langer D, Burtin C, et al. KNGF-richtlijn Chronisch obstructieve longziekten. Ned T Fys Supp/ 2008;118:1-60. 
18. Haskell WL, Lee IM, Pate RR, Powell KE, Blair SN, Franklin BA, Macera CA, Heath GW, Thompson PD, Bauman A. Physical activity and public health: updated recommendation for adults from the American College of Sports Medicine and the American Heart Association. Med Sci Sports Exerc 2007; 39:1423-34.

19. Society AT. Committee on Proficiency Standards for Clinical Pulmonary Function Laboratories, ATS statement: guidelines for the six-minute walk test. Am J Respir Crit Care Med 2002;166:111-7.

20. Enright PL, Sherrill DL. Reference equations for the six-minute walk in healthy adults. Am J Respir Crit Care Med 1998;158:1384-7.

21. Marshall AL, Smith BJ, Bauman AE, Kaur S. Reliability and validity of a brief physical activity assessment for use by family doctors. Br J Sports Med 2005;39:294-7.

22. Bestall JC, Paul EA, Garrod R, Garnham R, Jones PW, Wedzicha JA. Usefulness of the Medical Research Council (MRC) dyspnoea scale as a measure of disability in patients with chronic obstructive pulmonary disease. Thorax 1999;54:581-6.

23. van der Molen T, Willemse BW, Schokker S, ten Hacken NH, Postma DS, Juniper EF. Development, validity and responsiveness of the Clinical COPD Questionnaire. Health Quality Life Outcomes 2003;1:13.

24. Guyatt GH, Berman LB, Townsend M, Pugsley SO, Chambers LW. A measure of quality of life for clinical trials in chronic lung disease. Thorax 1987;42:773-8.

25. de Vet HC, Ostelo RW, Terwee CB, van der Roer N, Knol DL, Beckerman H, Boers M, Bouter LM. Minimally important change determined by a visual method integrating an anchor-based and a distribution-based approach. Qual Life Res 2007;16:131-42.

26. Miller WR. Enhancing patient motivation for health behavior change. I Cardiopulm Rehabil 2005;25:207-9.

27. Rollnick S, Butler CC, Stott N. Helping smokers make decisions: the enhancement of brief intervention for general medical practice. Patient Educ Couns 1997;31:191-203.

28. Cambach W, Chadwick-Straver RV, Wagenaar RC, van Keimpema AR, Kemper HC. The effects of a community-based pulmonary rehabilitation programme on exercise tolerance and quality of life: a randomized controlled trial. Eur Respir J 1997;10:104-13.

29. Roman M, Larraz C, Gomez A, et al. Efficacy of pulmonary rehabilitation in patients with moderate chronic obstructive pulmonary disease: a randomized controlled trial. BMC Fam Pract 2013;14:21.

30. Holland AE, Hill CJ, Rasekaba T, Lee A, Naughton MT, McDonald CF. Updating the minimal important difference for six-minute walk distance in patients with chronic obstructive pulmonary disease. Arch Phys Med Rehabil 2010;91:221-5.

31. Troosters T, Sciurba F, Battaglia S, Langer D, Valluri SR, Martino L, Benzo R, Andre D, Weisman I, Decramer M. Physical inactivity in patients with COPD, a controlled multi-center pilot-study. Respir Med 2010;104:1005-11.

32. Watz H, Waschki B, Meyer T, Magnussen H. Physical activity in patients with COPD. Eur Respir J 2009;33:262-72.

33. Harbers MM. Lichamelijke activiteit: Zijn er binnen Nederland verschillen naar regio? Bilthoven: RIVM, 2010.

34. Coronado M, Janssens JP, de Muralt B, Terrier P, Schutz Y, Fitting JW. Walking activity measured by accelerometry during respiratory rehabilitation. J Cardiopulm Rehabil 2003;23:357-64.

35. Egan C, Deering BM, Blake C, Fullen BM, McCormack NM, Spruit MA, Costello RW. Short term and long term effects of pulmonary rehabilitation on physical activity in COPD. Respir Med 2012;106:1671-9.

36. Mador MJ, Patel AN, Nadler J. Effects of pulmonary rehabilitation on activity levels in patients with chronic obstructive pulmonary disease. J Cardiopulm Rehabil Prev 2011;31:52-9.

37. 2 exercise training programs on physical activity in daily life in patients with COPD. Respir Care 2011;56:1799-807.

38. Faulkner J, Walshaw E, Campbell J, Jones R, Taylor R, Price D, Taylor AH. The feasibility of recruiting patients with early COPD to a pilot trial assessing the effects of a physical activity intervention. Prim Care Respir J 2010;19:124-30. 
39. Panos RJ, Eschenbacher W. Exertional desaturation in patients with chronic obstructive pulmonary disease. COPD 2009;6:478-87.

40. Troosters T. Physical inactivity in patients with COPD: the next step is ... action. Prim Care Respir J 2013;22:391-2. 



\section{Chapter 6}

Do patient characteristics and baseline burden of disease modify the effect of a physical exercise training programme on exercise capacity in patients with mild to moderate COPD?

Annemieke Fastenau, Jean WM Muris, Bjorn Winkens, Rik Gosselink, Karin CPM Aretz, Guus M Asijee, Onno CP van Schayck

Submitted 


\section{Abstract}

Exercise training in patients with COPD is effective in improving exercise capacity. To offer personalised care, it is important to understand which factors influence the effect of the treatment. In patients with moderate to severe COPD, there have been variables identified that (partly) explain the success of the treatment. We hypothesized that the treatment response in patients with mild to moderate COPD might be different from patients with moderate to severe COPD. This study therefore examined how patient characteristics and baseline burden of disease modified the effect of a physical exercise training programme on functional exercise capacity in patients with mild to moderate COPD in primary care. In this randomized controlled trial, data of 90 patients were analysed. The intervention group took part in a 4-month training programme, including endurance and/or interval training, resistance training, breathing exercises and stimulation to enhance daily physical activity. The control group received a shamtreatment in which no physiologic training stimulus would occur and also received stimulation to enhance daily physical activity. None of the patient characteristics or disease burden variables did significantly modify the effect of the exercise training programme on exercise capacity. However, explorative insight revealed that patients with a better baseline exercise capacity, less dyspnoea and fatigue and who were moderate physically active were likely to improve more in exercise capacity than patients with more baseline burden of their disease. 


\section{Introduction}

Pulmonary rehabilitation (PR) is very effective in reducing dyspnoea, increasing exercise capacity and improving quality of life in patients with moderate to severe COPD. ${ }^{1}$ As exercise training is the cornerstone of PR, exercise-related outcomes are consistently used to evaluate the efficacy of the intervention, especially the sixminute walk test (6MWT) is a widely used outcome measure. ${ }^{1}$ Despite the established efficacy on group level, individual patients' responses to exercise training are highly variable. Previous studies have reported that $23 \%$ up to $44 \%$ of patients showed no or minimal clinical relevant improvement in six-minute walk distance (6MWD) following pulmonary rehabilitation. ${ }^{2,3} \mathrm{PR}$ and exercise training cannot be offered to all COPD patients. To offer personalised care it is of the utmost importance to clarify which factors influence the efficacy of the treatment.

Some pulmonary rehabilitation studies have identified peripheral muscle weakness, less ventilatory limitation ${ }^{4}$, higher body mass index, hypoxia ${ }^{5}$ and younger age ${ }^{3}$ as independent determinants of a positive response in exercise capacity. Other studies found no baseline variables that could predict the response, including pulmonary function, ventilatory reserve ${ }^{2}$, body mass index and daily physical activity. ${ }^{3}$ To date, there have been no clear variables identified that consistently explain the success of the treatment in terms of improving exercise capacity.

All these studies were performed in patients with moderate to severe COPD referred to PR in a hospital or rehabilitation setting. In this patient category, it is assumed that a poorer baseline condition can leave more room for improvement. ${ }^{5,6}$ Furthermore, it is suggested that patients with a high pre-training 6MWD may be limited in their ability to improve in 6MWD, because mechanical factors such as stride length give rise to a ceiling effect. ${ }^{7}$ In a previous study, we demonstrated that a physical exercise training programme is effective in improving exercise capacity on group level in patients with mild to moderate COPD, despite the fact that 6MWD was close to normal values and less room for improvement seemed to be present. $^{8}$ In this study population, there was a broad variation in patient characteristics as well as diseaserelated factors, including pathology, symptoms, capacity and functioning. ${ }^{9}$ Due to this broad spectrum of patient characteristics and disease-related factors, we hypothesized that treatment response in patients with mild to moderate COPD might be different from patients with moderate to severe COPD and therefore investigated how the baseline status of the patient, in terms of lung function, degree of dyspnoea, exercise capacity and physical activity influences the efficacy of an exercise training programme COPD. 
Thus, the first aim of our study was to determine if there are any patient characteristics that influence the effect on functional exercise capacity following a physical exercise training programme. The second aim was to determine how baseline burden of disease (based on pathology, symptoms, capacity and functioning) modifies the effect a physical exercise training programme COPD on exercise capacity.

\section{Methods}

\section{Study design and participants}

This study is a randomized controlled trial performed in the primary care setting, approved by the ethics committee of Maastricht University. The trial has been registered at The Netherlands National Trial Register NTR1471. Patients were recruited from general practices in the southern part of the Netherlands, the Province of Limburg. Inclusion was based on COPD patients visiting their general practitioner because of dyspnoea, impaired exercise capacity, having a spirometry confirmed diagnosis of mild to moderate COPD $^{10}$ and having a stable situation (no exacerbations in the previous 8 weeks). Detailed information about the study protocol can be found elsewhere. $^{9}$

\section{Intervention group (Physical Exercise Training Programme (PETP))}

For the PETP, the Dutch Guideline Physiotherapy in COPD served as a framework. ${ }^{11}$ There were four major aims: improvement in exercise capacity, muscle strength, daily physical activity and breathing technique. ${ }^{9}$ The physical training component entails endurance training and/or interval training and can for example be performed on a treadmill or cycle ergometer. ${ }^{11}$ Walking speed on the treadmill is executed with an intensity of $75 \%$ or higher of the results of the six-minute walk test (6MWT). Ratings of perceived exertion and dyspnoea of five and higher on the modified Borg-scale $(0-10)$ are used to tailor exercise intensity. ${ }^{12}$ Throughout the training period patients were advised to do at least 30 minutes of moderate intense physical activities on at least five days a week according to the ACSM-recommendation for physical activity. ${ }^{13}$ The PETP consisted of 2 supervised sessions per week, with a duration of 60-90 minutes per session, depending on group size. These sessions took place with 1-5 patients at the time. Patients were requested to perform an additional training session per week at home, including walking and/or cycling. 


\section{Control group (sham-treatment)}

Patients in the control group participated in a sham-treatment, which consisted of 30 minutes once a week "exercise" training, for example on a treadmill or cycle ergometer, with a perceived exertion and dyspnoea of 2 or lower on a modified Borgscale. $^{14}$ In this way, no physiologic training stimulus would occur. There were no breathing exercises or resistance training. Furthermore, the same advises on daily physical activities were given as in the intervention group.

\section{Measurements}

At inclusion, demographic data, including age, sex, body mass index (BMI), $F E V_{1}$, years of diagnosis COPD, smoking history and co-morbid diseases were recorded. Both the intervention and control group received assessment and treatment at physiotherapy practices. Measurements were done at baseline assessment, on completion of the programme (at 4 months) and during follow-up (at 6 months).

\section{Exercise capacity}

Functional exercise capacity was measured by the six-minute walking test (6MWT) with reference values from Enright. ${ }^{15}$ This test was executed according to ATS instructions ${ }^{16}$, except that a standard 30-meter corridor was not always feasible, but the minimal length of a corridor was 10 meter. Oxygen saturation and heart rate were measured in rest and during the test. The lowest oxygen saturation and highest heart rate during the test were recorded. Afterwards, perceived fatigue and dyspnoea were measured on a modified Borg scale ranging from zero (nothing at all) to ten (very, very severe). ${ }^{17}$

\section{Peripheral muscle strength}

Handgrip force (HGF) was evaluated using a hydraulic dynamometer (Yamar Preston, Jackson MI). Values were related to normal values proposed by Mathiowetz. ${ }^{18}$

\section{Physical activity}

Self-reported daily physical activity was assessed by the brief physical activity assessment tool. ${ }^{19}$ 


\section{Dyspnoea}

Level of dyspnoea was assessed by the Medical Research Council (MRC) dyspnoea score. $^{20}$

\section{Statistical analysis}

Numerical variables were expressed as mean (SD) and categorical ones as number (\%). The differences between intervention and control group, and completers and noncompleters were assessed using independent-samples t-tests for numerical variables and Chi-square tests for categorical variables. A completer is defined as a patient with the outcome (6MWT) measured at all three occasions. To assess whether a baseline variable (patient characteristic or baseline disease burden) is an effect modifier, the effect on the differences in mean 6MWD between treatment and control at 4 and 6 months were estimated per variable using linear mixed models with time, baseline variable $X$, time*group, time* $X$, and time*group* $X$ as fixed factors, and an unstructured covariance structures for repeated measurements. The patient characteristics age, gender and $\mathrm{BMI}$ and the following disease burden characteristics were considered as effect modifiers: 6-minute walk distance, Borg score fatigue, Borg score dyspnoea, lowest oxygen saturation during 6MWT, oxygen saturation in rest, $\mathrm{FEV}_{1}(\mathrm{~L}), \mathrm{MRC}$ Dyspnoea score, handgrip force (KgF) and physical activity. For 6MWD, the baseline variable $X$ was removed from the fixed part of the model, since it was already included in the dependent variable. The variable Time was included as a categorical variable and parameters were estimated using restricted maximum likelihood (REML) estimation.

$P$-values $\leq 0.05$ were considered statistically significant. All analyses were performed using IBM SPSS Statistics for Windows (Version 21.0, Armonk, NY: IBM Corp).

\section{Results}

In total 104 patients were randomized. Due to a time lag from inclusion to baseline measurement at the physiotherapy practice, 14 patients ( 7 male and 7 women) were excluded because of exacerbations or new/unknown comorbidities. Data from 90 patients were retained for intention-to-treat purposes. Seven patients in the PETPgroup did not complete the training programme (15\% drop-out rate) and 2 more patients could not be re-assessed for follow-up at 6 months. In the control group, 12 patients dropped out during the treatment period ( $27 \%$ drop-out rate) and another 3 patients were not able to be re-assessed at 6 months. One patient who failed to 
attend the 4-month measurement was capable to be re-assessed at 6 months. Statistical analyses revealed that there were no significant differences in clinical characteristics between patients in the intervention and control group nor between the patients who dropped out $(n=23)$ and patients who completed the programme $(n=67)$. Table 6.1 shows the baseline characteristics of the patients.

Table 6.1 Baseline characteristics.

\begin{tabular}{|c|c|c|c|}
\hline & $\begin{array}{l}\text { Overall } \\
(n=90)\end{array}$ & $\begin{array}{c}\text { PETP } \\
(n=46)\end{array}$ & $\begin{array}{c}\text { Control Group } \\
(n=44)\end{array}$ \\
\hline \multicolumn{4}{|l|}{ General characteristics } \\
\hline Gender (male/female) & $44 / 46$ & $27 / 19$ & $17 / 27$ \\
\hline Age (years) & $62.5 \pm 9.9$ & $62.4 \pm 9.1$ & $62.6 \pm 10.8$ \\
\hline $\mathrm{BMI}\left(\mathrm{kg} / \mathrm{m}^{2}\right)$ & $27.8 \pm 4.9$ & $27.2 \pm 4.2$ & $28.4 \pm 5.4$ \\
\hline \multicolumn{4}{|l|}{ Pulmonary characteristics } \\
\hline $\mathrm{FEV}_{1}(\mathrm{~L})$ & $2.1 \pm 0.6$ & $2.1 \pm 0.7$ & $2.0 \pm 0.6$ \\
\hline $\mathrm{FEV}_{1} \%$ pred. & $74.2 \pm 13.5$ & $74.4 \pm 14.8$ & $74.0 \pm 12.2$ \\
\hline $\mathrm{FEV}_{1} / \mathrm{FVC}(\%)$ & $58.9 \pm 8.4$ & $57.3 \pm 9.4$ & $60.5 \pm 7.0$ \\
\hline GOLD-classification (I/II) & $24 / 66$ & $14 / 32$ & $10 / 34$ \\
\hline \multicolumn{4}{|l|}{ Years of diagnosis COPD } \\
\hline$<1$ year & $25.8 \%$ & $26.7 \%$ & $25 \%$ \\
\hline $1-5$ years & $50.6 \%$ & $48.9 \%$ & $52.3 \%$ \\
\hline$>5-10$ years & $21.3 \%$ & $22.2 \%$ & $20.5 \%$ \\
\hline$>10$ years & $2.2 \%$ & $2.2 \%$ & $2.3 \%$ \\
\hline \multicolumn{4}{|l|}{ Smoking status } \\
\hline Smoker & $37.9 \%$ & $45.5 \%$ & $30.2 \%$ \\
\hline Stopped smoking & $54 \%$ & $47.7 \%$ & $60.5 \%$ \\
\hline Never smoked & $8 \%$ & $6.8 \%$ & $9.3 \%$ \\
\hline \multicolumn{4}{|l|}{ Dyspnoea } \\
\hline MRC dyspnoea score (1-5) & $2.4 \pm 0.8$ & $2.4 \pm 0.8$ & $2.4 \pm 0.8$ \\
\hline \multicolumn{4}{|c|}{ Physical activity } \\
\hline \multicolumn{4}{|c|}{30 min. moderate intense physically active: } \\
\hline - 5 times per week & $15.3 \%$ & $11.6 \%$ & $19.0 \%$ \\
\hline - 3-4 times per week & $20.0 \%$ & $25.6 \%$ & $14.3 \%$ \\
\hline - 1-2 times per week & $29.4 \%$ & $37.2 \%$ & $21.4 \%$ \\
\hline - 0 times per week & $35.3 \%$ & $25.6 \%$ & $45.2 \%$ \\
\hline \multicolumn{4}{|c|}{20 min. vigorous intense physically active: } \\
\hline - 3 times per week & $1.2 \%$ & $0 \%$ & $2.4 \%$ \\
\hline - 1-2 times per week & $23.5 \%$ & $23.3 \%$ & $23.8 \%$ \\
\hline - 0 times per week & $75.3 \%$ & $76.7 \%$ & $73.8 \%$ \\
\hline \multicolumn{4}{|l|}{ Physical fitness } \\
\hline 6MWD (m) & $491.2 \pm 91.1$ & $500.9 \pm 89.3$ & $481.1 \pm 92.9$ \\
\hline 6MWD (\%pred.) & $95.8 \pm 15.2$ & $95.3 \pm 14.4$ & $96.3 \pm 16.1$ \\
\hline Handgrip force (\%pred.) (n=41/39) & $88.5 \pm 20.8$ & $87.7 \% \pm 22.7$ & $89.3 \% \pm 18.7$ \\
\hline
\end{tabular}

Data are presented as mean \pm SD for continuous variables and as number or percentage for categorical variables. BMI: Body Mass Index, FEV1: Forced Expiratory Volume in one second, FVC: Forced Vital Capacity, GOLD: Global initiative for chronic Obstructive Lung Disease, MRC: Medical Research Council, 6MWD: sixminute walking distance. 


\section{Effect of patient characteristics}

Age, gender and BMI did not significantly modify the intervention effect on functional exercise capacity $(0.559<p<0.843)$.

\section{Effect of baseline burden of disease}

None of the disease burden variables did significantly modify the effect of the physical exercise training programme on functional exercise capacity (all $p \geq 0.172$ ). For 4 variables, however, there was a clear difference in treatment effect for different baseline values, in such a way that patients with less disease burden had more improvement in exercise capacity. For baseline 6MWD (test for effect modification: $p=0.472)$, Borgscore fatigue $(p=0.172)$, Borg score dyspnoea $(p=0.183)$ and moderate physical activity $(p=0.684)$, this clear difference was seen at 4 months and increased even more at 6 months. As example, a graphical representation of the influence of baseline 6MWD on exercise capacity is shown in Figure 6.1. In this figure, only baselines values of $320 \mathrm{~m}$ (minimum value), $490 \mathrm{~m}$ (median value) and $650 \mathrm{~m}$ (maximum value) are shown.

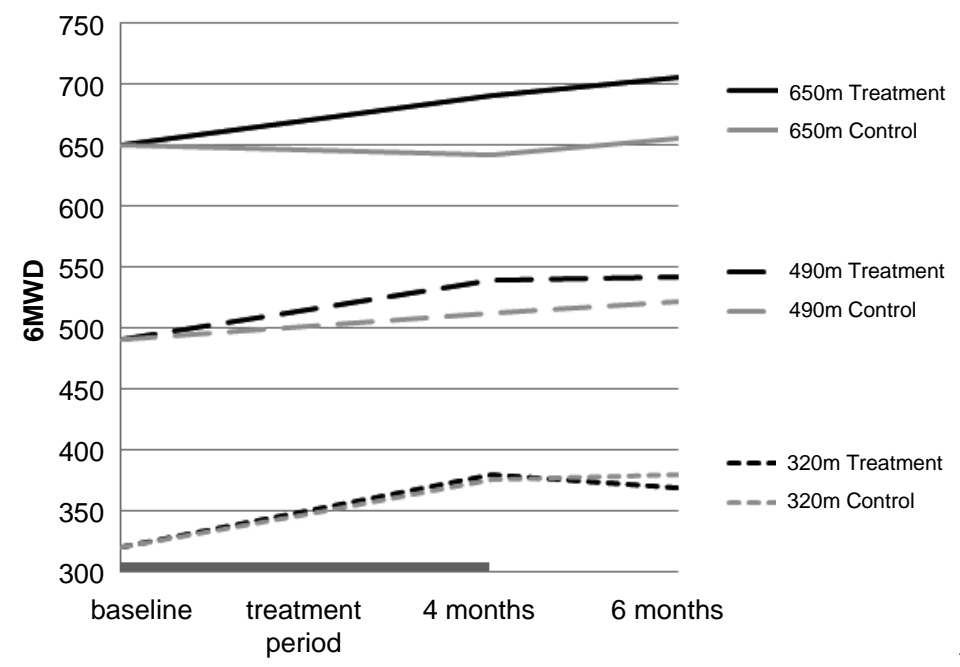

Figure 6.1 Treatment effect for different baseline values of 6MWD. 
Figure 6.1 shows that for patients with a higher baseline 6MWD, the difference in improvement in exercise capacity between intervention and control group is larger than for patients with a lower baseline 6MWD. In other words, the better the exercise capacity at baseline, the larger the treatment effect. At 4 and 6 months, patients in the intervention group with a baseline 6MWD of $650 \mathrm{~m}$, improved respectively $49 \mathrm{~m}$ and $51 \mathrm{~m}$ more than patients in the control group with a baseline 6MWD of $650 \mathrm{~m}$, which is clearly a clinically relevant difference.

Also for handgrip force (test for effect modification: $p=0.296$ ) and oxygen saturation in rest $(p=0.403)$ clear differences were seen in treatment effect for different baseline values, but in opposite direction. Patients with a lower handgrip force or oxygen saturation in rest increased more in exercise capacity than patients with a higher handgrip force or oxygen saturation in rest.

For $\mathrm{FEV}_{1}$ (test for effect modification: $\left.p=0.923\right)$, MRC Dyspnoea score $(p=0.686)$ and lowest oxygen saturation during 6MWT $(p=0.442)$, there were no clear differences in treatment effect for different baseline values.

\section{Discussion}

\section{Main findings}

We found no patient characteristics and disease burden variables that did significantly modify the effect of the physical exercise training programme COPD on functional exercise capacity. However, patients with better baseline exercise capacity, Borg scores Dyspnoea and Fatigue and those with moderate physical activity were likely to improve more in exercise capacity than patients with more baseline burden of their disease.

\section{Strengths and limitations of the study}

A strength of our study is the unique study population of patients with COPD GOLD I and II in primary care. Furthermore, to identify factors that could modify the effect of the treatment by means of a RCT has an added value compared to the current observational/cohort studies, because this is the most rigorous way to determine the cause-effect relation between treatment and outcome. In our statistical analysis, we used linear mixed-models. Advantages are that there is a correction for baseline differences to gain efficacy and the use of all available data, also for patients who had missing data (assuming missing at random). 
A limitation of the study is the low power of the study, due to a small sample size. A further limitation is that in this study only self-reported physical activity was assessed. We were only able to measure objective physical activity with an accelerometer-based activity monitor in a subgroup of 51 patients. ${ }^{9}$ Objective physical activity might have provided more insight.

\section{Interpretation of findings in relation to previously published work}

In accordance with Garrod et al. and Selzler et $a l^{2,6}$, we found no baseline variables that made a significant contribution to the effect of the treatment. It still remains unclear which clinical variables can predict individual success to exercise training. ${ }^{6}$ In healthy persons, several studies have shown marked individual differences in responsiveness to exercise training. ${ }^{21}$ There is evidence that genetic variability is a key contributor to the heterogeneity of exercise responsiveness, apart from clinical indices such as age and comorbidity burden. ${ }^{21,22}$ Clinical variables that did predict a positive response to PR in some studies were only explained by a small percentage of the variance. ${ }^{4}$ So, it seems that many other variables, like socioeconomic status, education, motivation and coping style, which were not assessed in the present study, might influence the responsiveness to exercise training in patients with COPD in combination with genetic contributions.

We were particularly interested in the influence of baseline burden of disease on improvement in exercise capacity. Surprisingly, we found that patients with a better baseline exercise capacity, less dyspnoea and fatigue and were moderate physically active had the largest treatment effect. Our results are opposite to the hypothesis in previous studies in patients with moderate to severe COPD that patients with greater initial deconditioning have more room for improvement and might be able to have more benefits from exercise training. It might be that the responsiveness to exercise training in patients with a better preserved exercise capacity is less influenced by disease-specific consequences and are more limited by other factors (like genetic features, coping style and motivation). Furthermore, our results do not support the existence of a ceiling effect in the 6MWT. Patients with a large baseline 6WMD improved most in exercise capacity.

Other results were that patients with a low baseline handgrip force and the lowest oxygen saturation in rest showed the largest treatment effect. This is in line with Troosters et al. $^{4}$, who found that baseline strength was a significant predictor of improvement in exercise tolerance and Vagaggini et al. ${ }^{5}$ who found that hypoxemic patients improved more in exercise capacity than other subgroups. 


\section{Future perspectives}

Based on the current knowledge on the influence of patient characteristics and disease burden, there are no indications to explicitly exclude certain patients from an exercise training programme. Future research should take into account the role of behavioural and socio-economic factors. Furthermore, objective physical activity assessment is needed to gain more insight in the role of daily physical activity, apart from exercise training sessions, in the success of the treatment.

\section{Conclusions}

The current study found no baseline patient characteristics and burden of disease variables that significantly modified the effect of the physical exercise training programme on functional exercise capacity in patients with mild to moderate COPD. Explorative insight revealed that patients with a better baseline exercise capacity, less dyspnoea and fatigue and who were moderate physically active had the largest treatment effect. These results do not support the hypothesis that patients with a greater initial deconditioning have more room for improvement and might be able to have more benefits from exercise training. 


\section{References}

1. Spruit MA, Singh SJ, Garvey C, ZuWallack R, Nici L, Rochester C, Hill K, Holland AE, Lareau SC, Man WD, Pitta F, Sewell L, Raskin J, Bourbeau J, Crouch R, Franssen FM, Casaburi R, Vercoulen JH, Vogiatzis I, Gosselink R, Clini EM, Effing TW, Maltais F, van der Palen J, Troosters T, Janssen DJ, Collins E, GarciaAymerich J, Brooks D, Fahy BF, Puhan MA, Hoogendoorn M, Garrod R, Schols AM, Carlin B, Benzo R, Meek P, Morgan M, Rutten-van Mölken MP, Ries AL, Make B, Goldstein RS, Dowson CA, Brozek JL, Donner CF, Wouters EF; ATS/ERS Task Force on Pulmonary Rehabilitation. An Official American Thoracic Society/European Respiratory Society Statement: Key Concepts and Advances in Pulmonary Rehabilitation. Am J Respir Crit Care Med 2013;188:e13-64

2. Garrod R, Marshall J, Barley E, Jones PW. Predictors of success and failure in pulmonary rehabilitation. Eur Respir J 2006;274:788-94.

3. Walsh JR, McKeough ZJ, Morris NR, Chang AT, Yerkovich ST, Seale HE, Paratz JD. Metabolic disease and participant age are independent predictors of response to pulmonary rehabilitation. $J$ Cardiopulm Rehabil Prev 2013;334:249-56.

4. Troosters T, Gosselink R, Decramer M. Exercise training in COPD: how to distinguish responders from nonresponders. J Cardiopulm Rehabil 2001;211:10-7.

5. Vagaggini B, Costa F, Antonelli S, De Simone C, De Cusatis G, Martino F, Santerini S, Paggiaro P. Clinical predictors of the efficacy of a pulmonary rehabilitation programme in patients with COPD. Respir Med 2009;1038:1224-30.

6. Selzler AM, Simmonds L, Rodgers WM, Wong EY, Stickland MK. Pulmonary rehabilitation in chronic obstructive pulmonary disease: predictors of program completion and success. COPD. 2012;95:53845.

7. Jenkins SC. 6-Minute walk test in patients with COPD: clinical applications in pulmonary rehabilitation. Physiotherapy 2007;93:175-82.

8. Fastenau A, van Schayck OC, Winkens B, Aretz K, Asijee GM, Gosselink R, Muris JWM. Efficacy of a Physical Exercise Training Programme COPD in primary care: a randomized controlled trial. Submitted for publication.

9. Fastenau A, van Schayck OC, Gosselink R, Aretz KC, Muris JW. Discrepancy between functional exercise capacity and daily physical activity: a cross-sectional study in patients with mild to moderate COPD. Prim Care Respir J 2013;22:425-30.

10. Vestbo J, Hurd SS, Agustí AG, Jones PW, Vogelmeier C, Anzueto A, Barnes PJ, Fabbri LM, Martinez FJ, Nishimura M, Stockley RA, Sin DD, Rodriguez-Roisin R.. Global strategy for the diagnosis, management, and prevention of chronic obstructive pulmonary disease: GOLD executive summary. Am J Respir Crit Care Med 2013;1874:347-65.

11. Gosselink R, Langer D, Burtin C, et al. KNGF-richtlijn Chronisch obstructieve longziekten. Ned T Fys supp/ 2008; 1184.

12. Gosselink R, Decramer M. Rehabilitation in chronic obstructive pulmonary disease [Revalidatie bij chronische obstructieve longziekten]. Maarssen: Elsevier Gezondheidszorg; 2001.

13. Haskell WL, Lee IM, Pate RR, Powell KE, Blair SN, Franklin BA, Macera CA, Heath GW, Thompson PD, Bauman A. Physical activity and public health: updated recommendation for adults from the American College of Sports Medicine and the American Heart Association. Med Sci Sports Exerc. 2007;398:1423-34.

14. Mahler DA, Horowitz MB. Perception of breathlessness during exercise in patients with respiratory disease. Med Sci Sports Exerc 1994;269:1078-81.

15. Enright PL, Sherrill DL. Reference equations for the six-minute walk in healthy adults. Am J Respir Crit Care Med 1998;158:1384-7.

16. ATS statement: guidelines for the six-minute walk test. Am J Respir Crit Care Med 2002;1661:111-7.

17. Borg GA. Psychophysical bases of perceived exertion. Med Sci Sports Exerc 1982;145:377-81.

18. Mathiowetz V, Kashman N, Volland G, Weber K, Dowe M, Rogers S. Grip and pinch strength: normative data for adults. Arch Phys Med Rehabil 1985;662:69-74. 
19. Marshall AL, Smith BJ, Bauman AE, Kaur S. Reliability and validity of a brief physical activity assessment for use by family doctors. Br J Sports Med 2005;395:294-7.

20. Fletcher CM. Standardised questionnaire on respiratory symptoms: a statement prepared and approved by the MRC Committee on the Aetiology of Chronic Bronchitis (MRC breathlessness score). BMJ 1960;2:1965.

21. Bouchard C, Rankinen T. Individual differences in response to regular physical activity. Med Sci Sports Exerc 2001;336 Suppl:S446-51; discussion S52-3.

22. Buford TW, Hsu FC, Brinkley TE, Carter CS, Church TS, Dodson JA, Goodpaster BH, McDermott MM, Nicklas BJ, Yank V, Johnson JA, Pahor M; LIFE Research Group. Genetic influence on exercise-induced changes in physical function among mobility-limited older adults. Physiol Genomics. 2014;465:149-58. 



\title{
Chapter 7
}

\author{
General discussion
}


Chapter 7 


\section{Introduction}

The main aim of this thesis was to evaluate the efficacy of a physical exercise training programme for patients with mild to moderate COPD in primary care compared to advices by health care professionals on enhancing daily physical activity. This research theme evolved from the current scientific gap in the knowledge of the effectiveness of rehabilitation/exercise training and increasing daily physical activity in this subgroup of COPD patients and the developing interest in daily clinical practice in earlier treatment potentials. Patients with mild to moderate COPD are not yet affected by substantial airflow obstruction, but systemic consequences have been found to be present and also physical inactivity. The programme aimed to combine improvement of both exercise capacity and daily physical activity. As a result, interactions between daily physical activity, physical fitness and daily functioning are a recurrent subject in this thesis. The main findings of the study are summarized and the practical implications for clinical practice as well as future research possibilities are considered.

\section{Reflection of the main findings}

\section{Baseline findings}

This study showed that there was a large variation in baseline characteristics, perceived symptoms and disabilities of the included patients. Some patients only experienced mild dyspnoea, whereas others were hardly able to leave the house because of their breathlessness. Some patients were able to walk more than $6 \mathrm{~km} / \mathrm{h}$ on a six-minute walk test, whereas others only walked just over $3 \mathrm{~km} / \mathrm{h}$. In general, the included patients had clearly less airflow obstruction than patients usually included in rehabilitation studies. ${ }^{1}$ Exercise capacity in our study population was reasonable, compared to healthy persons of the same age. However, in approximately 20 percent of the patients, oxygen saturation during the six-minute walk test was below $90 \%$, which possibly indicates pulmonary restraints. The level of daily physical activity was remarkably low, even when these findings are compared to patients with moderate to severe COPD in other studies. ${ }^{2,3}$ Thirty-three percent of the patients had a step count of around 5000 or less, which is seen as one of the benchmarks of 'sedentarism'. ${ }^{4}$ The mean Physical Activity Level (PAL) of 1.45 also shows the sedentary behaviour of our study population, since a PAL of 1.4-1.69 defines a predominantly sedentary activity level. ${ }^{5}$ We could identify a discrepancy between functional exercise capacity and daily physical activity in patients with mild to 
moderate COPD. This is in contrast to other studies, in which patients with more severe COPD were included, where a stronger relationship was found. ${ }^{3,6-8}$ Our study results support the hypothesis of Leidy ${ }^{9}$, who proposed that exercise capacity and physical activity are two different concepts. If exercise capacity is better, a person can choose whether to be physically active or not. So, the assessment of daily physical activity is of additional value to assessment of exercise capacity.

\section{Trial findings}

The trial showed that a four-month physical exercise training programme is effective in improving exercise capacity. Furthermore, significant improvements were seen in muscle strength (shoulder abduction strength at the end of the programme and hand grip force at follow-up measurement) and a subdomain of health-related quality of life (CRQ mastery domain at follow-up). To our knowledge, the present study is one of the first studies showing the efficacy of a Physical Exercise Training Programme in patients with mild to moderate COPD recruited, assessed and trained in primary care. Pulmonary function in our study (mean $\mathrm{FEV}_{1} \%$ predicted=74\%) was substantially higher than in other pulmonary rehabilitation (PR) studies in primary care/community based (mean $\mathrm{FEV}_{1} \%$ predicted $\left.50-62 \%\right)^{10-14}$ Four of these studies also found significant improvements in exercise capacity and/or muscle strength ${ }^{10-12,14}$, whereas one found no significant changes. ${ }^{13}$

The significant improvements in physical fitness components in our trial did not result in a significant between-group difference in daily physical activity. Results from other studies investigating whether PR increases activity level are inconsistent ${ }^{15}$, i.e. some studies demonstrated statistically significant increases in activity level ${ }^{11,16-19}$, whereas others have not. ${ }^{7,20-24}$ No study characteristics seem to consistently explain these differences. ${ }^{15}$ This shows that, up to now, there is little understanding in the mechanisms of translating improvements in exercise capacity into enhanced daily physical activity.

The global perceived effectiveness scores were very high in both groups, the far majority of the patients considered themselves as slightly or much improved as a result of the treatment. None of the patients scored a worsening of the perceived effect. It is believed that perceived effectiveness is a global assessment of effectiveness and captures more domains of effectiveness than the other outcome measures. ${ }^{25}$ These high scores might be due to the active role that the patient can play in the mastery of his/her disease by exercise training. It is suggested that pulmonary rehabilitation may influence self-efficacy for coping with exertional breathlessness, by improving confidence and reducing fear of activity. ${ }^{26,27}$ 
It is known that individual responses to exercise training are highly variable. In our trial, we found that substantial improvement in exercise capacity ( $\geq 25 \mathrm{~m}$ on $6 \mathrm{MWT}$ ) was seen in $76 \%$ of the patients in the intervention group and in $50 \%$ of the patients in the control group, which was significantly different. None of the studied patient characteristics or disease burden variables (in terms of lung function, degree of dyspnoea, exercise capacity and physical activity) significantly modified the effect of the programme on exercise capacity. These results are in accordance with the studies of Garrod $^{28}$ and Selzler. ${ }^{29}$ In other studies, peripheral muscle weakness, less ventilatory limitation ${ }^{30}$, higher body mass index, hypoxia ${ }^{31}$ and younger age ${ }^{32}$ have been detected as independent determinants of a positive response in exercise capacity. So far, there is no consensus about the existence of predictive factors that consistently explain the success of the treatment in terms of improving exercise capacity.

Although none of the determinants significantly modified the effect of the treatment, explorative analyses revealed that patients with less baseline burden of the disease were likely to improve more in exercise capacity than patients with more baseline burden of their disease. These results do not support the hypothesis that patients with a greater initial deconditioning have more room for improvement. ${ }^{29,31,33}$ Furthermore, the finding that patients with a large baseline 6WMD improved most in exercise capacity do not underpin the existence of a ceiling effect in the 6MWT. ${ }^{34}$ It might be that patients with mild disease and moderate degree of dyspnoea are likely to benefit the most from exercise training, because they may be able to push themselves harder during exercise training and achieve greater levels of cardiovascular fitness than those with more severe disease. ${ }^{35}$

\section{Methodological considerations}

The study described in this thesis had several methodological challenges, which should be considered when interpreting the results. This section describes the 3 most important considerations.

\section{Contamination}

In our randomized controlled trial (RCT), we have used individual randomization to find evidence for the efficacy of a physical exercise training programme. To avoid the issue of contamination, it might have been better to have chosen cluster randomization. However, in preparation of the study, we had observed that 
physiotherapists were not very keen to deliver a treatment without a proper training programme, because of the proven effectiveness of pulmonary rehabilitation in patients with moderate to severe COPD. In the case of cluster randomization, recruitment of sufficient participating physiotherapists with treating only control patients would have been impossible.

To tackle contamination in the treatment protocols, we have trained and instructed the physiotherapists thoroughly in advance of the study and monitored and instructed them throughout the intervention period. Another strategy to minimize contamination is that patients of the intervention and control group have not been in the same physiotherapy setting at the same time. So, the physiotherapists were able to focus their mind on just one treatment at a time.

In our randomized controlled trial, physiotherapists and patients could not be blinded, since they were aware of the treatment procedures. Moreover, physiotherapists conducted both the measurements and treatment in patients. Due to practical considerations it was not feasible for a single researcher to perform all measurements in many different practice settings. To assure a high quality and univocal treatment, the participating physiotherapists were trained and instructed extensively before the start of the trial. Also, throughout the intervention period, the researcher checked the compliance with the treatment protocol continuously by visiting the participating practices, telephone calls and email correspondence.

\section{Variability}

The six-minute walk tests were performed on different track lengths, which will influence the variability. An advantage of the randomization on patient level instead of physiotherapy practice level was that patients were assigned to smaller and longer track lengths in a non-differential manner and that there was an equal distribution of patients from the intervention group and control group per physiotherapy practice. As we were interested in the difference scores (4 or 6 months minus baseline measurement) and participants were assessed on the same track lengths on all occasions, we think that the variability is acceptable. On the other hand, the variability in track length may play a more influencing role when our results are compared to sixminute walk distances in other studies with standardised track lengths of $30 \mathrm{~m}$. In the study of Beekman ${ }^{36}$, it was found that the use of a $10 \mathrm{~m}$ course significantly reduced the distance that patients with COPD achieve on a 6MWT compared to a 30 course. 


\section{Reliability}

Objective physical activity was measured with an accelerometer-based activity monitor (Dynaport Minimod, McRoberts BV) for three days and nights, because it has been shown that three days of measurement provides an acceptable intraclass reliability coefficient. ${ }^{37}$ In healthy adults, however, an acceptable measurement may range from three to seven days. It is possible that, in our study population, three days of measurement was not sufficient to collect representative data.

\section{Role of pulmonary rehabilitation/exercise training on local and systemic effects of COPD}

It seems that there is a complex interrelationship between COPD, physical activity levels, local and systemic consequences, comorbidities and behavioural patterns. A prominent symptom in patients with COPD is dyspnoea. Exertional dyspnoea is a major cause of exercise limitation and is usually multifactorial, reflecting skeletal muscle dysfunction, the consequences of dynamic hyperinflation, increased respiratory load or defective gas exchange. ${ }^{15}$ Above this, dyspnoea is a perception and is further shaped by patient's experiences. ${ }^{38}$ Hence, inactivity may be a "learned behaviour" to avoid dyspnoea. A vicious circle ensues in which deconditioning reinforces dyspnoea, causing further deconditioning resulting in impaired exercise capacity and profound physical inactivity. ${ }^{39}$

Physical inactivity results in muscle impairment in COPD, and this latter is characterised by alterations in fibre type, reduced capillarisation and oxidative enzyme capacity and altered energy metabolism. ${ }^{40}$ These metabolic impairments of the muscle demand an increase in ventilation contributing to exercise intolerance and dyspnoea. ${ }^{39}$ Skeletal muscle dysfunction can result in reduced strength, quality of life, increased risk of hospitalisation and mortality. ${ }^{40-42}$ Several features of skeletal muscle dysfunction can be stabilised or reversed by pulmonary rehabilitation/exercise training. ${ }^{42}$ Exercise training leads to improved oxidative capacity and efficiency of skeletal muscles, which lead to a reduced ventilatory requirement for a given work rate. This in turn, may reduce dynamic hyperinflation, thereby contributing to a reduction in exertional dyspnoea. ${ }^{15}$

Physical inactivity is also linked with increased levels of systemic inflammation and markers of oxidative stress. ${ }^{39,43}$ So, physical inactivity and systemic inflammation seem to be interrelated ${ }^{44}$. Loprinzi $^{45}$ found an inverse relationship between physical activity and systemic inflammation among current or former smokers with COPD. ${ }^{45}$ It is suggested that regular physical activity may lower inflammatory markers in patients with COPD. ${ }^{45}$ 
In conclusion, pulmonary rehabilitation/exercise training targets particularly the systemic manifestations in COPD and the benefits arise from the improvements that can be made on these systemic effects. ${ }^{44}$ Until now, the pharmacological treatment of patients with COPD has been centred mainly on the lungs and is primarily symptomatic. Pulmonary rehabilitation addresses important extrapulmonary components that are not targeted by any pharmacological treatment and might therefore the reason for its overwhelming efficacy. ${ }^{15}$ The benefit of pulmonary rehabilitation/exercise training might still be underestimated and underused in patients with $\operatorname{COPD}^{46}$. Life style interventions (including enhancement of daily physical activity), and pulmonary rehabilitation specifically, are essential components of patient care and should be considered in patients with COPD. ${ }^{15,47}$ Overall, increasing physical activity and pulmonary rehabilitation seem to be the only broad approaches that target many aspects of COPD. ${ }^{44,46}$

However, all these above findings derive from knowledge from patients with moderate to severe COPD who are treated in specialized care. Are there indications that the systemic effects apply to the same extent to patients with mild to moderate COPD? The limited data available in this patient category is not consistent. The percentage of patients suffering from skeletal muscle dysfunction, low fat-free mass or quadriceps weakness ranges from $10-40 \%$ in different studies ${ }^{48-54}$, compared to a percentage of $>50 \%$ of the patients with (very) severe COPD. ${ }^{42,50,53}$ Moreover, Seymour $^{52}$ found no significant difference in the prevalence of muscle weakness between GOLD stages, whereas Carrai ${ }^{53}$ did.

So, it is questionable whether the interrelationships between local, systemic consequences and behavioural factors apply to the same amount for patients in the milder disease stages, as only a fraction of this population suffers from clear systemic consequences. In this patient category, should the focus be on behavioural change with the main goal to postpone or avoid consequences of systemic manifestations, instead of counteracting these?

\section{Practical implications, barriers and facilitators, and future directions}

\section{Implementation and practical considerations}

Few pulmonary rehabilitation studies of a multidisciplinary nature have been performed in the primary care setting. The potential advantages of pulmonary rehabilitation delivered in primary care include cost-effectiveness, increased 
accessibility, greater patient comfort and satisfaction. ${ }^{55,56}$ Our study showed that a physical exercise training programme is feasible in a primary care setting; general practitioners and nurse practitioners were willing to refer patients to an exercise training programme, physiotherapists were capable to assess and treat the patients and the patients were motivated to participate in the programme. As a result, we successfully implemented an exercise training programme for COPD in primary care in our studied region. Except for $\mathrm{Casey}^{57}$, other studies in a primary care setting described clear difficulties to recruit patients and met with numerous barriers. ${ }^{13,58}$

A formal feasibility study was not performed, but during the study, we have encountered barriers and facilitators that we would like to mention in this chapter. Barriers exist at multiple levels, from individual level to local and national healthcare level. Individual level will be subdivided at the three participating levels: general practice level, physiotherapy level and patient level.

On general practitioner level, we noticed that general practitioners and nurse practitioners possessed hardly any diagnostic tools to reliable assess daily physical activity and exercise capacity. So, poorly insight into these parameters might result in scant follow-up actions, like referral to an exercise training programme. Nurse practitioners indicated that they have many items to complete in a COPD consultation and might give priority to stop smoking, spirometry and medication inhalation. Another barrier was that general practitioners and nurse practitioners were unfamiliar with the reimbursement procedures for an exercise training programme, due to complex regulations on national and local level and repeatedly changing procedures in the Netherlands and might therefore be reluctant to refer patients to an exercise training programme. Furthermore, for general practitioners and nurse practitioners the criteria for patient referral were not always evident as well as referral to which physiotherapy practice.

On physiotherapy level, the main impediment was the lack of experience in the treatment of patients with mild to moderate COPD. Currently, the far majority of patients with COPD in the physiotherapy practice exists of patients with moderate to severe COPD following a maintenance programme after pulmonary rehabilitation in secondary or tertiary care. In these patients, complete assessment and initiation of the training programme has already been done in the pulmonary rehabilitation setting. Patients with mild to moderate COPD referred from the general practitioner arrive relatively blank at the physiotherapy practice, so more expertise is required from the physiotherapist. Another limitation was that sufficient equipment and accommodation is demanded for a physiotherapist to execute a physical exercise 
training programme COPD, which is not feasible for a large part of physical therapy practices.

On patient level, it might be a barrier that patients in milder disease stages may not be aware of their symptoms, because of adaptation of their lifestyle to avoid unpleasant symptoms, like dyspnoea. As a result, patients with mild to moderate COPD might not feel the urge to take effective measures. A lack of insight in personal physical activity levels might be another limitation. Lastly, lack of time was a frequently recurrent comment to refuse participation in the exercise training programme. Many of the patients in the milder disease stages of COPD have work commitments that interfere with the opening hours of physiotherapy practices.

We also experienced some facilitators of good implementation of multidisciplinary exercise training programmes for COPD in primary care. A well-established cooperation on local level between general practice and physiotherapy practice and clear responsibilities resulted in satisfactory implementation. Another facilitator was the awareness of benefits from exercise training and physical activity. Furthermore, the reimbursement of exercise training programmes for patients with mild to moderate COPD has a major positive impact on implementation. At the start of the inclusion period of our study, reimbursement for the programme existed, due to state subsidy for innovative projects. After a year, reimbursement ceased as a result of policy changes and inclusion of patients was minimized. Patients were not eager to pay for the programme and general practitioners and nurse practitioners were not inclined to refer patients any more. Our experienced barriers and facilitators are summarized in Table 7.1.

Table 7.1 Barriers to and facilitators of implementation of multidisciplinary exercise training programmes in primary care.

Barriers to implementation of multidisciplinary exercise training programmes in primary care

- On general practice level:

- Few diagnostic tools available to measure exercise capacity and daily physical activity

- Many tasks to perform during a COPD consult

- Unfamiliarity with reimbursement procedures

- Unfamiliarity with referral of whom and to which physiotherapy practice

- On physiotherapy practice level:

- Minor expertise with the assessment and treatment of patients with mild to moderate COPD

- Requirement of spacious accommodation and expensive equipment

- On patient level:

- Minor symptoms and decline in functional capabilities

- Unfamiliarity with personal physical activity behaviour

- Lack of time / interference with daily routines

Facilitators of implementation of multidisciplinary exercise training programmes in primary care

- Presence of good cooperation between general practice and physiotherapy practice

- Awareness of benefits of exercise training or physical activity in COPD

- Reimbursement for a physical exercise training programme 
Our experiences are partly in accordance with findings in literature. Primary care professionals in another study identified low knowledge of pulmonary rehabilitation, low knowledge of the referral process, difficulties with access to PR and doubts about the need to further promote exercise behaviour change in this patient group as barriers to referral. ${ }^{59}$ According to general practitioners, referral would be improved by integrating pulmonary rehabilitation into standard care through financial incentive and improved flow of information regarding referral and services. ${ }^{59}$ From a patient's point of view, there have been numerous barriers identified to participation in physical activity and pulmonary rehabilitation, including lack of time, fluctuation of symptoms or existence of comorbidities, financial difficulties, lack of perceived progress and belief in sufficient exercise behaviour. ${ }^{60}$ Facilitators of participation in exercise programmes include motivation and regaining control over the symptoms/disease, the social aspect of exercising together and professional support. $^{60,61}$

\section{Future directions of a physical exercise training programme COPD in primary care}

Following on the previous paragraph, proposals on diminishing the barriers are put forward. A first practical suggestion regarding implementation would be that objective measurement of daily physical activity is an essential part of assessment in primary care, since the lack of insight in and availability of tools for measuring daily physical activity in patients was an observed barrier. More detailed information enables health care professionals to deliver personalised care. Another suggestion to enhance implementation of an exercise training programme would be to make good use of a physiotherapeutic consultation to assess and record the disease burden of a patient with COPD. Difficulties with referral criteria, including the lack of information on disease burden, was a barrier for general practitioners and nurse practitioners to refer patients to the programme. Boer ${ }^{62}$ stated that standardised functional capacity testing is difficult to implement in routine general practice care. So, the aim of a physiotherapeutic consult is to perform a number of important measurements, like the six-minute walk test, muscle strength measures and health-related quality of life questionnaires and to give feedback on the disease burden of the patient. Especially, as from 2001, a physiotherapeutic consultation is an existing treatment procedure in the Netherlands, which enables general practitioners to involve the expertise of a physiotherapist. Up till now, this possibility is underused in patients with COPD. 
The content of our physical exercise training programme turned out to be suitable for enhancing physical fitness components of patients with mild to moderate COPD, and to maintain the benefits for at least 2 months after the programme and the supervision has ended. However, the long term benefits are unknown. From the literature, it is known that the gains of pulmonary rehabilitation in patients with moderate to severe COPD tend to diminish after about 1 year. ${ }^{63-65}$ On the other hand, physical activity levels in our study were not increased after 4 months, but there was the tendency of a gain after 6 months. This is in accordance to the work of Pitta and co-workers, who have shown that changing physical activity behaviour only occurred after 6 months of pulmonary rehabilitation. ${ }^{17}$ Physical optimisation may be reached within 6-10 weeks, whereas behavioural research suggests that modifying behavioural patterns and coping styles take months. ${ }^{66}$

Maintenance of the benefits of pulmonary rehabilitation or an exercise training programme in primary care, as well as changes in physical activity levels are important goals for the long lasting effects on symptoms, exercise capacity, hospital admissions and mortality. The optimal strategy to meet this aim has not yet been ascertained. ${ }^{67}$ Several available options for the maintenance of benefits of pulmonary rehabilitation have been described, including maintenance programmes, telephone contacts and monthly supervised reinforcement sessions, lifestyle activity interventions and home exercise training. ${ }^{64,68-70}$ A recent meta-analysis suggested that post-pulmonary rehabilitation/exercise programmes are superior to traditional care in maintaining exercise capacity in the medium term (6 months), but not in the long term ( $\geq 1$ year) and have no sustained effect at all with regard to health-related quality of life. ${ }^{71}$

A number of intervention studies have been performed to improve daily physical activity in patients with COPD. De Blok ${ }^{72}$ studied the effects of a lifestyle physical activity counselling programme with feedback of a pedometer during PR. This study showed that the number of steps per day increased on top of the rehabilitation effect, but this was not statistically significant. ${ }^{72} \mathrm{~A}$ pilot study that combined a pedometer with a website demonstrated that it is feasible and safe for patients with COPD and that they increased their daily walking with a mean of 1263 steps per day (approximately $1.0 \mathrm{~km}$ ). ${ }^{73}$ The absence of a control group however, was a limitation. A study that assessed the effects of Nordic Walking on daily physical activity and exercise capacity in patients with COPD showed improvements on both. In addition to the short-term effects, Nordic Walking created a long-term effect on the training results even after an un-coached observation period of 6 months. ${ }^{74}$ The authors hypothesized that the maintained increase in daily physical activities in their COPD patients might be due to the type of training method used, a modified everyday 
movement (walking), which resulted in a transfer into patients' daily life. Moreover, after an unsupervised period of six months, it turned out that $63 \%$ of the patients had adopted Nordic Walking as regular physical exercise.

In the theory of behaviour change, an iterative process of feedback, goal setting and motivation are critical components. ${ }^{73,75}$ These components could be provided by using a pedometer/accelerometer with on-instrument data and a personal webpage. Good examples are the "Every Step Counts walking programme" ${ }^{73}$ and the "It's LiFe! Tool". 76

So, our vision for the future concerning exercise training programmes or physical activity programme for patients with mild to moderate COPD in primary care, is that it should aim both to improve and maintain exercise capacity and daily physical activity. The exercise training programme from our intervention protocol can be retained and should be accompanied by incorporating lifestyle physical activities like walking and cycling outdoors, stair-climbing and gardening. ${ }^{72}$ These items should be complemented with a monitoring and feedback tool that incorporates feedback, goal setting and motivational messages components.

In a future project, it is planned to combine the results of the present study with the It's LiFe! Tool study. ${ }^{76}$

In addition, the contribution of the exercise training component and the physical activity/lifestyle component in the total programme needs to be personalised per patient, as the results of the present study indicate that a substantial part of our study population had a reasonably well baseline exercise capacity in combination with a poor daily physical activity level. Moreover, from other studies it is known that approximately a quarter of the patients with mild to moderate COPD suffer from clear systemic consequences ${ }^{48,53,54}$, which entails that the larger part does not experience muscle dysfunction. So, we propose that in a large group of patients, priority might be given to behavioural change regarding physical activity as opposed to exercise training.

\section{Conclusion}

A physical exercise training programme for patients with mild to moderate COPD, as applied in our intervention study, turned out to be effective in improving exercise capacity. Daily physical activity patterns did not significantly differ between the intervention and control group. As a recommendation, daily physical activity should 
be assessed by objective measurement in primary care patients with COPD in addition to the assessment of exercise capacity to deliver personalized care. No determinants were identified that significantly modified the effect of the treatment. However, explorative analyses showed that patients with less baseline burden of the disease were likely to improve more in exercise capacity than patients with more baseline burden of their disease.

The programme was acceptable and feasible in a primary care setting, but needs to be refined in order to maintain improvements in exercise capacity for the long term and to enhance daily physical activity. Future studies should incorporate life style physical activities that copy everyday movements. Moreover, optimisation of behavioural change could be achieved by feedback mechanisms, goal setting and motivational messages, for example by using a pedometer or accelerometer in combination with a personal webpage. This strategy will be beneficial to the patient to lessen the disease burden for the long term. 


\section{References}

1. Lacasse Y, Goldstein R, Lasserson TJ, Martin S. Pulmonary rehabilitation for chronic obstructive pulmonary disease. The Cochrane database of systematic reviews 2006(4):CD003793.

2. Troosters T, Sciurba F, Battaglia S, Langer D, Valluri SR, Martino L, Benzo R, Andre D, Weisman I, Decramer M. Physical inactivity in patients with COPD, a controlled multi-center pilot-study. Respir Med 2010;104:1005-11.

3. Watz H, Waschki B, Meyer T, Magnussen H. Physical activity in patients with COPD. Eur Respir J 2009; 33:262-72.

4. Tudor-Locke C, Hatano Y, Pangrazi RP, Kang M. Revisiting "how many steps are enough?". Med Sci Sports Exerc 2008;40(7 Suppl):S537-43.

5. Black AE, Coward WA, Cole TJ, Prentice AM. Human energy expenditure in affluent societies: an analysis of 574 doubly-labelled water measurements. Eur J Clin Nutr 1996;50:72-92.

6. Pitta F, Troosters T, Spruit MA, Probst VS, Decramer M, Gosselink R. Characteristics of physical activities in daily life in chronic obstructive pulmonary disease. Am J Respir Crit Care Med 2005; 171:972-7.

7. Mador MJ, Patel AN, Nadler J: Effects of pulmonary rehabilitation on activity levels in patients with chronic obstructive pulmonary disease. J Cardiopulm Rehabil Prev 2011;31:52-9.

8. Zwerink M, van der Palen J, van der Valk P, Brusse Keizer M, Effing T. Relationship between daily physical activity and exercise capacity in patients with COPD. Respir Med 2013;107:242-8.

9. Leidy NK. Using functional status to assess treatment outcomes. Chest 1994;106:1645-6.

10. van Wetering CR, Hoogendoorn M, Mol SJ, Rutten van Molken MP, Schols AM. Short- and long-term efficacy of a community-based COPD management programme in less advanced COPD: a randomised controlled trial. Thorax 2010;65:7-13.

11. Effing $\mathrm{T}$, Zielhuis $\mathrm{G}$, Kerstjens $\mathrm{H}$, van der Valk $\mathrm{P}$, van der Palen J. Community based physiotherapeutic exercise in COPD self-management: a randomised controlled trial. Respir Med 2011;105:418-26.

12. Cambach W, Chadwick Straver RV, Wagenaar RC, van Keimpema AR, Kemper HC. The effects of a community-based pulmonary rehabilitation programme on exercise tolerance and quality of life: a randomized controlled trial. Eur Respir J 1997;10:104-13.

13. Roman M, Larraz C, Gomez A, Ripoll J, Mir I, Miranda EZ, Macho A, Thomas V, Esteva M. Efficacy of pulmonary rehabilitation in patients with moderate chronic obstructive pulmonary disease: a randomized controlled trial. BMC Fam Pract 2013;14:21.

14. Amin S, Abrazado M, Quinn M, Storer TW, Tseng CH, Cooper CB. A controlled study of communitybased exercise training in patients with moderate COPD. BMC Pulm Med 2014;14:125.

15. Spruit MA, Singh SJ, Garvey C, Zuwallack R, Nici L, Rochester C, Hill K, Holland AE, Lareau SC, Man WD et al. An Official American Thoracic Society/European Respiratory Society Statement: Key Concepts and Advances in Pulmonary Rehabilitation. Am J Respir Crit Care Med 2013;188:e13-e64.

16. Mercken EM, Hageman GJ, Schols AM, Akkermans MA, Bast A, Wouters EF. Rehabilitation decreases exercise-induced oxidative stress in chronic obstructive pulmonary disease. Am J Respir Crit Care Med 2005;172:994-1001.

17. Pitta F, Troosters T, Probst VS, Langer D, Decramer M, Gosselink R. Are patients with COPD more active after pulmonary rehabilitation? Chest 2008;134:273-80.

18. Sewell L, Singh SJ, Williams JE, Collier R, Morgan MD. Can individualized rehabilitation improve functional independence in elderly patients with COPD? Chest 2005;128:1194-200.

19. Walker PP, Burnett A, Flavahan PW, Calverley PM. Lower limb activity and its determinants in COPD. Thorax 2008;63:683-9.

20. Coronado M, Janssens JP, de Muralt B, Terrier P, Schutz Y, Fitting JW. Walking activity measured by accelerometry during respiratory rehabilitation. J Cardiopulm Rehabil 2003;23:357-64.

21. Dallas MI, McCusker C, Haggerty MC, Rochester CL, Zuwallack R, Northeast Pulmonary Rehabilitation C. Using pedometers to monitor walking activity in outcome assessment for pulmonary rehabilitation. Chron Respir Dis 2009;6:217-24. 
22. Steele BG, Belza B, Cain KC, Coppersmith J, Lakshminarayan S, Howard J, Haselkorn JK. A randomized clinical trial of an activity and exercise adherence intervention in chronic pulmonary disease. Arch Phys Med Rehabil 2008;89:404-12.

23. Probst VS, Kovelis D, Hernandes NA, Camillo CA, Cavalheri V, Pitta F. Effects of 2 exercise training programs on physical activity in daily life in patients with COPD. Respir Care 2011;56:1799-807.

24. Egan C, Deering BM, Blake C, Fullen BM, McCormack NM, Spruit MA, Costello RW. Short term and long term effects of pulmonary rehabilitation on physical activity in COPD. Respir Med 2012; 106:1671-9.

25. Van Wetering CR: Clinical evaluation and cost-effectiveness of a community-based COPD management program. PhD thesis. Maastricht: Maastricht University; 2010.

26. Williams V, Bruton A, Ellis-Hill C, McPherson K. The effect of pulmonary rehabilitation on perceptions of breathlessness and activity in COPD patients: a qualitative study. Prim Care Respir J 2010;19:45-51.

27. Hogg L, Grant A, Garrod R, Fiddler H. People with COPD perceive ongoing, structured and socially supportive exercise opportunities to be important for maintaining an active lifestyle following pulmonary rehabilitation: a qualitative study. Journal of physiotherapy 2012;58:189-95.

28. Garrod R, Marshall J, Barley E, Jones PW. Predictors of success and failure in pulmonary rehabilitation. Eur Respir J 2006;27:788-94.

29. Selzler AM, Simmonds L, Rodgers WM, Wong EY, Stickland MK. Pulmonary rehabilitation in chronic obstructive pulmonary disease: predictors of program completion and success. COPD 2012;9:538-45.

30. Troosters T, Gosselink R, Decramer M. Exercise training in COPD: how to distinguish responders from nonresponders. J Cardiopulm Rehabil 2001;21:10-7.

31. Vagaggini B, Costa F, Antonelli S, De Simone C, De Cusatis G, Martino F, Santerini S, Paggiaro P. Clinical predictors of the efficacy of a pulmonary rehabilitation programme in patients with COPD. Respir Med 2009;103:1224-30.

32. Walsh JR, McKeough ZJ, Morris NR, Chang AT, Yerkovich ST, Seale HE, Paratz JD. Metabolic disease and participant age are independent predictors of response to pulmonary rehabilitation. J Cardiopulm Rehabil Prev 2013;33:249-56.

33. Kruis AL, van Adrichem J, Erkelens MR, Scheepers H, In 't Veen H, Muris JW, Chavannes NH. Sustained effects of integrated COPD management on health status and exercise capacity in primary care patients. Int J Chron Obstruct Pulmon Dis 2010;5:407-13.

34. Jenkins SC. 6-Minute walk test in patients with COPD: clinical applications in pulmonary rehabilitation. Physiotherapy 2007;93:175-82.

35. Golmohammadi K, Jacobs P, Sin DD. Economic evaluation of a community-based pulmonary rehabilitation program for chronic obstructive pulmonary disease. Lung 2004;182:187-96.

36. Beekman E, Mesters I, Hendriks EJ, Klaassen MP, Gosselink R, van Schayck OC, de Bie RA. Course length of 30 metres versus 10 metres has a significant influence on six-minute walk distance in patients with COPD: an experimental crossover study. Journal of physiotherapy 2013;59:169-76.

37. Pitta F, Troosters T, Probst VS, Spruit MA, Decramer M, Gosselink R. Quantifying physical activity in daily life with questionnaires and motion sensors in COPD. Eur Respir J 2006;27:1040-55.

38. De Peuter S, Van Diest I, Lemaigre V, Verleden G, Demedts M, Van den Bergh O. Dyspnea: the role of psychological processes. Clinical psychology review 2004;24:557-81.

39. Decramer M, Rennard S, Troosters T, Mapel DW, Giardino N, Mannino D, Wouters E, Sethi S, Cooper $\mathrm{CB}$. COPD as a lung disease with systemic consequences--clinical impact, mechanisms, and potential for early intervention. COPD 2008;5:235-56.

40. Maltais F, LeBlanc P, Jobin J, Casaburi R. Peripheral muscle dysfunction in chronic obstructive pulmonary disease. Clinics in chest medicine 2000;21:665-77.

41. Maltais F, LeBlanc P, Whittom F, Simard C, Marquis K, Belanger M, Breton MJ, Jobin J. Oxidative enzyme activities of the vastus lateralis muscle and the functional status in patients with COPD. Thorax 2000;55:848-53.

42. Franssen FM, Rochester CL. Comorbidities in patients with COPD and pulmonary rehabilitation: do they matter? European respiratory review : an official journal of the European Respiratory Society 2014;23:131-41. 
43. Powers SK, Kavazis AN, DeRuisseau KC. Mechanisms of disuse muscle atrophy: role of oxidative stress. American journal of physiology Regulatory, integrative and comparative physiology 2005;288: R337-44.

44. Evans RA, Morgan MD. The systemic nature of chronic lung disease. Clinics in chest medicine 2014; 35:283-93.

45. Loprinzi PD, Walker JF, Lee H. Association Between Physical Activity and Inflammatory Markers Among U.S. Adults with Chronic Obstructive Pulmonary Disease. American journal of health promotion : AJHP 2013.

46. Nussbaumer-Ochsner Y, Rabe KF: Systemic manifestations of COPD. Chest 2011;139:165-73.

47. Vestbo J, Hurd SS, Agusti AG, Jones PW, Vogelmeier C, Anzueto A, Barnes PJ, Fabbri LM, Martinez FJ, Nishimura $\mathrm{M}$ et al. Global strategy for the diagnosis, management, and prevention of chronic obstructive pulmonary disease: GOLD executive summary. Am J Respir Crit Care Med 2013;187: 347-65.

48. Steuten LM, Creutzberg EC, Vrijhoef HJ, Wouters EF. COPD as a multicomponent disease: inventory of dyspnoea, underweight, obesity and fat free mass depletion in primary care. Prim Care Respir J 2006; 15:84-91.

49. Agusti A, Soriano JB. COPD as a systemic disease. COPD 2008;5:133-8.

50. Schols AM, Soeters PB, Dingemans AM, Mostert R, Frantzen PJ, Wouters EF. Prevalence and characteristics of nutritional depletion in patients with stable COPD eligible for pulmonary rehabilitation. The American review of respiratory disease 1993;147:1151-6.

51. Vestbo J, Prescott E, Almdal T, Dahl M, Nordestgaard BG, Andersen T, Sorensen TI, Lange P. Body mass, fat-free body mass, and prognosis in patients with chronic obstructive pulmonary disease from a random population sample: findings from the Copenhagen City Heart Study. Am J Respir Crit Care Med 2006;173:79-83.

52. Seymour JM, Spruit MA, Hopkinson NS, Natanek SA, Man WD, Jackson A, Gosker HR, Schols AM, Moxham J, Polkey MI et a.: The prevalence of quadriceps weakness in COPD and the relationship with disease severity. Eur Respir J 2010;36:81-8.

53. Carrai R, Scano G, Gigliotti F, Romagnoli I, Lanini B, Coli C, Grippo A. Prevalence of limb muscle dysfunction in patients with chronic obstructive pulmonary disease admitted to a pulmonary rehabilitation centre. Clin Neurophysio 2012;123:2306-11.

54. van Wetering CR, van Nooten FE, Mol SJ, Hoogendoorn M, Rutten Van Molken MP, Schols AM. Systemic impairment in relation to disease burden in patients with moderate COPD eligible for a lifestyle program. Findings from the INTERCOM trial. Int J Chron Obstruct Pulmon Dis 2008;3:443-51.

55. Nici L, Donner C, Wouters E, Zuwallack R, Ambrosino N, Bourbeau J, Carone M, Celli B, Engelen M, Fahy $\mathrm{B}$ et al. American Thoracic Society/European Respiratory Society statement on pulmonary rehabilitation. Am J Respir Crit Care Med 2006;173:1390-413.

56. Arnardottir RH, Sorensen S, Ringqvist I, Larsson K. Two different training programmes for patients with COPD: a randomised study with 1-year follow-up. Respir Med 2006;100:130-9.

57. Casey D, Murphy K, Devane D, Cooney A, McCarthy B, Mee L, Newell J, O'Shea E, Scarrott C, Gillespie $\mathrm{P}$ et al. The effectiveness of a structured education pulmonary rehabilitation programme for improving the health status of people with moderate and severe chronic obstructive pulmonary disease in primary care: the PRINCE cluster randomised trial. Thorax 2013;68:922-8.

58. Faulkner J, Walshaw E, Campbell J, Jones R, Taylor R, Price D, Taylor AH. The feasibility of recruiting patients with early COPD to a pilot trial assessing the effects of a physical activity intervention. Prim Care Respir J 2010;19:124-30.

59. Johnston KN, Young M, Grimmer KA, Antic R, Frith PA. Barriers to, and facilitators for, referral to pulmonary rehabilitation in COPD patients from the perspective of Australian general practitioners: a qualitative study. Prim Care Respir J 2013;22:319-24.

60. Thorpe O, Johnston K, Kumar S. Barriers and enablers to physical activity participation in patients with COPD: a systematic review. J Cardiopulm Rehabil Prev 2012;32:359-69.

61. Harris D, Hayter M, Allender S. Improving the uptake of pulmonary rehabilitation in patients with COPD: qualitative study of experiences and attitudes. Br J Gen Pract 2008;58:703-10. 
62. Boer LM, Asijee GM, van Schayck OC, Schermer TR. How do dyspnoea scales compare with measurement of functional capacity in patients with COPD and at risk of COPD? Prim Care Respir J 2012;21:202-7.

63. Cambach W, Wagenaar RC, Koelman TW, van Keimpema AR, Kemper HC. The long-term effects of pulmonary rehabilitation in patients with asthma and chronic obstructive pulmonary disease: a research synthesis. Arch Phys Med Rehabil 1999;80:103-11.

64. Ries AL, Kaplan RM, Myers R, Prewitt LM. Maintenance after pulmonary rehabilitation in chronic lung disease: a randomized trial. Am J Respir Crit Care Med 2003;167:880-8.

65. Griffiths TL, Burr ML, Campbell IA, Lewis-Jenkins V, Mullins J, Shiels K, Turner-Lawlor PJ, Payne N, Newcombe RG, lonescu AA et al. Results at 1 year of outpatient multidisciplinary pulmonary rehabilitation: a randomised controlled trial. Lancet 2000;355:362-8.

66. Wempe JB, Wijkstra PJ. The influence of rehabilitation on behaviour modification in COPD. Patient Educ Couns 2004;52:237-41.

67. Corhay JL, Dang DN, Van Cauwenberge H, Louis R. Pulmonary rehabilitation and COPD: providing patients a good environment for optimizing therapy. Int J Chron Obstruct Pulmon Dis 2014;9:27-39.

68. Brooks D, Krip B, Mangovski-Alzamora S, Goldstein RS. The effect of postrehabilitation programmes among individuals with chronic obstructive pulmonary disease. Eur Respir J 2002;20:20-9.

69. Berry MJ, Rejeski WJ, Miller ME, Adair NE, Lang W, Foy CG, Katula JA. A lifestyle activity intervention in patients with chronic obstructive pulmonary disease. Respir Med 2010;104:829-39.

70. Spencer LM, Alison JA, McKeough ZJ. Maintaining benefits following pulmonary rehabilitation: a randomised controlled trial. Eur Respir J 2010;35:571-7.

71. Beauchamp MK, Evans R, Janaudis-Ferreira T, Goldstein RS, Brooks D. Systematic review of supervised exercise programs after pulmonary rehabilitation in individuals with COPD. Chest 2013;144:1124-33.

72. de Blok BM, de Greef MH, ten Hacken NH, Sprenger SR, Postema K, Wempe JB. The effects of a lifestyle physical activity counseling program with feedback of a pedometer during pulmonary rehabilitation in patients with COPD: a pilot study. Patient Educ Couns 2006;61:48-55.

73. Moy ML, Weston NA, Wilson EJ, Hess ML, Richardson CR. A pilot study of an Internet walking program and pedometer in COPD. Respir Med 2012;106:1342-50.

74. Breyer MK, Breyer-Kohansal R, Funk GC, Dornhofer N, Spruit MA, Wouters EF, Burghuber OC, Hartl S. Nordic walking improves daily physical activities in COPD: a randomised controlled trial. Respir Res 2010;11:112.

75. Anderson ES, Wojcik JR, Winett RA, Williams DM. Social-cognitive determinants of physical activity: the influence of social support, self-efficacy, outcome expectations, and self-regulation among participants in a church-based health promotion study. Health Psychol 2006;25:510-20.

76. Verwey R, van der Weegen S, Spreeuwenberg M, Tange H, van der Weijden T, de Witte L. A monitoring and feedback tool embedded in a counselling protocol to increase physical activity of patients with COPD or type 2 diabetes in primary care: study protocol of a three-arm cluster randomised controlled trial. BMC Fam Pract 2014;15:93. 
Summary

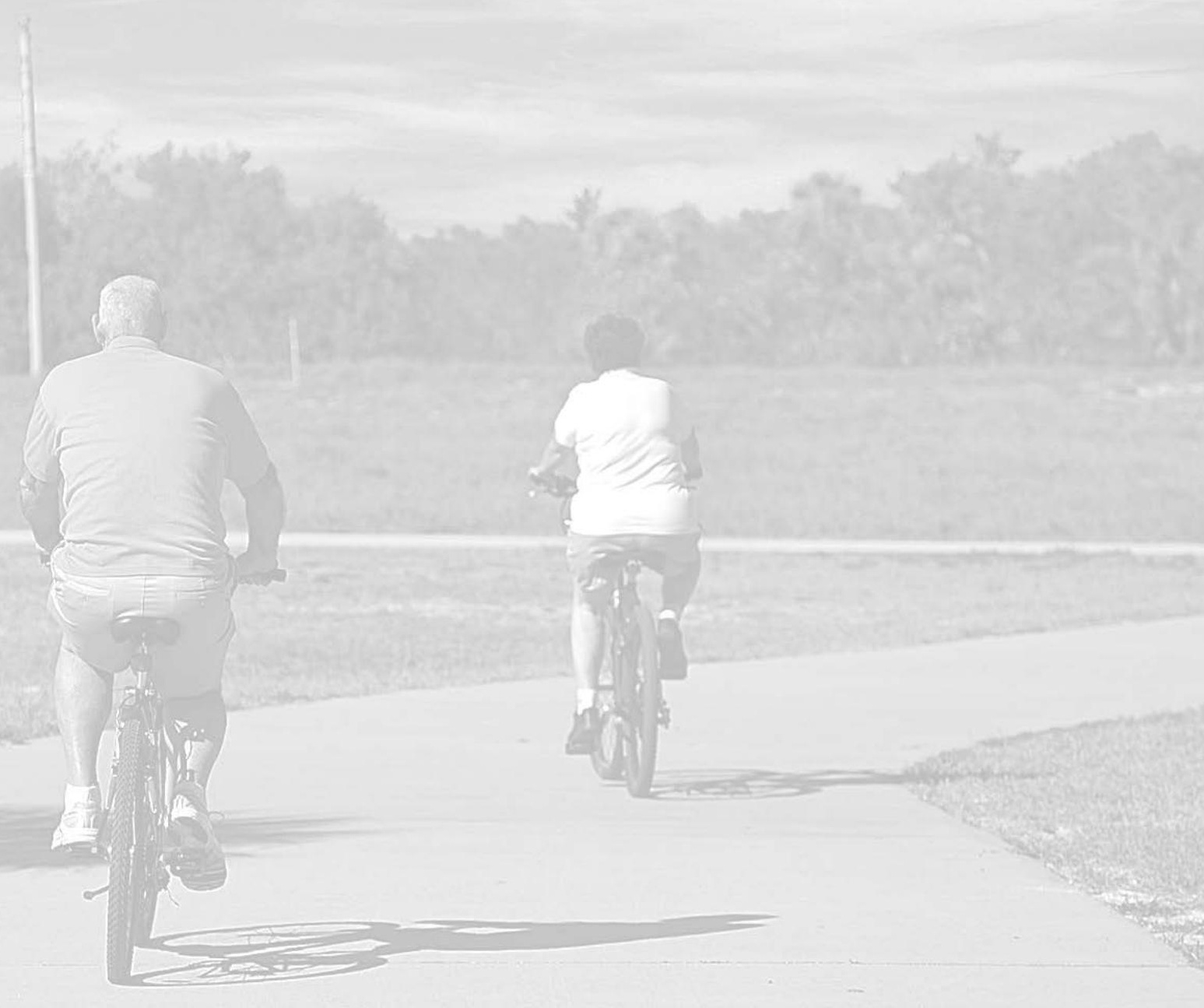




\section{Summary}

The efficacy of pulmonary rehabilitation in patients with moderate to severe COPD in secondary or tertiary care is evident, as it reduces dyspnoea, increases exercise capacity and improves quality of life. The purpose of this thesis was to study the efficacy of a physical exercise training programme for patients with mild to moderate COPD in primary care. The programme was designed to improve physical fitness and to promote daily physical activity. Special attention is given to the relationship between exercise capacity and daily physical activity, because it is increasingly becoming clear that these are two different concepts.

Chronic obstructive pulmonary disease is the commonest chronic lung disease. Over the last two decades, there is growing evidence of systemic manifestations in COPD patients and their negative effects on the functioning of these patients. In chapter 1 , a general introduction is presented of the disease and its systemic consequences, with the main focus on skeletal muscle dysfunction and exercise intolerance. Pulmonary rehabilitation, with exercise training as main component, aims to reverse the systemic manifestations of COPD and aims to break the vicious circle of breathlessness, avoidance of physical activities, deconditioning, skeletal muscle dysfunction and more breathlessness. The concepts of exercise training and physical activity are often mixed up and are therefore broadly explained. In some regions in the Netherlands, disease management programmes for COPD, including referral possibilities to an exercise training programme, were already implemented in primary care. However, no data were yet available on the added value of a physical exercise training programme compared to the advice on increasing daily physical activity in usual care. So, we developed and studied the efficacy of such a training programme.

Patients with COPD, even those in the early stages, are usually very inactive. If they were able to increase their level of physical activity, it is likely that they would experience substantial health benefits. Therefore, current COPD guidelines recommend that patients increase their levels of regular physical activity. But currently, referral to pulmonary rehabilitation (PR) or a physical exercise training programme (PETP) in primary care is based primarily upon lung function and complaints of dyspnoea and deconditioning. In chapter $\mathbf{2}$, we propose the use of data from actual physical activity, not only as an outcome measure in clinical research, but also as a starting point for treatment, to fine-tune coaching and exercise training for the individual patient with COPD. 
In chapter 3, the study design of a randomized controlled trial of a physical exercise training programme for patients with mild to moderate COPD is described. Patients with mild to moderate airflow obstruction ( $\mathrm{FEV}_{1} \geq 50 \%$ of predicted), dyspnoea and a physically inactive lifestyle were randomized to an intervention or control group. The intervention group received a 4-month physical exercise training programme at a local physiotherapy practice, which included exercise training, resistance training, breathing exercises and advises on how to increase the level of physical activity. The control group received usual care, i.e. advises on how to increase the level of physical activity and a sham treatment at a local physiotherapy practice of which no physiological training stimulus could be expected. Primary outcome was functional exercise capacity at 4-months measured on the six-minute walk distance. Secondary outcomes included peripheral muscle strength, physical activity in daily life, health related quality of life, Medical Research Council (MRC) dyspnoea score and patients' perceived effectiveness. Follow-up measurement took place at 6 months after baseline.

In chapter 4, the relationship between functional exercise capacity and physical activity in patients with mild to moderate COPD is investigated in a cross-sectional study. Functional exercise capacity appeared to be close to normal values, but more than $20 \%$ of the patients had an oxygen saturation below $90 \%$ during the six-minute walk test, indicating a significant decrease in oxygenation during exertion. Daily physical activity was clearly diminished. With a mean Physical Activity Level of 1.45 and a mean of 6459 steps per day, the patients can be classified as 'sedentary' and 'low active'. No significant correlations were observed between six-minute walk distance (\% predicted) and any of the physical activity variables (steps per day, movement intensity during walking, total active time, total walking time, physical activity level, and time spent in moderate physical activity). Therefore, it is concluded that there is a discrepancy between functional exercise capacity and daily physical activity in patients with mild to moderate COPD, which indicates that these variables represent two different concepts.

The results of a randomized controlled trial evaluating the efficacy of a physical exercise training programme in patients with mild to moderate COPD in primary care are presented in chapter $\mathbf{5}$. This study showed that the programme is effective in improving exercise capacity. For the secondary outcomes, significant improvements were seen in muscle strength (handgrip force at 6 months and shoulder abduction strength at 4 months), and CRQ mastery sub score at 6 months. No significant between-group differences were seen in daily physical activity (except for steps per 
walking period at 6 months), breathlessness, health-related quality of life and global perceived effectiveness of the treatment.

Overall, the physical exercise training programme demonstrated to be effective in improving exercise capacity. However, individual patients' responses to exercise training are highly variable. To offer personalised care, it is important to understand which factors influence the effect of the treatment. In chapter 6, we examined how patient characteristics and baseline burden of disease modified the effect of a physical exercise training programme on functional exercise capacity in patients with mild to moderate COPD. None of the patient characteristics or disease burden variables did significantly modify the effect of the intervention. However, explorative insight revealed that patients with a better baseline exercise capacity, less dyspnoea and fatigue and who were moderate physically active had the largest treatment effect. These results do not support the hypothesis that patients with a greater initial deconditioning have more room for improvement and might be able to have more benefits from exercise training.

In chapter 7, the general discussion of this thesis is described. The connection between the chapters are put forward and methodological considerations are discussed. The special role of pulmonary rehabilitation/exercise training in addressing the local and systemic effects in COPD is elaborated upon. This non-pharmacological treatment seems to be the only broad approach that targets many aspects of COPD. Unfortunately, the practical use of pulmonary rehabilitation and exercise training programmes are underused. In our primary care setting, we encountered various barriers, including poor insight by the caregivers and patients themselves in physical activity levels, unfamiliarity with reimbursement procedures, lack of time and the purchase of materials and equipment to perform such a programme. Facilitators of the implementation of multidisciplinary exercise training programmes in primary care included good cooperation between general practice and physiotherapy practice and the awareness of benefits from exercise training and physical activity. Refinement of a physical exercise training programme for patients with mild to moderate COPD should be made to maintain the improvements in exercise capacity for the long term and to enhance daily physical activity levels. Incorporating more physical training modalities that copy everyday-life activities and creating behavioural change by components of feedback, goal-setting and motivation might be a supplement to the current exercise training programme. Taken together, this thesis provides several new insights in the efficacy of an exercise training programme in patients with mild to moderate COPD, the relationship between exercise training and 
daily physical activity, and emphasizes the need for more research on the nonpharmacological treatment and/or lifestyle changes in this patient category. 
Samenvatting 


\section{Samenvatting}

De effectiviteit van longrevalidatie in de tweede en derde lijn bij patiënten met matig en ernstig Chronic Obstructive Pulmonary Disease (COPD) is evident. Het is gebleken dat door longrevalidatie de kortademigheid van de patiënten vermindert, de inspanningscapaciteit verbetert en de kwaliteit van leven toeneemt. Het doel van het onderzoeksproject dat beschreven is in dit proefschrift was om te bestuderen wat de effectiviteit is van een beweegprogramma voor patiënten met licht tot matig COPD in de eerste lijn. Het beweegprogramma was ontwikkeld om de fysieke fitheid te verbeteren en om fysieke activiteiten in het dagelijks leven te stimuleren. De begrippen 'trainen' en 'bewegen' en de samenhang en verschillen hiertussen vormen de rode draad door het proefschrift heen.

COPD wordt traditioneel gezien als chronische longziekte. Sinds twee decennia is er een toenemend bewijs voor het optreden van systemische effecten als gevolg van de aanwezigheid van COPD en de negatieve effecten hiervan op het functioneren van patiënten. In hoofdstuk 1 wordt een algemene introductie gegeven over de aandoening en de bijkomende systemische gevolgen, waarbij de focus ligt op stoornissen in skeletspieren en beperkingen in inspanningscapaciteit. Longrevalidatie, met inspanningstraining als belangrijkste pijler, heeft als doel de systemische gevolgen van COPD tegen te gaan en om de vicieuze cirkel van kortademigheid, vermijden van fysieke inspanning, verslechteren van de lichamelijke conditie, achteruitgang van spierfunctie en toename van kortademigheid te doorbreken. De termen 'trainen' en 'bewegen' worden in de huidige literatuur en communicatie veelvuldig door elkaar gebruikt en om die reden wordt er in de inleiding ruim aandacht besteed aan deze begrippen.

In sommige regio's in Nederland was er al diverse jaren geleden een implementatie op gang gekomen van COPD zorgprogramma's in de eerste lijn, inclusief verwijsmogelijkheden voor een beweegprogramma. Dit geschiedde, ondanks het feit dat er nog geen wetenschappelijk bewijs was voor de meerwaarde van een beweegprogramma boven het gebruikelijke advies om meer te bewegen in het dagelijks leven. Dat was voor ons de aanleiding om een dergelijk beweegprogramma te ontwikkelen en de effectiviteit ervan te bestuderen.

Patiënten met COPD zijn over het algemeen erg inactief, zelfs degenen in het beginstadium van de aandoening. Indien deze patiënten hun fysieke activiteitenniveau zouden weten op te krikken dan lijkt het aannemelijk dat er veel gezondheidswinst behaald zou kunnen worden. Om die reden wordt in huidige COPD richtlijnen het advies gegeven dat patiënten zouden moeten werken aan het verhogen van hun dagelijkse fysieke activiteiten. Tot nu toe wordt er in de zorg echter nog 
weinig aandacht besteed aan het objectief meten van het beweeggedrag en worden verwijzingen naar longrevalidatie of een beweegprogramma COPD vooral gedaan op basis van longfunctie, kortademigheidsklachten en een verminderde conditie en niet op basis van mate van fysieke activiteiten in het dagelijks leven. In hoofdstuk 2 stellen we voor om objectieve data van dagelijkse fysieke activiteiten niet alleen te gebruiken als uitkomstmaat voor klinisch onderzoek, maar ook als startpunt van de behandeling van de individuele patiënt om op die manier de coaching en het trainingsprogramma zo specifiek mogelijk in te kunnen stellen.

In hoofdstuk $\mathbf{3}$ wordt het studieprotocol beschreven van onze gerandomiseerde interventiestudie naar de effectiviteit van een beweegprogramma voor patiënten met licht tot matig COPD in de eerste lijn. Patiënten met een licht tot matige luchtwegobstructie ( $\mathrm{FEV}_{1} \geq 50 \%$ van de voorspelde waarde), kortademigheid en een fysiek inactieve leefstijl werden gerandomiseerd over een interventie- of controlegroep. De patiënten in de interventiegroep namen deel aan een 4-maanden durend beweegprogramma in de lokale fysiotherapiepraktijk. Het beweegprogramma bestond uit inspanningstraining, krachttraining, ademhalingsoefeningen en adviezen over het verhogen van het fysieke activiteitenniveau in het dagelijks leven. De patiënten in de controlegroep ontvingen de gangbare zorg, d.w.z. adviezen over het verhogen het fysieke activiteitenniveau in het dagelijks leven, en een pseudobehandeling in de lokale fysiotherapiepraktijk, waarvan geen fysiologische trainingsprikkel verwacht kon worden. De primaire uitkomstmaat was de functionele inspanningscapaciteit op 4 maanden, gemeten door middel van de 6-minuten wandeltest (6MWT). Secundaire uitkomstmaten waren perifere spierkracht, fysieke activiteiten in het dagelijks leven, gezondheid gerelateerde kwaliteit van leven, Medical Research Council (MRC) dyspneu score en het globaal ervaren effect van de behandeling. De follow-up meting vond plaats op 6 maanden na de baseline meting.

In hoofdstuk 4 wordt de relatie tussen functionele inspanningscapaciteit en fysieke activiteit bij patiënten met licht tot matig COPD bestudeerd door middel van een cross-sectionele studie. De functionele inspanningscapaciteit van de patiënten bleek in de buurt van de normaalwaarden te liggen. Echter, meer dan $20 \%$ van de patiënten had een zuurstofsaturatie onder de $90 \%$ tijdens de 6-minuten wandeltest, wat een aanzienlijke daling in zuurstofvoorziening tijdens inspanning indiceert. De dagelijkse fysieke activiteit was duidelijk verminderd bij de deelnemende patiënten. Met een gemiddeld Fysiek Activiteitenniveau van 1.45 en een gemiddelde van 6459 stappen per dag kunnen de patiënten geclassificeerd worden als 'sedentair' en 'laag-actief'. Er werd geen correlatie gevonden tussen de 6-minuten wandelafstand (6MWD) en een van de fysieke activiteiten variabelen (stappen per dag, bewegingsintensiteit tijdens het lopen, totale actieve tijd, totale looptijd, fysieke activiteitenniveau en tijdsduur 
van matige fysieke activiteit). Naar aanleiding van deze resultaten is de conclusie dat er een discrepantie bestaat tussen functionele inspanningscapaciteit en dagelijkse fysieke activiteiten bij patiënten met licht tot matig COPD. Dit wijst erop dat deze twee uitkomstmaten verschillende begrippen vertegenwoordigen.

De resultaten van de gerandomiseerde interventiestudie naar de effectiviteit van een beweegprogramma bij patiënten met licht tot matig COPD in de eerste lijn worden weergegeven in hoofdstuk 5. De studie toonde aan dat het beweegprogramma effectief is in het verbeteren van de inspanningscapaciteit. Voor de secundaire uitkomstmaten bleek dat er significante verbeteringen gevonden werden in spierkracht (handknijpkracht op 6 maanden en schouder abductiekracht op 4 maanden) en de CRQ sub score beheersing op 6 maanden. Er werden geen significante verschillen tussen de groepen gevonden in dagelijkse fysieke activiteit (behalve stappen per loopperiode op 6 maanden), kortademigheid, gezondheid gerelateerde kwaliteit van leven en globaal ervaren effect van de behandeling.

Op groepsniveau was dus aangetoond dat het beweegprogramma COPD effectief was in het verbeteren van de inspanningscapaciteit. Echter, op individueel niveau bleken de effecten enorm te variëren. Om op maat gesneden zorg te bieden, is het belangrijk om te begrijpen welke factoren het effect van de behandeling beïnvloeden. In hoofdstuk 6 hebben we onderzocht hoe patiënt karakteristieken en baseline ziektelast het effect van de behandeling op functionele inspanningscapaciteit bepalen bij patiënten met licht tot matig COPD. Geen van de patiënt karakteristieken of baseline ziektelast variabelen wijzigde het effect van de interventie significant. Echter, de data lieten zien dat patiënten die op baseline een betere inspanningscapaciteit, minder kortademigheidsklachten en matig fysiek actief waren het grootste behandeleffect hadden. Deze resultaten ondersteunen niet de hypothese dat patiënten met een groter initieel conditieverlies de meeste ruimte voor verbetering zouden hebben en meer baat zouden hebben bij inspanningstraining.

In hoofdstuk 7 wordt de algemene discussie van dit proefschrift beschreven. De samenhang tussen de hoofdstukken komt naar voren en methodologische overwegingen worden bediscussieerd. Er wordt uitgeweid over de speciale rol van longrevalidatie/ inspanningstraining in de aanpak van de lokale en systemische effecten bij COPD. Deze non-farmacologische behandeling lijkt de enige brede aanpak te zijn die zich richt op de vele aspecten (lokaal in de long en systemisch) van COPD. Helaas is het tot op heden zo dat het gebruik van longrevalidatie en beweegprogramma's COPD onderbenut is. In onze eerstelijns setting liepen we tegen diverse barrières aan, inclusief slecht inzicht van de zorgverleners en de patiënten zelf in het beweeggedrag van de patiënten, onbekendheid met het vergoedingensysteem, gebrek aan tijd en de verplichting te investeren in de aanschaf van materialen en 
ruimtes om een dergelijk beweegprogramma uit te kunnen voeren. Bevorderende factoren voor de implementatie van multidisciplinaire beweegprogramma's in de eerste lijn zijn een goede samenwerking tussen de huisartspraktijk en fysiotherapiepraktijk en de kennis over de gunstige effecten van trainen en bewegen. Verfijning van het beweegprogramma voor patiënten met licht tot matig COPD zal gedaan moeten worden om de verbetering in inspanningscapaciteit te handhaven voor de lange termijn en om de dagelijkse fysieke activiteiten te verhogen. Het incorporeren van meer trainingsmodaliteiten, die alledaagse bewegingen nabootsen, en gedragsverandering bewerkstelligen door onderdelen van feedback, het stellen van doelen en motivatietechnieken toe te passen zouden een toevoeging kunnen zijn op het bestaande beweegprogramma.

Resumerend, dit proefschrift verschaft diverse nieuwe inzichten in de effectiviteit van een beweegprogramma voor patiënten met licht tot matig COPD in de eerste lijn, de relatie tussen trainen en bewegen in het dagelijks leven en benadrukt de noodzaak van meer onderzoek naar de niet-farmacologische behandeling en/of leefstijl veranderingen in deze patiëntencategorie. 
Valorization 


\section{Valorization}

The research conducted within the scope of this PhD-trajectory has not only led to scientific output, but has also contributed to availability of the knowledge for social and practical use. In this chapter, the resulting products, activities and processes will be described for different target groups, such as primary care professionals, patients and policy makers. Lastly, future directions of implementation opportunities will also be dwelled upon.

\section{Relevance}

COPD is a leading cause of morbidity and mortality worldwide and results in a substantial social and economic burden that is increasing the upcoming years. ${ }^{1,2}$ In the European Union, the total direct costs of respiratory disease are estimated to be about $6 \%$ of the total health care budget, with COPD accounting for $56 \%$ of this cost of respiratory disease. ${ }^{3}$

In the previous chapters of this thesis, the benefits of pulmonary rehabilitation on patients' level are extensively described. Additionally, pulmonary rehabilitation was also found to have positive effects on economic and social level by (significantly) reducing the number of hospital admissions, hospital days, emergency room visits and physician visits. ${ }^{4-6}$ Physical activity in daily life is also considered as important in COPD given the fact that inactivity is associated with poor functional status, higher risk of hospital admissions and mortality. ${ }^{7,8}$

Consequently, maintaining adequate levels of exercise capacity and physical activity in patients with mild to moderate COPD seems necessary to have a positive impact on person and society.

\section{Target groups}

The results presented in this thesis are of relevance to several sectors/groups of society. Of course, first of all for patients with COPD themselves. With the current knowledge of the benefits of exercise training and physical activity, a patient can take his/her own responsibility as part of self-management to change the impact of the disease. Secondly, individual health care providers in primary care should encourage and motivate patients to follow an exercise training programme and/or increase daily physical activity. This should be more underlined in the COPD guidelines of the Dutch College of General practitioners (NHG) and the Royal Dutch Society for Physical Therapy (KNGF) than to this date. 
With the introduction in 2010 of the chain DTC (Diagnosis Treatment Combination) for COPD in primary care in several regions in the Netherlands, the importance of multidisciplinary care groups was evident in the facilitation of implementation of COPD management programmes, including physical exercise training programmes. These regional care groups for COPD, generally consisting of general practitioners and physiotherapists with the support of a pulmonologist, developed COPD care for their region and negotiated with medical insurance companies for reimbursement of the programme. So, the results of this thesis might be of interest to the medical insurance companies and policy makers like the Dutch Ministry of Health, Welfare and Sport in order to make comparative financial assessments.

Recently, the local authorities have been handed over more and more care assignments from the government, so nowadays they are in the position (and forced) to organize community care. The results of this thesis are interesting to the local authorities, for example to develop sports facilities and groups for the elderly outside the health care setting. Many cities have already done so, for example Maastricht with "Maastricht Sport" (www.maastrichtsport.nl). An example from abroad is an initiative in Catalunia (Spain) where, in collaboration with city engineers, walking circuits were designed in the city to fit the needs of patients with COPD. ${ }^{9}$ The use of these walking trails did increase physical activity in patients who completed a pulmonary rehabilitation programme. These trails could not only be beneficial for patients with COPD, but also for patients with obesity or Type II Diabetes Mellitus. ${ }^{10}$ Local policy makers should attempt to provide incentives (financial and other) to promote health enhancing behaviour, rather than focussing on treating the consequences of physical inactivity. Partial reimbursement of health club fees is a good example, an initiative which has been studied in patients with diabetes. ${ }^{10,11}$

Another highly important task group is the Lung foundation Netherlands. This patients' association promotes the interests of people with chronic lung disease through the entire country by providing information, advices and experiences (www.longfonds.nl). Information on exercise training and physical activity could be more pronounced and focussed in their communication.

\section{Activities and products}

From 2008 till present, several activities have been performed and products have been developed to increase the awareness of the benefits of exercise training and daily physical activity in COPD. Hereafter, these activities and products are described per target group. 


\section{Patients}

To inform patients about the value of increasing functional capacity and daily physical activity, we have developed a video message from patients' perspectives in collaboration with the Long foundation Netherlands. This video message was made visible on their website and could be used by health care professionals for educational purposes. For the local television in Maastricht area, a short documentary/video production was made of a COPD patient with his personal experiences of an exercise training programme. The programme was called "Good Veurein".

\section{Health care professionals in primary care}

In collaboration with the Dutch College of General practitioners (NHG), we developed a patient brochure "COPD and physical activity", which could serve as written work accompanying the advices of general practitioners or practice nurses to stimulate patients with COPD on becoming more physically active. Under the authority of the Chain of Care Foundation COPD (Stichting Keten Kwaliteit COPD), we have developed several products to facilitate collaboration between general practitioners and physiotherapists and implement exercise training programmes COPD in primary care. Among these products are a step-by-step plan to organise a meeting with health care professionals in primary care who are involved in COPD care, a communication format, referral schemes, overview of the reimbursement system and the content of an exercise training programme.

In cooperation with Fastguide, an ICT company, we have developed a multidisciplinary Electronic Patient Dossier (EPD) COPD to facilitate collaboration and communication between general practices and physiotherapy practices. In this way, health care professionals could have direct access to the treatment and health outcomes of their patients with COPD.

Lastly, the importance of exercise training and physical activity is put forward during educational presentations for general practitioners, practice nurses and physiotherapists.

\section{Policymakers}

To implement exercise training programmes in daily care and to improve quality of the given care, we participated in several expert groups, including COPD and Asthma General Practitioners Advisory Group (CAHAG), the Dutch Paramedical Institute (NPI), the Netherlands Institute for Sport and Physical Activity (NISB), the regional care groups ZIO (Maastricht area) and Meditta (Sittard area). In these two regions, we have 
contributed to the development of the Diagnosis Treatment Combination (DTC) of COPD care.

\section{Future directions}

We would like to extend our activities and products as described above, like creating awareness of the benefits of exercising and daily physical activity to the patients with COPD and health care professionals and keep on participating in expert groups. But another major step would be to intensify consultations with medical insurance companies and the local authorities. With the medical insurance companies, (shortterm) reimbursement could be discussed. Currently, reimbursement for patients with moderate to very severe COPD who participate in a pulmonary rehabilitation trajectory is rather extensive in the Netherlands. On the other hand, reimbursement for a physical exercise training programme in primary care for patients with mild to moderate COPD is very limited. Until now, not many economic evaluations of pulmonary rehabilitation programmes have been performed, but Griffiths and coworkers and Hoogendoorn and co-workers have shown that their outpatient rehabilitation programme and interdisciplinary community-based programme respectively, were cost-effective. ${ }^{12,13}$ Golmohammadi et al. (2004) also demonstrated the potential cost-effectiveness of pulmonary rehabilitation programmes. Notably, they found that patients with COPD GOLD stage I experienced the largest benefits and most impressive reductions in the total costs. It is suggested that patients with mild disease (with moderate degree of dyspnoea) are likely to benefit the most from pulmonary rehabilitation, possibly because they may be able to push themselves harder during exercise training and achieve greater levels of cardiovascular fitness than those with more severe disease. ${ }^{14}$ COPD experts, the Dutch Ministry of Health, Welfare and Sport and medical insurance companies should reconsider a wellbalanced reimbursement system for patients in all COPD categories.

The intention of a physical exercise training programme COPD in primary care is that it is a starting point for patients to improve their exercise capacity and to become physically more active in daily life. Ideally, patients should continue exercising outside the health care setting, on their own (for example by walking, cycling, swimming alone or with friends/family) or in (facilitated) groups. In our opinion, local authorities could play an important part in the link between exercising in health care and "post" health care and therefore collaboration between local authorities and local health care professionals should be intensified. 
When exercise training programmes and daily physical activity facilitations are implemented, it is also important to monitor and evaluate these interventions over time to make adjustments and address potential barriers and problems. 


\section{References}

1. Lopez AD, Shibuya K, Rao C, Mathers CD, Hansell AL, Held LS, Schmid V, Buist S. Chronic obstructive pulmonary disease: current burden and future projections. Eur Respir J 2006;27:397-412.

2. Mathers CD, Loncar D. Projections of global mortality and burden of disease from 2002 to 2030. PLoS Med 2006;3:e442.

3. Vestbo J, Hurd SS, Agustí AG, Jones PW, Vogelmeier C, Anzueto A, Barnes PJ, Fabbri LM, Martinez FJ, Nishimura M, Stockley RA, Sin DD, Rodriguez-Roisin R. Global strategy for the diagnosis, management, and prevention of chronic obstructive pulmonary disease: GOLD executive summary. Am J Respir Crit Care Med 2013;187:347-65.

4. Cecins N, Geelhoed E, Jenkins SC. Reduction in hospitalisation following pulmonary rehabilitation in patients with COPD. Aust Health Rev 2008;32:415-22.

5. Singh SJ, Smith DL, Hyland ME, Morgan MD. A short outpatient pulmonary rehabilitation programme: immediate and longer-term effects on exercise performance and quality of life. Respir Med 1998;92:1146-54.

6. Raskin J, Spiegler P, McCusker C, ZuWallack R, Bernstein M, Busby J, DiLauro P, Griffiths K, Haggerty M, Hovey L, McEvoy D, Reardon JZ, Stavrolakes K, Stockdale-Woolley R, Thompson P, Trimmer G, Youngson $L$. The effect of pulmonary rehabilitation on healthcare utilization in chronic obstructive pulmonary disease: The Northeast Pulmonary Rehabilitation Consortium. I Cardiopulm Rehabil 2006;26:231-6.

7. Garcia-Aymerich J, Serra I, Gómez FP, Farrero E, Balcells E, Rodríguez DA, de Batlle J, Gimeno E, Donaire-Gonzalez D, Orozco-Levi M, Sauleda J, Gea J, Rodriguez-Roisin R, Roca J, Agustí AG, Antó JM; Phenotype and Course of COPD Study Group. Physical activity and clinical and functional status in COPD. Chest 2009;136:62-70.

8. Garcia-Aymerich J, Lange P, Benet M, Schnohr P, Antó JM. Regular physical activity reduces hospital admission and mortality in chronic obstructive pulmonary disease: a population based cohort study. Thorax 2006;61:772-8.

9. Pleguezuelos E, Pérez ME, Guirao L, Samitier B, Ortega P, Vila X, Solans M, Riera A, Moreno E, Merí A, Miravitlles M. Improving physical activity in patients with COPD with urban walking circuits. Respir Med 2013;107:1948-56.

10. Troosters T. Physical inactivity in patients with COPD: the next step is ... action. Prim Care Respir J 2013 Nov 23.

11. Pahor M. Consideration of insurance reimbursement for physical activity and exercise programs for patients with diabetes. JAMA 2011;305:1808-9.

12. Griffiths TL, Phillips CJ, Davies S, Burr ML, Campbell IA. Cost effectiveness of an outpatient multidisciplinary pulmonary rehabilitation programme. Thorax 2001;56:779-84.

13. Hoogendoorn $M$, van Wetering $C R$, Schols AM, Rutten-van Mölken MP. Is INTERdisciplinary COMmunity-based COPD management (INTERCOM) cost-effective? Eur Respir J 2010;35:79-87.

14. Golmohammadi K, Jacobs P, Sin DD. Economic evaluation of a community-based pulmonary rehabilitation program for chronic obstructive pulmonary disease. Lung 2004;182:187-96. 
Ervaringen van betrokkenen 


\section{Ervaringen van betrokkenen: een patiënt, een huisarts en een fysiotherapeut}

\section{Mevr. R.K, patiënte, die deelgenomen had aan het Beweegprogramma COPD}

- Waarom had $u$ besloten om mee te doen met het beweegprogramma COPD en het onderzoek?

Ik had een brief ontvangen van de huisarts met de vraag of ik aan het programma mee wilde doen. Voorheen had ik er geen notie van dat zoiets bestond. Voor mijn gezondheid doe ik alles, zolang ik maar geen medicijnen hoef te slikken. En vroeger heb ik veel gesport, (jazz)ballet, volleybal en yoga. Recenter ging ik $1 x$ per week zwemmen, maar daar ben ik mee opgehouden toen ik op die dag op mijn kleinkind ging passen.

- Wat is uw ervaring met het programma?

Als ik klaar was met de oefeningen dan had ik altijd een heel ander gevoel. Een voldaan gevoel. Letterlijk en figuurlijk was ik dan opgeleefd. Ik had dan bijvoorbeeld meer lucht. En ik vond het leuk om onder de mensen te zijn en om samen iets te doen.

- Heeft u er baat bij gehad en zo ja, op welke manier?

Ik ben sterker geworden, vooral in de benen. Dat merk ik bij het fietsen. Bij mij in de buurt is een heuveltje waar ik altijd eerst overheen moet en dat gaat nu heel goed. Verder merk ik het bij het opstaan vanuit hurken, eerst moest ik me ergens aan vasthouden en nu kan ik zo opstaan.

En ik ben gestopt met bepaalde medicijnen (tranquillizers tegen angsten), want ik heb meer zelfvertrouwen gekregen. Ik durf nu meer te ondernemen.

- U bent inmiddels klaar met het programma, bent $\mathrm{u}$ in beweging gebleven?

$J a$, ik ben met mijn oefenprogramma doorgegaan. Ik kom nu $2 x$ per week op basis van een strippenkaart. Die heb ik eind vorig jaar als cadeau gevraagd voor mijn verjaardag. Het is voor mij nogal duur en mijn kinderen vroegen me wat ik echt nodig had. Nou, dat dus!

Ik ben wel bijna door mijn strippen heen, dus nu moet ik maar denken aan Moederdag. En ik let dus 1x per week op mijn kleinkind en daar ga ik mee wandelen of mee naar de speeltuin. Dat deed ik eerst ook, maar toen was dat alleen dichtbij in de buurt. Sinds het beweegprogramma durf ik veel verder te gaan en ga ik ook met mijn kleinkind met de bus naar de stad. 
- Heeft u nog een tip voor andere COPD patiënten?

Ik zou zeggen dat ze moeten gaan sporten, hè! Ik maak ook altijd reclame daarvoor.

- Heeft u nog tips voor zorgverleners?

Tip voor de huisarts, hij kan mensen meer aansporen om te gaan sporten, hij moet er meer achteraan zitten. Het lijkt alsof de huisarts er alleen zit om medicijnen uit te schrijven. En hij kan er meer werk van maken dat het vergoed wordt. Alhoewel, dit ligt eigenlijk bij de zorgverzekeraar. Er wordt steeds meer afgenomen uit het pakket. Waarom wordt een dergelijk programma niet in het pakket meegenomen en moet je eerst wachten tot je in GOLD-stadium 2 of 3 komt. Nu kan dat nog voorkomen worden. "Moet je eerst doodziek worden voordat je een behandeling krijgt?!" En als mensen niet mee willen doen, doen ze toch niet mee.

- Een laatste woord?

Dat je je beter voelt ermee.

\section{Dhr N.M., huisarts (tijdens deelname aan het onderzoek was hij nog huisarts in opleiding)}

- Waarom had je besloten om mee te doen met de zorg rondom het beweegprogramma COPD en het onderzoek?

Ik heb besloten om mee te doen met het beweegprogramma COPD, omdat mijn opleider vroeg of ik wilde helpen met het uitwerken van de database voor het oproepen van patiënten voor het beweegprogramma. Omdat ik redelijk goed ben in excellen en databasen en omdat ik de zorg voor COPD' ers erg belangrijk en ook nog leuk vind, heb ik 'ja' gezegd op zijn vraag.

- Wat is je ervaring met het programma, of breder gezien, met bewegen bij de aandoening COPD?

Mijn opleider en de praktijkverpleegkundige zijn erg enthousiast over de DBC COPD en de mogelijkheden daarbinnen. Eerder was ik nogal sceptisch over de behandeldoelen die je kunt bereiken bij deze patiëntengroep. Naarmate het opleidingsjaar vorderde zag ik dat de mensen met COPD wel degelijk veel baat hebben bij de ondersteuning, begeleiding, de medicamenteuze behandeling en adviezen van de praktijkondersteuner. Ik zag ook dat bewegen veel voordelen biedt voor patiënten en de kwaliteit van leven met sprongen vooruit kan gaan. 
- Heb je gemerkt dat patiënten er baat bij hebben gehad en zo ja, op welke manier? $J a$, ik heb gezien dat bewegen voor mensen met COPD zeer belangrijk is. Er is zeer veel winst te behalen bij deze patiëntengroep ten aanzien van conditie en bewegen. Als deze patiënten weer meer kunnen bewegen en langer kunnen bewegen kunnen ze weer makkelijker mee doen in het normale dagelijkse leven, zoals gewoon boodschappen doen, gewoon naar buiten gaan en weer deelnemen aan het sociale verkeer. Ik denk dat dit bij deze groep patiënten van groot belang is en dat het zowel door de patiënt als door behandelaars onderschat wordt hoeveel winst er te behalen is.

- Wat doe je nu en heb je nog steeds met COPD patiënten te maken?

Op dit moment werk ik als waarnemer bij drie huisartsen. Ik heb op dit moment alleen zijdelings te maken met de zorg voor COPD patiënten, als deze bij mij op het spreekuur komen. In de toekomst hoop ik een eigen praktijk te krijgen of deel te nemen in een groepspraktijk en daar actief bezig te mogen gaan met de zorg voor mensen met COPD, maar ook Diabetes en Hart en Vaatziekten. Deze laatsten hebben vaak ook veel baat bij bewegen.

- Heb je nog een tip of advies voor collega zorgverleners?

$J a$, volgens mij is de sleutel voor succes voor het motiveren van patiënten voor beweegprogramma's de relatie die er bestaat tussen de praktijkondersteuner, de huisarts en de patiënt. Als men de mensen goed kent dan kun je ook op maat gesneden hulp aanbieden en inschatten of mensen ook gemotiveerd zijn of te motiveren zijn voor een beweegprogramma. Goede samenwerking tussen de POH/ verpleegkundige en de huisarts en kwalitatief goede nabesprekingen van de patiëntencontacten leveren uiteindelijk een langdurig en goed resultaat op voor deze patiëntengroep. Daarnaast (maar ik weet niet of dat alleen voor mij geldt) is het nodig om de scepsis ten aanzien van de resultaten van de behandeling van deze groep te laten varen.

- Heb je nog tips of adviezen voor COPD patiënten?

Ja, zoek actief naar mogelijkheden om "kwaliteit" van leven te bevorderen. Vaak is het wel mogelijk om weer meer conditie te krijgen of zijn er mogelijkheden om de ervaren klachten te verminderen. Bij COPD is het met name belangrijk om te behouden wat er aan mogelijkheden is, maar het is toch vaak mogelijk om ten aanzien van bewegen en conditie veel te verbeteren, waardoor er weer meer mogelijkheden zijn. 


\section{Dhr M.V., fysiotherapeut}

- Waarom had je besloten om mee te doen met de zorg rondom het beweegprogramma COPD en het onderzoek?

Toen Annemieke me benaderde voor het onderzoek, had ik om meerdere redenen interesse om mee te doen. Tot voor het onderzoek behandelde en begeleidde ik voornamelijk mensen met COPD, die in aanmerking kwamen voor een chronische machtiging. Deze mensen zijn vaak al langer inactief en hebben daardoor een lage functionele status.

Ik wilde ook wel eens graag mensen begeleiden, die nog veel klachten kunnen voorkomen, door hun leefstijl tijdig aan te passen. Daarnaast heb ik me voorgenomen om geregeld in een onderzoek te participeren en Annemieke had me snel overtuigd van de zinvolheid van haar onderzoek.

- Wat is je ervaring met het programma, of breder gezien, met bewegen bij de aandoening COPD?

In de afgelopen 6 jaar, dat ik mensen met COPD behandel, ben ik verbaasd geraakt over het aanpassingsvermogen van de mens met een chronische aandoening. Met de huidige meetinstrumenten zijn verbeteringen in o.a. uithoudingsvermogen, kracht en levenskwaliteit heel inzichtelijk te maken. Ik heb gemerkt, dat er heel veel te winnen valt bij deze patiëntengroep. Fysieke prestaties verbeteren door bewegen en de motivatie voor een actieve leefstijl neemt toe.

Mijn ervaring is, dat de cognities over COPD van de patiënt, vaak een obstakel vormen bij het gemotiveerd raken voor bewegen. Er bestaan vaak toch nog veel vooroorlogse ideeën over COPD.

- Heb je gemerkt dat patiënten er baat bij hebben en zo ja, op welke manier?

Het valt me op, dat patiënten er op diverse manieren baat bij hebben. De meeste mensen, die twee maal per week trainen, ervaren dat meer bewegen fijn voelt. Ze beginnen uit zichzelf al ideeën te vormen over de periode na het onderzoek, die gaat volgen. Eigenlijk overwegen de meesten mensen al om erna te gaan sporten bij een sportclub.

Veel mensen, die een half uur per week komen, geven aan, dat ze wel vaker willen bewegen en zijn meteen al op zoek naar alternatieven.

Alhoewel de mensen, die 2 maal per week komen fysiek meer vooruitgang boeken, zoeken veel mensen in de andere groep al vroeger een "eigen activiteit". 
- Heeft deelname aan/betrokkenheid bij het onderzoek je nieuwe inzichten/ ervaringen opgeleverd? Of heeft het op de een of andere manier een meerwaarde gehad?

Tijdens het begeleiden van de mensen met "milde" COPD in dit onderzoek ben ik ervan overtuigd geraakt, dat het zinvol is om mensen met COPD vroegtijdig te screenen op fysieke mogelijkheden en beweeggedrag. Je kunt sneller ingrijpen met een beweeginterventie als dit nodig is. Afhankelijk van de testresultaten, hebben sommigen wellicht alleen een beweegadvies nodig met laagfrequente monitoring.

- Heb je nog een tip of adviezen voor collega zorgverleners (fysiotherapeuten, huisartsen/ poh'ers)?

Aan de huisartsen/ poh'ers zou ik het advies willen geven, om mensen met COPD vroegtijdig naar een fysiotherapeut te sturen voor een screening. Binnen deze screening is relatief snel vast te stellen of het fysieke functioneren binnen de norm valt en of iemand aan de "beweegnorm" voldoet. Aan de hand van deze gegevens, kan er een advies volgen of een behandelvoorstel.

Dit valt voor de patiënt in de aanvullende verzekering. 

Dankwoord 


\section{Dankwoord}

Zo, nu ben ik dan eindelijk "afgestudeerd", zoals menigeen het verwoordde. Jaren geleden deed ik nog uitgebreide pogingen om uit te leggen dat ik al 2 keer afgestudeerd was en dat dit een promotieonderzoek betrof, en het "ook gewoon werk" was. Later bespaarde ik me de moeite, want het begrip promotieonderzoek laat zich moeilijk vatten in een enkele zin. Met terugwerkende kracht zie ik nu dat een dergelijk traject uit verschillende fases was opgebouwd en er verschillende functieomschrijvingen van toepassing waren. Eerst was daar de rol van plannenmaker met het uitdenken van het hele onderzoeksplan. Daarna werd ik accountmanager, want ik moest natuurlijk zorgverleners enthousiasmeren om mee te doen met mijn onderzoek. Als fysiotherapeut en docent moest ik mijn inhoudelijke kennis overdragen. Als kwaliteitscontroleur ging ik de praktijken langs om te monitoren of het allemaal verliep zoals de bedoeling was. De boekhouder in me zorgde ervoor dat alle data verzameld werden en op een ordentelijke manier in de database verwerkt werden. Als statisticus kon ik gaan stoeien met de data. En uiteindelijk ging ik als schrijver alle resultaten tot een mooi geheel opschrijven. In mijn toekomstige loopbaan zal ik vast van deze functies kunnen profiteren.

De combinatie van wetenschappelijk onderzoek doen en in het werkveld staan als fysiotherapeut beviel me goed. Natuurlijk lag mijn focus de afgelopen jaren op het promotietraject en merkte ik hoezeer ik werd meegezogen in de wetenschappelijke verdieping. Maar dan was daar het werken in de praktijk. Als ik weer eens zo werd opgeslokt door theoretische details (bijv. het beslissen wat we zouden doen met de data van een bepaalde CRQ-subscore die niet voor iedereen berekend kon worden) dan werd ik op mijn werkdagen in de praktijk (gelukkig) weer in de realiteit gezet. Daar hoorde ik COPD patiënten vol enthousiasme vertellen dat ze de afgelopen week iets hadden ondernomen wat ze in jaren niet hadden gedaan. Door het trainen/meer bewegen waren ze niet alleen fysiek beter geworden, maar hadden ze vooral weer meer zelfvertrouwen gekregen om dingen te gaan doen. Bepaalde verhalen/ uitspraken heb ik daarom ook als een soort "schaduwboekhouding" bijgehouden. Voor het geval er geen positieve resultaten uit mijn onderzoek zouden komen, dan had ik de mooie verhalen in ieder geval nog.

Al dit werk en deze ervaringen had ik natuurlijk nooit in mijn eentje kunnen doen en verkrijgen, daarom ben ik alle personen die er aan bijgedragen hebben dat ik het promotietraject heb kunnen afronden zeer dankbaar. 
Als allereerste wil ik de patiënten bedanken die hebben meegedaan aan mijn onderzoek. Veel dank ben ik ook verschuldigd aan de fysiotherapeuten die al het werk hebben uitgevoerd. Aangezien ik zelf fysiotherapeut ben, begrijp ik de extra belasting van het onderzoek naast de normale dagelijkse werkzaamheden. Vooral de behandeling van de controlegroep patiënten moet een behoorlijke uitdaging zijn geweest. De huisartsen en praktijkondersteuners/-verpleegkundigen wil ik hartelijk bedanken voor het zoeken naar en verwijzen van geschikte patiënten.

Jean, enorm bedankt voor je begeleiding in de afgelopen jaren. Natuurlijk heb ik je inhoudelijke bijdrage en je wetenschappelijke en praktische kennis gewaardeerd, maar ik ben je vooral zeer dankbaar voor het vertrouwen dat je in mij en in het traject hebt behouden tijdens de moeilijke periodes. De rust die je uitstraalde in een soms hectische academische wereld was prettig. Ik wens je veel succes en plezier met je hoogleraarschap en ik vind het mooi dat ik de eerste promovendus ben met jou als promotor!

Onno, ik heb vooral je wetenschappelijke expertise in het project zeer gewaardeerd. Dank voor alle snelle reacties op geschreven stukken en e-mails. Je vulde me goed aan met je eigenschap van snelle beslissingen nemen en "to the point" reageren, anders was ik nu waarschijnlijk nog over van alles en nog wat aan het filosoferen geweest.

Rik, je bent als relatieve buitenstaander bij mijn project betrokken geweest, maar je hebt een enorm belangrijke functie vervuld. Je inhoudelijke expertise, betrokkenheid en toegankelijkheid zijn ongekend. Indrukwekkend de rust die je uitstraalt en dat je altijd klaar staat voor feedback en adviezen, of het nu gaat om een promovendus van buiten of voor de "gewone" fysiotherapeut in de praktijk. Heeft een dag bij jou ook echt maar 24 uur?

Bjorn, je hebt vooral in de eindfase van mijn project een belangrijke rol gespeeld, maar ik ben erg blij dat je deel uitmaakt van mijn promotieteam. De samenwerking heb ik als zeer aangenaam ervaren en ik vond het mooi om te merken dat je je ook inhoudelijk interesseerde voor het onderwerp. Je prettige kritische kijk op de zaken vind ik zeer bijzonder.

Karin, jij hebt enorm veel werk verzet. Allereerst was je een kei in het invoeren van alle data, het maakte je niet uit in welke vorm het aangeleverd werd (gegevens uit het EPD, standaard formats of iets minder standaard formats). Vervolgens heb je een hele overzichtelijke database opgebouwd en daarna hebben we gezamenlijk nog heel wat 
analyses in SPSS uitgevoerd. Het was natuurlijk een noodzakelijk onderdeel van het werk, maar door jouw humor en gezelligheid werd het nooit een saai onderdeel. Hartelijk dank!

Mascha en echtgenoot Rob Ummels, bedankt voor het rondbrengen en ophalen van de lunchtrommels met Dynaports + andere meetgegevens in de fysiotherapiepraktijken tijdens de laatste fase van mijn onderzoek.

Harry en Jolanda, mijn COPD fysiotherapiecollega's uit de Heerderrein, ik ben jullie zeer veel dank verschuldigd. Door jullie onuitputtelijke inzet om patiënten te overtuigen om mee te doen aan mijn onderzoek kon ik het voor elkaar krijgen om genoeg patiënten te includeren, zelfs in de moeilijke periode dat de financiering via de DBC COPD ten einde kwam. Verder denk ik dat we trots mogen zijn op wat we bereikt hebben voor de fysiotherapeutische COPD zorg in Maastricht en omstreken (want ze komen inmiddels vanuit alle kanten naar ons toe). Ik kijk ernaar uit om samen met jullie de COPD zorg op een nog hoger plan te tillen!

John, Harry en Rex, ik waardeer het enorm dat ik alle vrijheid heb gekregen om mijn werkzaamheden bij de Heerderrein en de UM te combineren, ook al was het voor de praktijk niet altijd even handig dat ik in de loop der tijd steeds minder ging werken.

Alle andere collega's uit de praktijk, ik heb het altijd prettig gevonden om op maandag en vrijdag in de praktijk te werken door de goede sfeer. Het voelde altijd aan als een warm bad!

De leden van de leescommissie en de leden van de Corona wil ik bedanken voor hun deskundige feedback en de tijd die ze hebben geïnvesteerd in het lezen van dit proefschrift.

Ine, je bent echt de moeder van de vakgroep Huisartsgeneeskunde. Ik hoop dat je beseft hoe belangrijk jouw functie is. Jij bent het aanspreekpunt in geval van slechte tijden en euforische tijden. Altijd kunnen we bij jou terecht voor een luisterend oor. Ik zal je nog komen bezoeken, hoor!

Tanja de Bruijn, bij aanvang van mijn onderzoek had ik wat directer met je te maken als secretaresse van Onno. Na je carrièremove naar belangrijke PR-dame van CAPHRI hebben we minder contact gehad, maar ik vond het leuk dat we eens in de zoveel tijd bijkletsten tijdens een kopje koffie en thee. 
Marga en Jos, het is zo fijn dat jullie er zijn bij de vakgroep. Alle ICT-problemen worden in een mum van tijd vakkundig verholpen.

(Oud-)kamergenoten Jasper, Marika, Jolien, Arianne, Tiny en Robert, het was fijn om jullie als kamergenoot te hebben gehad. Dank voor alle wijze adviezen en gezellige babbels.

Buur-kamergenoten en collega promovendi, Anneke, Annerika, Annemieke en Jeanny, jullie waren ook fijne collega's en leuk dat jullie interesse toonden in mij en mijn onderzoek, ondanks dat ik niet de gezelligste collega moet zijn geweest. Vanwege mijn parttime onderzoeksschap was ik er vaak niet en als ik er was dan bleef mijn kamerdeur dicht, omdat ik me dan helemaal op mijn onderzoek stortte.

Rob, Erik, Emmylou en Conny, bedankt voor de samenwerking met jullie projectgroep. Het was fijn om gezamenlijk te brainstormen en ervaringen uit te wisselen.

Erie van den Heuvel en Ellen Breevoort, dank voor jullie inzet wat betreft financiële en ondersteunende middelen. Jullie hebben naar mijn idee één van de moeilijkste functies, want er is altijd te weinig geld voor te veel zaken, die gedaan moeten worden.

Guus Asijee, het was prettig om jou ook bij de projectgroep te hebben gehad. Jij keek altijd met een frisse en open blik naar alle stukken en dat leverde weer andere inzichten op.

Rob van Lummel en medewerkers, het was fijn om met jullie samen te werken. Ik kreeg altijd vlotte en accurate reacties en feedback op mijn vragen en verzoeken. Jullie mogen trots zijn op het bedrijf McRoberts. Het meten van fysieke activiteiten was zo'n beetje mijn hobby geworden.

De collega's van het COPD en Astma docententeam van het NPI, ik vind het heerlijk om met jullie de cursussen te geven vanwege jullie enthousiasme, gedrevenheid en gezelligheid.

Tiny Wouters, bedankt voor de mooie lay-out en het altijd zeer tijdig bewerken van de stukken. 
Hans en Kenneth, dankzij jullie enthousiasme en begeleiding tijdens mijn stage Bewegingswetenschappen ben ik er pas achter gekomen hoe leuk het is om wetenschappelijk onderzoek te doen en heb ik ontdekt dat het bij mij past.

Mijn schoonouders Jo en Jessie, door jullie heb ik ervaren in welke mate de ziekte COPD de levens van een persoon en zijn directe omgeving kan beïnvloeden. Helaas kan Jo deze bijzondere dag niet mee maken. Jessie, bedankt voor al je goede zorgen, wijsheid en energie. Ga vooral door met je wandelingen. Misschien dat ik vanaf nu tijd heb om af en toe met je mee te wandelen, in Maastricht en omstreken of in Frankrijk.

Toine en Sanny, het is heerlijk om zo'n schoonfamilie te hebben bij wie de deur letterlijk en figuurlijk altijd open staat. Bedankt voor alle heerlijke etentjes, het altijd klaarstaan voor ons en de gezellige vakanties.

Paranimfen Pee en Sandra, ik ben erg blij dat jullie mijn paranimfen willen zijn. Jullie zijn twee hele sterke dames, die ondanks vele tegenslagen nog zo rustig en positief in de wereld staan, daar heb ik veel bewondering voor. Pee, ik ben ook zeer blij met je hulp voor me bij de vakgroep.

Sandra, je blijft altijd mijn grote zus tegen wie ik met veel plezier blijf opkijken. Ik hoop zo voor je dat je been nu snel een keer geneest en dat je eindelijk kunt gaan genieten in het mooie Zwitserland. Ik ben nu klaar met mijn promotietraject en als jij weer helemaal fit bent dan gaan we dat wat mij betreft een keer uitgebreid vieren!

Herman en Sieta, jullie zijn hele lieve ouders en bedankt dat jullie me altijd gesteund hebben in de keuzes die ik heb gemaakt en het vertrouwen dat jullie in me hebben gehad. Mijn interesse in bewegen is duidelijk met de paplepel ingegoten, jullie gaven en geven nog altijd het goede voorbeeld. Nu moet ik dit voorbeeld weer gaan volgen, want mijn theoretische kennis over bewegen is de afgelopen jaren weliswaar gegroeid, maar praktisch gezien ben ik alleen maar minder gaan bewegen.

Yves en Yfke, mijn twee kanjers! Ik zou een heel boek over jullie vol kunnen schrijven, maar ik wil vooral benadrukken dat jullie het allerbelangrijkste zijn in mijn leven en dat ik enorm gelukkig ben met jullie tweetjes. Yves, heel erg bedankt voor je geduld, je liefde, je goede zorgen voor Yfke en mij, je humor en je relativeringsvermogen. Dat zijn natuurlijk de allerbelangrijkste zaken, maar daarnaast wil ik je ook bedanken voor de meer praktische zaken, zoals alle keren dat ik na een lange werkdag gewoon kan komen aanschuiven aan tafel, je me altijd helpt met de hele ICT-infrastructuur in ons 
huis en de, voor een niet-wetenschapper, enorme wetenschappelijke redenaties over allerlei kwesties (en ja, je hebt inderdaad vaak gelijk). Je was vroeger, toen ik je leerde kennen fan van basketbalspeler Magic Johnson. Wat ik van hem weet, is dat hij een super goede basketballer was. Maar wat hem uniek maakte, was dat hij zijn teamgenoten beter maakte. Wat dat betreft lijk je op hem, want door diezelfde eigenschap bij jou heb ik kunnen presteren in mijn promotietraject.

Lieve Yfke, iedere dag is een feest met jou. Ik geniet enorm van je energie en vrolijkheid. En ik zou willen dat ik een beetje van je fantasie zou hebben. Je verrast me elke dag weer. 
Curriculum Vitae 


\section{Curriculum Vitae}

Annemieke Fastenau was born on 30 January 1976 in Zutphen, the Netherlands. In 1994 she graduated from secondary school at Stedelijke Scholengemeenschap in Maastricht. As she was interested in sports and medicine, she decided to study Physiotherapy at the Hogeschool van Amsterdam. She followed extracurricular courses, including a training period at professional football club AFC Ajax providing medical assistance for a youth team (including a trip abroad to football club AC Milan, Italy). And she also did

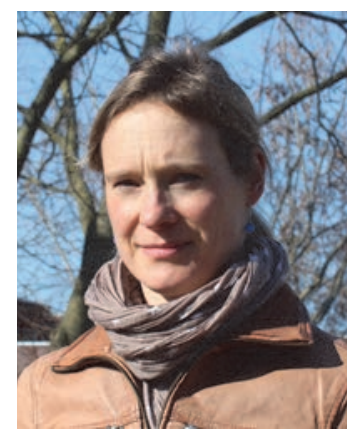
academic research in the dissecting room: anatomical and clinical contexts of the medial epicondylitis (golfer's elbow), which was rewarded with an honours degree (cum laude). After her graduation in 1998, she moved back to Maastricht and worked as physiotherapist in primary care practices and started to study Health Sciences, specialization Movement Sciences at Maastricht University. She combined this study with her work as a physiotherapist in Gezondheidscentrum De Heerderrein. She graduated in $\mathbf{2 0 0 3}$ with her final thesis nominated for two awards (incentive prize and student award) and continued to combine her clinical work as a physiotherapist with research activities as a junior academic researcher, respectively at the departments of Movement Sciences, Multidisciplinary Care of the Academic Hospital Maastricht, Anatomy and Embryology and Family Medicine of Maastricht University. In 2008, she began her work as a PhD student at the School for Public Health and Primary Care (CAPHRI) and since then, she was also involved as a teacher in regionally and nationally postgraduate courses on COPD. She currently is also a member of the COPD expert group of the Dutch Paramedical Institute (NPI) and the working group COPD of the regional care group ZIO. Her PhD thesis was approved in November 2014.

Annemieke is living together with Yves Delahaije and they have a daughter named Yfke. 
